\title{
Perceptions of supervisory behaviors and supervisory needs among licensed speech-language pathology assistants
}

Jean Suzanne Mead

West Virginia University

Follow this and additional works at: https://researchrepository.wvu.edu/etd

\author{
Recommended Citation \\ Mead, Jean Suzanne, "Perceptions of supervisory behaviors and supervisory needs among licensed \\ speech-language pathology assistants" (1998). Graduate Theses, Dissertations, and Problem Reports. \\ 3119. \\ https://researchrepository.wvu.edu/etd/3119
}

This Dissertation is protected by copyright and/or related rights. It has been brought to you by the The Research Repository @ WVU with permission from the rights-holder(s). You are free to use this Dissertation in any way that is permitted by the copyright and related rights legislation that applies to your use. For other uses you must obtain permission from the rights-holder(s) directly, unless additional rights are indicated by a Creative Commons license in the record and/ or on the work itself. This Dissertation has been accepted for inclusion in WVU Graduate Theses, Dissertations, and Problem Reports collection by an authorized administrator of The Research Repository @ WVU.

For more information, please contact researchrepository@mail.wvu.edu. 


\section{Perceptions of \\ Supervisory Behaviors and Supervisory Needs Among \\ Licensed Speech-Language Pathology Assistants}

Jean Suzanne Mead

Dissertation submitted to the Faculty of

West Virginia University in partial fulfillment of the requirements for the degree of

Doctor of Education

in

Educational Leadership Studies

Daisy E. Arredondo, Chair

Robert Angel

Phyllis C. Durden

Billy K. Gordon

Jack Yeager

December 4, 1998

Huntington - Morgantown

West Virginia

Keywords: Supervision, Speech Pathology, Support Personnel

Copyright 1998, Jean Suzanne Mead 
Perceptions of Supervisory Behaviors and Supervisory Needs Among

Licensed Speech-Language Pathology Assistants

Jean Suzanne Mead

\begin{abstract}
(ABSTRACT)
The purpose of this study was to identify supervisory behaviors that occurred and the extent to which they were perceived as necessary during supervisory interactions between licensed speech-language pathology assistants (SLPAs) and their supervising speech-language pathologists (SLPs). Surveys were mailed to the 173 licensed SLPAs in Louisiana, who were the population for this study, requesting information about the supervision received. Eighty-eight (51\%) completed and returned the survey.
\end{abstract}

The survey consisted of three parts. Part I contained 29 statements that were each rated twice using a Likert-type scale. The first rating indicated the extent to which supervisory behaviors occurred and the second rating indicated the extent to which the behaviors were perceived as needed. Part II contained open-ended questions and Part III collected demographic data about the participants.

The items on Part I of the survey were grouped into three categories: instructional, interrelational and general. The instructional category contained items about technical and professional aspects of supervision, the interrelational category consisted of behaviors concerned with the interpersonal relationship between the assistant and the supervisor, and the general category included supervisory behaviors initiated by the assistants, e.g. requesting meetings with the supervisor, informing the supervisor when assistance was needed, and self-analyzing professional behavior.

Data were analyzed using descriptive statistics, analysis of variance and content analysis. No significant differences were found between supervisory behaviors that occurred and those perceived as needed for the instructional and interrelational categories. General category behaviors occurred significantly more frequently than were perceived as needed. Significant differences were found on three individual items on Part I of the survey: supervisor dominance in the conference setting which occurred more than needed, and dyad communication via journal writing and email that occurred less than perceived as needed.

The content analysis supported the findings in the objective portion of the study. The majority of SLPAs $(81 \%)$ reported their supervisory needs were being met. They described their supervisors as patient, knowledgeable, available, supportive, professional, and open-minded. However, for some, the supervision was perceived as inadequate. For them, comments reflected a lack of supervisor patience, knowledge, availability, support, professionalism, and open-mindedness. 
DEDICATION

To Ryan and Stephanie 


\section{ACKNOWLEDGEMENTS}

I wish to thank:

Dr. Daisy E. Arredondo, who served as my dissertation chair. She offered words of encouragement and wisdom when I was not feeling "centered" and needed direction and guidance. She also worked unselfishly with me throughout this process as an editor and a mentor. Thank you Dr. Arredondo for your teaching quality and for limitlessly giving your time and knowledge;

My colleagues at Southeastern Louisiana University, who provided for the flexibility in my teaching and clinic schedules that allowed this work to happen. Thank you for the cards and words of encouragement, and for the food that sustained not only my body, but my soul;

My committee members, for their support, guidance, direction and patience:

Thank you, Dr. Robert Angel, Dr. Phyllis Durden. Dr. Billy Gordon, and Dr. Jack Yeager;

The technical staff at the Faculty Productivity Center at SLU, for the patience and guidance that were demonstrated as I progressed through each phase of this work. Thanks, Ravi and staff;

Other researchers in the field of communication disorders who offered direction and guidance throughout this project: Lillian Larson, Sandra Ulrich, Judy Rassi, Elizabeth McCrea, and Diane Paul-Brown;

Patricia Ruhlman, my Mom, for love and encouragement;

And last but not least, my children, Ryan and Stephanie, for their cheers:

"You can do it, Mom". 


\section{TABLE OF CONTENTS}

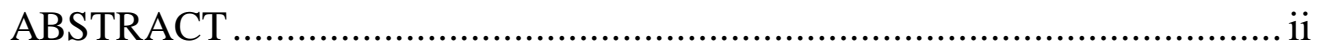

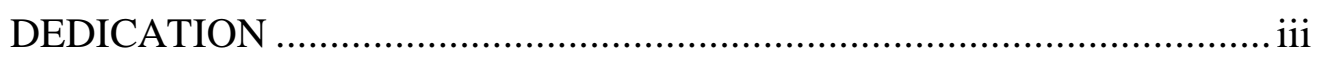

ACKNOWLEDGMENTS …....................................................... iv

LIST OF TABLES ................................................................ viii

\section{CHAPTER ONE}

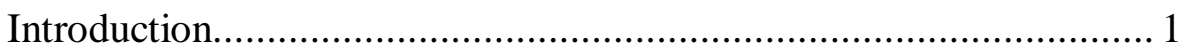

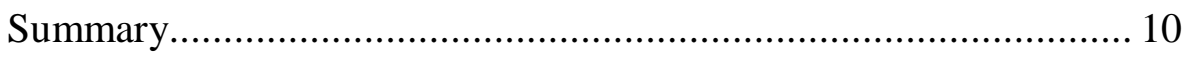

Statement of the Problem ........................................................ 11

Research Questions ........................................................ 12

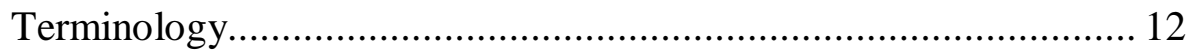

Significance of the Study................................................... 15

Limitations of the Study ..................................................... 16

\section{CHAPTER TWO}

Review of the Literature......................................................... 17

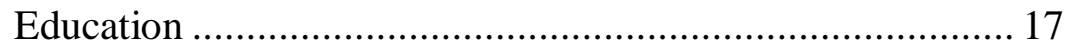

Historical and Theoretical Perspectives on Supervision........ 17

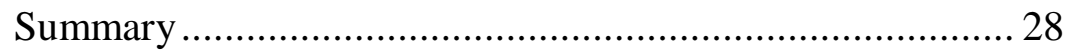

Communication Disorders ............................................. 30

Historical and Theoretical Perspectives on Supervision........ 30

Summary ............................................................. 35

Perceptions of the Critical Aspects of Supervision .............. 36

The Interpersonal Relationship ..................................... 40 
Training in Supervision .............................................. 42

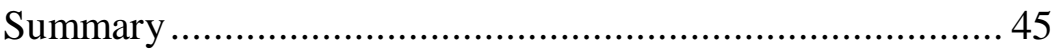

Supervision of Support Personnel ................................. 47

Occupational Therapy ............................................... 47

Physical Therapy .................................................... 48

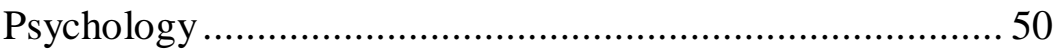

Speech-Language Pathology ........................................ 50

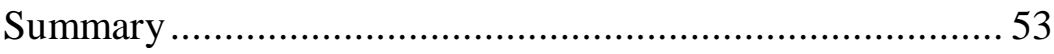

\section{CHAPTER THREE}

Research Design and Methodology ........................................ 54

Subjects................................................................ 54

Observations......................................................... 55

Analysis of Data ......................................................... 59

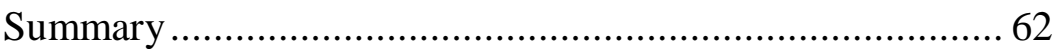

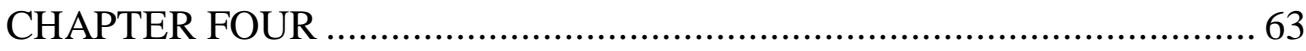

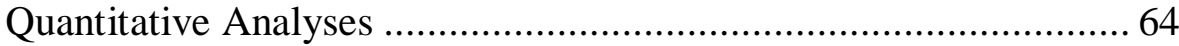

Qualitative Analysis ........................................................ 82

Summary

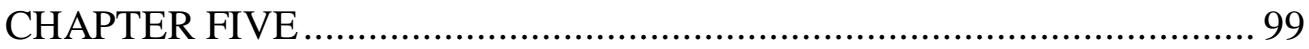

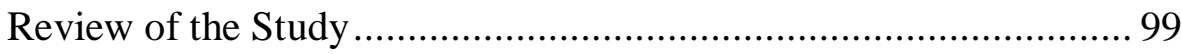

Interpretation of Results ................................................... 101

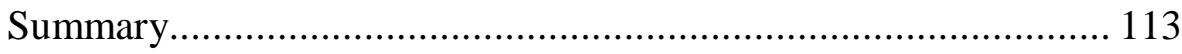

Limitations of the Study ....................................................... 117 
Suggestions for Further Research .......................................... 118

Summary of the Study ............................................................. 119

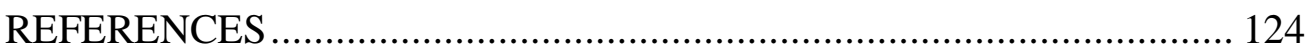

Appendix A: Letter to Subjects ..................................................... 140

Appendix B: Follow-up letter to Subjects....................................... 141

Appendix C: Permission to Adapt Instrument ...................................... 142

Appendix D: Survey Instrument.................................................... 143

Appendix E: List of Behavioral Variables that Constituted the

Instructional, Interrelational and General Categories.......... 146

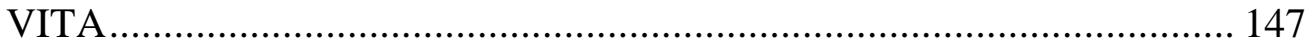




\section{LIST OF TABLES}

Table

Page

1 Cronbach's Alpha Coefficients ..................................................... 58

2 Descriptive Statistics for The Extent To Which Supervisory

Behaviors Occurred and The Extent To Which They Were Needed........ 66

3 Analysis of Variance of Rating Scale Items:

The Extent to Which Supervisory Behaviors Occurred

and The Extent to Which They Were Needed.....

4 Ten Highest Ranked Behaviors According to the Extent

the Behaviors Were Needed

5 Analysis of Variance for Categories of

Supervisory Behaviors

6 Analysis of Variance for the Instructional Category:

A Demographic Analysis .75

7 Analysis of Variance for the Interrelational Category:

A Demographic Analysis

8 Analysis of Variance for the General Category:

A Demographic Analysis 79

9 Frequency Distribution and Measures of

Central Tendency for Selected Demographic Variables 


\section{Chapter I}

\section{Introduction}

Supervision in human communication disorders has been the topic of research projects reported in dissertations, journal articles and conference presentations for many years. These studies have been based primarily on the supervision of speech-language pathology and audiology students and on individuals completing a clinical fellowship year (CFY). Recently, however, the American Speech-Language Hearing Association (ASHA) proposed guidelines for the training, credentialing, use, and supervision of speech-language pathology assistants (ASHA, 1996). The guidelines were proposed in an effort to expand quality speech-language pathology services by officially credentialing speech-language pathology assistants (SLPAs). The purpose of this study was to explore the supervisory component of the recommended guidelines. Specific goals of the study were to identify the supervisory behaviors that occurred during supervisory interactions between licensed SLPAs and their supervising speech-language pathologists (SLPs), and to determine the extent to which those supervisory behaviors were perceived as necessary by licensed SLPAs.

Researchers in the field of communication disorders (Atkins, 1996; Crago \& Pickering, 1987; Larson, 1981; Myers, 1980; Oratio, 1977; Pickering, 1984; Russell, 1976; Schneider, 1989; Tihen, 1984) have recognized the importance of perceptions of supervisory behaviors, expectations, and needs concerning the supervisory process for students completing clinical practica. Regarding the required supervision for individuals completing a clinical fellowship year, detailed procedures and guidelines are in place, however, limited published research is available concerning the supervisory relationship 
or the perceived supervisory needs of clinical fellows. The bulk of literature concerning supervision in communication disorders is related to student clinicians and, to date, no research has been conducted concerning the perceived supervisory behaviors and needs for licensed SLPAs.

As speech-language pathology assistants become officially recognized through an ASHA credentialing program, and because of the mandatory supervision that is described in the recommended guidelines, the focus of supervision in communication disorders will expand from that of student clinicians and clinical fellows to include the supervision of practicing, professional SLPAs. This study examined the perceived supervisory behaviors and supervisory needs of licensed SLPAs.

The specific goals of the study were to (a) identify the extent to which certain supervisory behaviors occurred during supervisory interactions, (b) examine the extent to which those supervisory behaviors were perceived as needed by speech-language pathology assistants, (c) determine whether or not there were significant differences between supervisory behaviors that occurred and supervisory behaviors that were perceived as needed by SLPAs, and (d) investigate whether demographic variables such as age, gender, work setting, years of experience as an assistant, level of licensure, and level of education were related to the speech-language pathology assistants' perceived supervision and supervisory needs.

The Legislative Council (LC) of the American Speech-Language Hearing Association, faced with the challenge of expanding quality speech, language, and audiology services, approved a position statement that supported the establishment of categories of support personnel in speech pathology and audiology (ASHA, 1995). The 
LC developed and then approved guidelines for the training, credentialing, use, and supervision of speech-language pathology and audiology assistants, one category of support personnel (ASHA, 1996). In November of 1996, the LC sanctioned a strategic plan to implement the recommended guidelines within a three year period extending from June 1, 1998 through June 30, 2001 (ASHA, 1997).

For many years, the American Speech-Language-Hearing Association has acknowledged the use of support personnel and recommended guidelines for their employment and supervision have been in place since 1969 (ASHA, 1970). The most recent guidelines developed were specifically for the category of speech-language pathology assistants.

The specific training and credentialing requirements established by ASHA for the speech-language pathology assistants do not preclude use of appropriately trained and supervised support personnel (e.g. less skilled aide level). However, official recognition through an ASHA credentialing program is limited to the speechlanguage pathology assistant (ASHA, 1996, p.23).

Criteria for the academic and clinical training for the SLPAs, as well as the registration process and supervision requirements were outlined in the proposed guidelines. The academic and clinical requirements included (a) completion of post secondary coursework in the field of communication disorders, obtaining the minimum of an associate degree; and (b) completion of supervised fieldwork in at least two different settings. The recommended guidelines also proposed a process for registering SLPAs which would include submitting an application and fees to ASHA and maintaining registration through an annual renewal process (ASHA, 1996). Furthermore, the guidelines recommended that SLPAs be supervised by an ASHA certified speechlanguage pathologist (ASHA, 1996). 
In setting forth guidelines for the supervision of SLPAs, ASHA identified the amount and type of supervision for the assistant, as well as the educational and clinical experience requirements of the supervisor. ASHA proposed that the supervision of assistants should be $30 \%$ for the first 90 days of employment with at least $20 \%$ direct and after 90 days the supervision should be at least $20 \%$ with at least $10 \%$ direct (ASHA, 1996). Direct supervision involves on- site, in-view observation of the activity performed by the SLPA and indirect supervision involves alternative methods of supervision such as demonstration or record review (ASHA, 1996). The minimum recommended qualifications for those who supervise SLPAs are (a) hold a current certificate of clinical competence, (b) complete two years of clinical experience as an ASHA certified SLP, and (c) complete one pre-service course (minimum one graduate credit or 15 hours) in supervision or one Continuing Education Unit (CEU) in activities or courses pertaining to supervision (ASHA, 1996).

In 1995, prior to the development of ASHA's proposed guidelines for the training, credentialing, use, and supervision of speech-language pathology assistants, the Louisiana State Board of Examiners in Speech Pathology and Audiology developed and implemented procedures for licensing SLPAs. Some differences in criteria existed between the nationally proposed guidelines and Louisiana law (LA Act 892 \& Rules, 1996) regarding licensure requirements for the SLPA.

The process for licensing SLPAs in Louisiana is two tiered. To be eligible for full licensure as an SLPA in Louisiana, the assistant must have earned the minimum of a baccalaureate degree or equivalent in communication disorders, completed 100 supervised hours of practice through a university program, and completed 125 additional 
supervised clinical practica hours either through a university program or as on-the-job training. To be eligible for a provisional license, the assistant must have earned a baccalaureate degree in communication disorders or equivalent and completed a minimum of 100 supervised practica hours through a university program. Once the additional 125 practica hours have been obtained either through a university program or as on-the-job training, the provisional assistant may be eligible for full licensure. After all practica requirements have been met, the individual applies to the Louisiana State Board of Examiners in Speech Pathology and Audiology and requests a license upgrade from provisional to full licensure status.

The amount and type of supervision required for the fully licensed SLPA in Louisiana is "no less than one hour on-site, in-view and one hour of alternative methods weekly" (LA Act 892 \& Rules, 1995, 1996 p. 7). The supervisory requirements for the provisional SLPA are "no less than three hours on-site, in-view and two hours of alternative methods weekly" (LA Act 892 \& Rules, 1996 p. 7). The recommended minimum supervision requirements proposed by ASHA are $30 \%$ of the first 90 work days, at least $20 \%$ of client contact time must be supervised, and $20 \%$ subsequently with a minimum of $10 \%$ direct. (ASHA, 1996).

Louisiana law requires those who supervise speech-language pathology assistants to be fully licensed speech-language pathologists. In Louisiana, some fully licensed SLPs have not obtained the master's degree because at the time they were hired, a bachelor's degree was required for licensure. They were "grand-fathered" in at full licensure status. Hence, none of the other ASHA proposed requirements for those who 
supervise assistants, such as maintaining the certificate of clinical competence and the educational and clinical experience requirements were specified, thus were not required. Speech-language pathology assistants are practicing professionals whose work is complex and multi-faceted. They work in schools, rehabilitation centers, hospitals, or other medical or educational settings. According to the ASHA guidelines, registered or licensed SLPAs perform duties within a limited scope of practice and always under the supervision of certified SLPs. For example, the assistants are able to implement therapeutic measures as directed and advised by the supervising SLP but they may not develop the therapeutic plan. They may perform screenings but they may not interpret the findings. They may not conduct diagnostic evaluations, but they may assist the speech-language pathologist in doing so (ASHA 1995). Even though they work within a limited scope of practice, SLPAs demonstrate far more professional independence than the student supervisee who is completing clinical practica. Students completing clinical practica assignments must be directly supervised for $25 \%$ of all therapy sessions and $50 \%$ of all diagnostic sessions and a supervisor must be on site at all times (ASHA, 1993).

The significance of supervision in the field of communication disorders has been assumed for some time with the primary focus being on the preparation of students and those completing a clinical fellowship year (CFY). The supervisory process as it has been practiced and studied in the supervision of undergraduate and graduate practica students and those completing their CFY in speech-language pathology and audiology "has evolved through adaptation and modification of supervision models from other fields" (Smith, 1989 p. 269). Main sources come from the education literature (Blumberg, 1968, 1980; Cogan, 1973; Dussault, 1970; Goldhammer, 1969; Goldhammer, 
Anderson, \& Krajewski, 1980; Mosher \& Purpel, 1972), business management (Argyris, 1962; Bennis, 1989; Covey, 1991; Fiedler, 1967; Gouran, 1980; Hersey \& Blanchard, 1982; Likert, 1967) and social work, counseling and psychology (Carkhuff, 1969a, 1969b; Kadushin, 1976; Maslow, 1970; Rogers, 1961, 1977; Vargus, 1977).

The earliest educational programs that were developed for those embarking on a career in communication disorders included supervised clinical practica as a requirement for the certification of speech-language pathologists (Paden, 1970). Supervision seems to be the one aspect of the educational process that has affected all speech-language pathologists. The traditional goals of supervision in the field of communication disorders focused on a process that fostered professional independence. The supervisee ultimately obtained the certificate of clinical competence which, when granted, allowed the holder to provide independent practice and to supervise clinical practica of student trainees and clinical fellows.

The tasks of supervision for those obtaining the certificate of clinical competence have been well defined. The speech-language pathology student and the clinical fellow complete a specified amount of training under certified speech-language pathologists. Ultimately, the student or clinical fellow gained professional independence after completing all requirements for the certificate of clinical competence.

In 1985, ASHA published a position paper delineating the rights and responsibilities of supervisors and supervisees in the field of communication disorders. One component of the paper described the following thirteen tasks of clinical supervision: 
1. Establishing and maintaining an effective working relationship with the supervisee.

2. Assisting the supervisee in developing clinical goals and objectives.

3. Assisting the supervisee in refining assessment skills.

4. Assisting the supervisee in developing and refining management skills.

5. Demonstrating for and participating with the supervisee in the clinical process.

6. Assisting the supervisee in observing and analyzing assessment and treatment sessions.

7. Assisting the supervisee in the development and maintenance of clinical and supervisory records.

8. Interacting with the supervisee in planning, executing, and analyzing supervisory conferences.

9. Assisting the supervisee in evaluation of clinical performance.

10. Assisting the supervisee in developing skills of verbal reporting, writing, and editing.

11. Sharing information regarding ethical, legal, regulatory, and reimbursement aspects of professional practice.

12. Modeling and facilitating professional conduct.

13. Demonstrating research skills in the clinical or supervisory processes (ASHA, 1985, p. 60).

In order to supervise clinical practica, ASHA required that all supervisors hold the certificate of clinical competence. The certificate can be obtained after an individual meets specific requirements. Those requirements are successful completion of (a) a master's degree through a Council on Academic Accreditation (CAA) accredited training program, (b) 350 hours of supervised clinical practica, and (c) a clinical fellowship year (CFY). The CFY is defined as a transition phase between supervised graduate practica and independent delivery of service. The individual must also pass the national examination of speech-language pathology or audiology (ASHA, 1991a).

The proposed minimum requirements for those who supervise SLPAs are different than the requirements for those who supervise individuals completing clinical practica and CFYs. Significant differences are the educational and the clinical experience requirements, beyond obtaining the certificate of clinical competence, which are required for those that supervise assistants. 
These thirteen tasks of supervision may also be appropriate for the supervision of SLPAs; however, the goals of the supervision will differ from the traditional goals. Since the proposed recommended guidelines for the supervision of SLPAs included lifelong supervision by a licensed or certified speech-language pathologist, producing an independent SLP is not the goal of supervision for SLPAs. The goals of the supervision for assistants are not yet clear. It seems safe to presume, however, that assuring quality of services to clients and providing instructional support to the assistant may be two goals of the supervision. This presumption is based on the fact that SLPAs will typically enter the work force with limited academic and clinical experiences as compared to SLPs.

While the primary focus of supervision in communication disorders has been toward the training of students, the profession has long been aware of the importance of supervision for the practicing professional. Kleffner (as cited in Anderson, 1988) stated his concern for carrying supervision into the employment setting:

Thus far in the report, supervision has been viewed only in relation to the internship year. In the broader professional perspective, this view of supervision is unnecessarily narrow. If we provide supervision only for the purpose of guiding and monitoring the work of the inexperienced clinical personnel, we have failed to capitalize on a most important strength and growth in the profession. It is clinical foolhardiness, at the very least, even to imply that supervision should cease as soon as nine months of supervised experience is completed. The place of supervision in a clinical program is changed rather than diminished as those being supervised gain in experience. As the experience of the staff increases, so does the opportunity for creative contribution by the supervisor to the program and to the client. None of us is so adept, so experienced, and so insightful in our clinical endeavors that we cannot stand to gain from the insights into clinical tasks which the overview of the supervisor -clinical consultant- makes possible. Clinical supervision is a necessary and desirable component in any truly comprehensive clinical service program. (p. 20).

The lack of focus on supervision for the practicing professional may be due to several factors, including the isolation of speech pathologists, i.e. often there is only one 
employed per facility, and the documented national shortage of speech-language pathologists in the schools (ASHA, 1998). The supervision of fully licensed and certified speech-language pathologists is usually administrative or programmatic in nature.

In order for the supervision of assistants to be meaningful to them as practicing professionals, and manageable for the supervisor, some model of supervision that proceeds beyond the direct, clinical model may be incorporated. Some other models of professional supervision commonly used in the education, business and social work professions such as peer coaching, peer supervision and reflective supervision may prove to be more effective for the licensed SLPA.

This research investigated the supervisory relationship between licensed SLPAs and their supervising SLPs. It extended earlier research conducted by Larson (1981) which examined the perceptions of the supervisory needs and expectations of experienced vs. inexperienced student clinicians. For the purposes of this research, a modified version of Larson's survey was administered to study the perceived supervisory behaviors and needs that pertained to licensed SLPAs.

\section{Summary}

In an effort to expand quality speech-language pathology services, the Legislative Council of the American-Speech-Language-Hearing Association sanctioned a strategic plan to implement guidelines for the training, credentialing, use, and supervision of speech-language pathology assistants (ASHA, 1996). The required supervision component of the strategic plan was the focus of this investigation. The state of 
Louisiana is one of only a few states that developed and implemented procedures for licensing speech pathology assistants prior to the development of ASHA's proposed guidelines. Even though some discrepancies existed between Louisiana law (LA Act 892 $\&$ Rules, 1995, 1996) and the nationally proposed guidelines concerning standards for the supervision of SLPAs, it nevertheless, offered an opportunity to study the supervisory relationship. This investigation was important because no research had been conducted, to date, that examined the supervisory relationship between licensed SLPAs and their supervising SLPs. The study was conducted in an effort to develop an understanding of the supervisory process between professionals in the field of communication disorders and to offer practical recommendations for the effective supervision of SLPAs.

\section{Statement of the Problem}

The purpose of this study was to investigate the supervisory relationship between licensed speech-language pathology assistants and their supervising speech-language pathologists. Specifically the study was designed, to explore supervisory behaviors that occurred during supervisory interactions as perceived by the assistants, to examine the extent to which certain supervisory behaviors were perceived as needed by the practicing speech-language pathology assistants, to determine whether or not any differences existed between the supervisory behaviors that occurred and the supervisory behaviors that were perceived to be needed, and to investigate whether demographic variables such as age, gender, years of experience as an assistant, level of licensure, and level of education were related to the speech-language pathology assistants' perceived supervision and supervisory needs. 


\section{Research Questions}

The following research questions were asked:

1. What supervisory behaviors occurred during the supervisory interactions between licensed speech-language pathology assistants and their supervising speech-language pathologists?

2. What were the perceived supervisory needs of the speech-language pathology assistants?

3. What differences, if any, existed between supervisory behaviors that occurred and those that were perceived as being needed?

4. What demographic variables, if any, predicted speech-language pathology assistants' perceptions of supervisory behaviors that occurred and those that were perceived as necessary?

\section{Terminology}

For the purposes of this study, terms have been defined as follows:

1. ASHA refers to the American Speech-Language-Hearing Association which is the national governing body for speech-language pathologists and audiologists.

2. CAA refers to the Council on Academic Accreditation which accredits graduate training institutions' speech-language pathology and audiology programs.

3. CCC refers to the Certificate of Clinical Competence which is granted, by ASHA, in speech-language pathology and in audiology which allows the holder to provide independent practice and supervise clinical practica of student trainees. The 
certificate can be obtained after an individual completes specific coursework, supervised practicum, and supervised professional experience. The individual must also pass the national examination of speech-language pathology or audiology.

4. CEU refers to continuing education unit. One hour of professional education study is equivalent to .1 of an ASHA CEU.

5. CFY refers to clinical fellowship year. Individuals who seek the certificate of clinical competence in speech-language pathology and/ or audiology must obtain professional experience for one year or an equivalent of one year. The clinical fellowship year is a transitional phase between supervised graduate practicum and independent delivery of services.

6. Clinical Clock Hours are defined as supervised client contact hours that are accumulated in the evaluation and treatment of children and adults with disorders of speech, language and hearing. Students must obtain 350 clinical clock hours in the professional area for which the certificate of clinical competence is sought.

7. Clinical supervision is defined as a model of supervision that contains three phases: pre- and post observation conferences, observation and feedback. It emphasizes supervisee-supervisor interaction and the professional development of both parties.

8. Credentialing is defined as a "Mechanism for formal recognition. It may take different forms such as recognition, registration, or certification. Certification is the type of credential ASHA awards professionals. Another type of credential, such as registration (with specified requirements), will be developed for speech-language pathology assistants" (ASHA, 1997). 
9. Direct supervision is defined as on-site, in-view observation and guidance by a speech-language pathologist while an assigned activity is performed by support personnel such as an assistant (ASHA, 1997).

10. Dysphasia is a swallowing disorder.

11. Immediacy refers to communication behaviors which enhance physical and psychological closeness with another that is associated with increased affective learning, perceived cognitive learning and motivation (Andersen, 1979; Christophel, 1990; Frymier, 1993; Gorham, 1988; Mehrabian, 1971).

12. "Indirect supervision means those activities other than direct observation and guidance conducted by a speech-language pathologist that may include demonstration, record review, review and evaluation of audio-or video- taped sessions, and/ or interactive television" (ASHA, 1997).

13. Legislative Council (LC) refers to elected members of ASHA who make up the organization's legislative body.

14. Mentoring is defined as "The process by which one person learns from the knowledge and experience of another" (Slater, 1993). "It involves the formation of professional relationships between senior (mentor) and junior (mentee) professionals for the purpose of professional development" (Lass et al., 1994).

15. A screening refers to a pass-fail procedure to identify individuals who may require further assessment.

16. Speech-language pathology assistants are paraprofessionals in speechlanguage pathology; they are directly supervised by individuals who hold state licensure or the certificate of clinical competence. 
17. A speech-language pathologist refers to an individual with a degree and/or certification in Speech-language pathology who is qualified to diagnose speech, language, and voice disorders and to prescribe and implement therapeutic measures.

18. Supervisee refers to an individual who is developing professional skill through the guidance of a supervisor. In communication disorders the individual may be completing a clinical practicum course, a clinical fellowship year or may be employed as support personnel in speech-language pathology.

19. Supervising speech-language pathologist is defined as a speech-language pathologist who is certified by the American Speech-Language-Hearing Association and/or licensed by the state (where applicable) who oversees the work of students or speech-language pathology assistants.

20. Supervisor is defined as one who facilitates the growth of another through observation, analysis, conferences, evaluation, support, challenge, motivation, leadership, and information sharing.

21. Support personnel in speech-language pathology are people who, after academic and/or on-the-job-training, perform tasks as prescribed, directed and supervised by certified speech-language pathologists. There are different levels of support personnel based on training and scope of responsibilities.

\section{Significance of the Study}

The study of perceived supervisory behaviors and supervisory needs of licensed SLPAs is important because the quality of speech-language pathology services provided by assistants may be affected by the level of instruction, support and professional growth 
afforded by supervisory interactions. No empirical work has been done linking the perceived supervisory behaviors and the supervisory needs of SLPAs. The greatest importance of this study is in developing an understanding of the supervisory process between professionals in the field of communication disorders. Consequently, definite practical results will evolve and specific recommendations are made regarding critical supervisory behaviors for licensed SLPAs.

\section{Limitations of the Study}

This study will be limited to speech-language pathology assistants in the state of Louisiana. It is reasonable to assume that some subjects may be hesitant to respond if the supervision they receive is not adequate according to ASHA or Louisiana Law regulations or other reasons. Others may not respond because of time constraints on their jobs. To the extent that these limitations are true, study conclusions may not be generalizable. 


\section{Chapter II}

\section{Review of the Literature}

The research literature relevant to this study has been divided into three major sections. The first section reviews historical and theoretical perspectives of supervision in the field of education. The second section describes supervision in communication disorders including an examination of the evolution of supervision in communication disorders and relevant theoretical perspectives. Additionally, in this section, literature relative to perceptions of the most critical supervisory behaviors, the interpersonal relationships between supervisors and supervisees, and the professional preparation of supervisors is presented. The third section presents information pertinent to the supervision of support personnel in occupational therapy, physical therapy, psychology and speech-language pathology.

\section{Education}

\section{Historical and Theoretical Perspectives on Supervision}

Literature relative to supervision in educational settings can be traced to the late nineteenth century. Prior to the turn of the century, supervision was described mostly in terms of monitoring and inspecting the teacher's classroom performance, as well as the physical space, where the teaching occurred (Anderson, 1993). This monitoring and inspection usually was accomplished by lay people, often government officials (Anderson, 1993).

Supervision in the schools began to emerge as part of educational administrative practice around the turn of the century, primarily because of increased levels of 
bureaucracy and the public demand for more control over the curriculum (Bolin, 1987).

The first system wide attempt to reform curriculum in education can be traced to 1922

(Tanner \& Tanner, 1987). It was then, that classroom teachers in Denver participated in an effort to improve the quality of instruction in public schools by reforming the curriculum. While implementing the new curriculum, it became clear that specialists would be needed to manage the process, hence the "professionalization" of supervisors (Tanner \& Tanner, 1987, p.46). Consequently, two early fundamental concepts of supervision were, "the emphasis of supervision should be on the improvement of instruction" and "supervision and curriculum development are a complementary process" (Tanner \& Tanner 1987, p. 46).

In the early 1900s, differences of opinions regarding the roles and expectations for supervisors were evident. For example, supervisors continued to be seen as inspectors who commanded excellence and suggested improvements (Bolin \& Panaritis, 1992) or as trainers for implementing and developing new curriculum (Tanner \& Tanner, 1987).

During the early twentieth century, Fayol's (1916) principles of scientific management were adopted for use in the field of education to improve efficiency in the organization. The theory of scientific management that he developed described five functions of managers: to plan, organize, command, coordinate and control. These functions were designated to help managers define goals and establish strategies to accomplish them, coordinate activities, motivate personnel, direct, communicate, resolve conflicts and monitor activities as they were being accomplished. Moreover, implementation of the functions, as applied to education, were seen as ways to deal with 
teacher deficits and as a way to provide on-the-job training for teachers (Bolin \& Paranitis, 1992).

In 1927, the Committee on Supervision of the National Education Association (NEA) Department of Superintendence (as cited in Bolin \& Panaritis 1992 p. 35) defined supervision in the following manner, "supervision has as its object the development of a group of professional workers who attack their problems scientifically, free from the control of tradition and actuated in the spirit of inquiry". They also reported that the Association for Supervision and Curriculum Development Yearbook writers, George E. Strayer and Zenos E. Scott (1930), dedicated a chapter of the book to supervision and described ideas of "creative supervision" which they thought would combine the scientific with the democratic (Bolin \& Paranitis, 1992).

Wilhelms, in 1946 (as cited in Bolin \& Panaritis 1992) attempted to broaden the view of supervision, expanded the definition of supervision to include assumptions that the good supervisor was an organizer and facilitator of opportunity. In 1955, Burton and Brueckner (as cited in Bolin \& Panaritis 1992) published a textbook that reflected interest in cooperative, collaborative group work. In the 1950s and 60s, supervision, while still defined as a technical service (Bolin \& Paranitis, 1992), began to encompass all aspects that affected professional growth and development (Burton \& Brueckner, 1955).

In the early 1960s, teacher educators, Morris Cogan and Robert Goldhammer, began developing, studying and practicing what we now know as clinical supervision. Their efforts described the beginnings of a supervisory method born out of frustration in helping students, as well as veteran teachers, to grow and develop in their professional skills. Cogan (1973) described clinical supervision as a collegial process that involved 
planning, observing, analyzing and conferencing. He contrasted clinical supervision with more general supervision. General supervision focused on outside the classroom behaviors such as developing curricula and writing lesson plans or reports for parents. Clinical supervision emphasized direct classroom observation and an analysis of the inclass behaviors.

Cogan (1973) described clinical supervision as a "cycle of supervision" (p.7) that included the following eight phases: establishing the teacher-supervisor relationship, planning with the teacher, planning the observation strategy, observing the instruction, analyzing the teaching/ learning process, planning the strategy of the conference, the conference and renewed planning. Weinrich (1997) suggested that the concept of clinical supervision was developed as a way to evaluate the performance of student teachers that was not perceived as vague, subjective, and based on criteria that was unknown to the supervisee.

Goldhammer (1969) proposed five stages describing a similar cycle of clinical supervision: pre-observation conference, observation, analysis and strategy, supervision conference and post conference analysis. The purpose of the model was to "attempt to begin systematic practice and to focus on new specializations of roles and functions in supervision" (p.10).

Since Cogan's and Goldhammer's work, researchers in the field of education have studied alternate methods or models for accomplishing supervisory goals. Pajak (1993) described four models of supervision that included the original clinical models, humanistic/artistic models, technical/ didactic models and the developmental reflective models. The original clinical models included Goldhammer's and Cogan's models which 
have been previously described. Pajak also included Mosher and Purpel's (1972) model as an original clinical model. Mosher and Purpel proposed three stages in the clinical observation cycle: (1) planning the teaching, (2) observation of the teaching and (3) evaluation or analysis of the teaching. Mosher and Purpel were primarily concerned with the development of beginning teachers and out of that concern they identified distinct phases that beginning teachers go through as they come to differentiate themselves personally and professionally. The phases included job expectations, personal concerns, and personal role definitions. The job expectations phase was concerned with what administrators and colleagues expected of the new teacher regarding their teaching qualities, curriculum and instruction. The personal concerns phase dealt with what the teachers expected of themselves in terms of what they would like to achieve, what they would like their teaching to be like and what their level of commitment was for accomplishing their professional goals as teachers. The personal role development involved the supervisors in assisting the teachers in developing productive coping mechanisms while the teaching skills were being developed. Mosher and Purpel also advocated group supervision that would allow the supervisor to act as a facilitator and to allow the supervisees to learn from each other.

Beyond the original clinical models, Pajak (1993) described humanistic and artistic models of supervision such as Arthur Blumberg's interpersonal focus on the perceptions of the supervisory process. Also, an artistic model of supervision, such as that described by Elliott Eisner was presented.

Blumberg (1968) conducted a study to determine the relationship between supervisory behavior and interpersonal relations. The results of his study demonstrated 
that supervisees perceived the quality of their supervisory interpersonal relationship to be generally positive when the supervisor's behavior consisted of both, high direct and high indirect behaviors. The high direct behaviors were telling and criticizing and the high indirect behaviors were reflecting and suggesting. The quality of the relationship was also considered positive when little emphasis was placed on the telling dimension and heavy emphasis was placed on asking and reflecting behaviors. Less positive evaluations appeared when teachers perceived their supervisors as incorporating a heavy emphasis on telling without including so much in the way of asking or reflecting. In other words, the supervisee could accept a great deal of "telling" by a supervisor if a great amount of asking and reflecting were also a part of the conference. Negative evaluations were also apparent when supervisors were perceived as being relatively passive, low direct and low indirect.

Blumberg (1974) suggested that discrepancies between perceptions and actual behavior may result from unmet needs and conflicts in expectations between the supervisor and the student. Blumberg (1974) further suggested "in many respects, how a person perceives the behavior of another is much more important than the behavior itself" (p.43).

Other researchers in the educational literature (Blumberg, Amidon \& Weber, 1967; Churukian and Cryan 1972; Gazda, 1973) have emphasized the interpersonal relationship as critical to successful supervisory interactions. For example, Churukian and Cryan (1972) also explored the relationship between student teachers and their supervisors in an effort to determine whether the quality of the relationship, as perceived by the supervisee, was related to the verbal style, direct or indirect, of the supervisor. 
Results of their study indicated that the degree of directness was not a factor that influenced the relationship, but rather it depended upon how individuals perceived the supervision they were getting as compared to what they wanted. Churukian and Cryan (1972) argued that the primary goal of supervisors should be to develop high quality interpersonal relationships with their supervisees in order to effectively maximize student learning.

Blumberg, Amidon, \& Weber (1967) emphasized that the success of the supervisory relationship was based primarily, on shared perceptions between the supervisee and the supervisor.

One could argue that a pre-condition for the type of interpersonal relationship just described would be a set of mutually shared perceptions concerning the nature of the dynamics of the supervisory interaction. That is, in order to create a productive maintenance and change climate, supervisors and teachers ought to have common perceptions of their relationship. If supervisor and teacher perceptions of their relationship are very dissimilar, then they are both working on a different set of assumptions concerning what takes place when they confront each other. This raises communicative barriers before verbal interaction even takes place (p. 2).

Gazda (1973) stated that successful interpersonal relationships are based on one's ability to accurately perceive the behaviors of others. This ability is shaped by factors such as one's own expectations, needs, preferences, knowledge, experiences, prejudices or fears (Larson, 1981). Cogan (1973) also recognized the importance of perception and advised supervisors to be aware of inferential sets and perceptual screens which "may block out some stimuli, bring others into sharp focus, or obscure, magnify, reduce and change the events perceived" (p. 36).

Eisner's (1982) "artistic" approach to supervision was described in the following manner. He said that supervisors must have keen powers of observation and they must 
be able to clearly describe what has been observed. Supervisors must also be skilled in interpreting what they observed, and then be able to effectively assess what has been observed, described, and interpreted. Eisner argued that scientific models of supervision do not allow for the subjectivity that is necessary to adequately deal with the many dynamics of classroom teaching. Eisner described several errors of "scientific" supervision. For example, he contended that the success of the lesson can not be determined by the absence or presence of certain teaching behaviors. He further stated that a scientific method of supervision focused on teacher weaknesses as opposed to their strengths and that highly prescriptive methods of supervision may diminish teacher creativity and satisfaction.

Technical and didactical models of supervision, as described by Pajak (1993) are presented by researchers Acheson and Gall (1992), Hunter (1986) and Joyce \& Showers (1982). Acheson and Gall (1992) defined supervision in terms of helping teachers decrease the gap between where they perform professionally now and where they would like to be ideally or where they may perform most effectively. They subscribe to three sequential elements in the supervisory process: planning, observation and feedback. Acheson and Gall (1992) also outlined five tasks of the supervisors that related to the improvement of classroom instruction. The five tasks were to: (1) provide unbiased feedback to teachers regarding their instruction, (2) diagnose and solve problems, (3) assist the teachers in developing and applying instructional techniques, (4) evaluating teacher performance for promotion and tenure purposes, and (5) helping the teacher acquire a positive attitude concerning ongoing professional growth. Acheson and Gall argued that within the clinical supervision model, and while accomplishing the tasks 
described, supervisors can help teachers develop a personal teaching style and at the same time analyze and improve their teaching skill.

Hunter (1986) described a model of clinical supervision that eliminated the preobservation conference. Instead, she advocated an extensive in-service training. She suggested developing common vocabulary concerning teaching events, and as a supervisor, she presented live or video taped teaching segments in order to demonstrate cause and effect relationships, which she argued were essential to successful teaching and learning.

Joyce and Showers (1982) argued that in order to promote professional growth by the transferring of skills from the more experienced teacher to the less experienced, a coaching process was essential. Coaching provided collegiality, technical feedback, analysis of application, assistance with adaptation, and support and facilitation during frequent opportunities to practice the skills being learned.

McGreal (1997) stated, that after reviewing the coaching literature, "there appears to be agreement that a strong trusting relationship needs to exist between the two parties, and that it will best be accomplished in a setting that is characterized by a visible collegial culture" (p. 96). He observed that unfortunately, the quality of relationship necessary to sustain "coaching" did not always exist between the teacher and the supervisor.

Glickman (1980, 1990) articulated a developmental model of supervision. His model encouraged supervisors to assess the cognitive development of the supervisee, and based on that assessment, to use one of three approaches to supervision. These approaches were described as directive, non-directive and collaborative. The directive 
approach is most suitable for teachers with a low stage of professional development. Non-directive supervision is best for those with moderate levels of professional development and collaborative supervision is advocated for teachers who have achieved high levels of professional development. Glickman outlined five steps that describe the directive approach: A pre-conference, observation, analysis and interpretation, post conference, and critique. The critique is a conference between the teacher and the supervisor to discuss what was most valuable and least valuable about the clinical cycle and what revisions were necessary. This discussion may take place either at the end of the post conference or during a separate meeting. The goal of the non-directive approach is reflective in nature. The outcome of that approach should be autonomous decisionmaking by the teacher. The tasks of the supervisor are to listen to the teacher, clarify ideas, reflect through continued paraphrasing, encourage the teacher, and present an opportunity for the teacher to commit to a particular decision. The collaborative approach is most suitable when teachers and supervisors have near equal levels of expertise, and both care deeply about a particular situation or problem.

The collaborative approach was also eloquently described by Sergiovanni (1992). He argued that in especially effective institutions, supervision is non-existent; it is instead, replaced by trust, professional norms, common goals, and high moral and ethical standards.

Costa and Garmston (1994) advocated a model of supervision that they described as "cognitive coaching". The fundamental assumptions of cognitive coaching are (a) behavior is influenced by perceptions, (b) teaching is decision making, (c) in order to change behaviors an alteration in the thought processes must occur, and (d) individuals 
continue to grow and develop intellectually throughout their lifetimes. Developing trust, facilitating learning, and developing teacher autonomy are three supervisory goals that encompass the process of cognitive coaching.

Other researchers emphasized the use of reflective practice and cognitive development as effective approaches for accomplishing the goals of supervision. For example, research based partially on Vygotsky's (1978) theory of "zone of proximal development", Reiman and Theis-Sprinthall (1993) and Kegan's (1994) writings about adult development, has been conducted by Arredondo and Rucinski (1998). They investigated the use of specific dialogic and reflective techniques as a means of developing the cognitive complexity of both mentors and mentees by examining the professional practices of the mentee. Following instruction on how to incorporate a support/ challenge form of dialogue and written comment, the mentors applied this "sophisticated strategy for supervision" (Arredondo \& Rucinski, 1998, p.306) to mentee professional behaviors. Methods of observation included journal writing, reflective conversation and professor review and feedback. Results of their research revealed that the methods of supervision outlined in the study "can foster important changes in cognitive structures" (p.310). Their overall contention is that the cognitive complexity of the supervisor/ mentor can be developed, then in turn the cognitive complexity of the supervisee/ mentee may also be enhanced. Such developmental growth is in essence the primary purpose of supervision/ teaching. 


\section{$\underline{\text { Summary }}$}

In the early part of this century, differences in opinions regarding the roles of supervisors in the public school systems were evident. The supervisors were viewed as either inspectors or trainers. The methods of scientific management were applied in an attempt to achieve the goals of supervision which were to modify or extinguish teacher deficits and to provide on-the-job training for teachers.

Between the 1920s and the 1950s, the definition of supervision was expanded to include a "creative" aspect to supervision (Bolin \& Panaritis, 1992). It was no longer considered strictly a scientific phenomena. Burton \& Brueckner (1955) described supervision as cooperative, collaborative group work. The goal of the collaborative work was to impact all aspects of professional growth and development.

In the 1960s and 1970s, Cogan and Goldhammer developed a methodology for accomplishing the goals of supervision. At this time, they differentiated between general and clinical supervision, with general supervision focusing on issues such as curriculum development, lesson plan and report writing and clinical supervision involving direct observation of classroom behavior. Clinical supervision was described as "a cycle of supervision" that involved phases that included planning, a pre-observation conference, observation, and analyzing the process. Other researchers slightly modified the original clinical model; however, the primary concepts remained (Hunter, 1986; Glickman, 1990). It was also during the 1960 s and the 1970 s that the significance of the interpersonal relationship between supervisors and supervisees became emphasized in the literature (Blumberg, 1968, 1974; Blumberg et al., 1967; Churkian \& Cryan, 1972; Gazda, 1973). 
In the 1980s, the scientific clinical models of supervision were challenged. For example, Eisner (1982) described an artistic model of supervision that focused on the supervisor's ability to observe, describe and interpret. He argued that scientific methods focused on teacher's weaknesses instead of their strengths and he also contended that highly prescriptive methods of supervision may diminish teacher creativity and satisfaction. During this time period, supervision was also studied from a coaching perspective. Coaching strategies promote professional growth by providing collegiality, technical feedback, support and frequent opportunities to practice the skills being learned (Joyce \& Showers, 1982).

In the 1990s, researchers were increasingly interested in the cognitive development of adults through reflective practice (Arredondo \& Rucinski, 1998; Kegan, 1994; Reiman \& Thies-Sprinthall, 1993). Arredondo \& Rucinski (1998) investigated the use of structured, reflective and dialogic techniques to promote professional growth and development among mentors and mentees. Results of their study revealed that by incorporating such specific techniques, both groups, the mentors and mentees, "described powerful effects on their reflective thinking" (p. 324) which ultimately lead to the development of more trusting relationships between the mentors and mentees. In light of the trusting relationships, the quality of teaching was perceived as being enhanced.

Clearly, supervision in the schools has evolved over the years through phases in which supervisors were viewed as inspectors and managers, then as observers and finally as coaches. The field has been explored from the scientific, the collaborative, the artistic and more recently the reflective. However, the fundamental purpose of supervision in the schools has remained constant for almost a century: to improve the quality of instruction. 


\section{Communication Disorders}

Historical and Theoretical Perspectives on Supervision

Paden (1970) reported that in 1938 the organization (American Speech Correction Association) which is now ASHA, set forth requirements that "speech correctionists" must hold the BA degree and that the educational requirements must include clinical practice. In those early years, the need for supervision was indirectly implied. "This contrasts sharply with current requirements for supervised clinical practica and the concentration of time spent in supervision that characterizes educational programs today" (Anderson, 1988, p. 14).

Anderson (1988) noted that in the early days, supervision focused on pointing out weaknesses, "The clock hours of experience should cover a variety of cases, so that the Associate will have had sufficient professional background to know his shortcomings, and to know when to seek expert guidance from Professional Members and Fellows" (ASHA, 1942). She also reported that this early thinking gave rise to the false notion that supervisors had all the answers.

During the 1940s and 50s there was an increase in interest in school practica and the necessary supervision when the bulk of communicatively disordered clients were seen in the public schools. Concerns regarding the establishment of school programs to provide the services and for universities in preparing the personnel for the programs were addressed. At that time there was an effort to establish requirements that would satisfactorily meet the needs of both the departments of education and the departments of speech pathology and audiology (Anderson, 1988). 
Backus (as cited in Anderson, 1988) commented about the preparation of speech pathologists and the quality of the supervision being provided:

For too long professionals' training consisted largely of courses dealing with etiology of speech and hearing disorders. Courses called 'methods of therapy' provided few laboratory experiences for students. What laboratory experiences there were consisted mostly of therapy with adult clients; when clinical practice with children was available, it was largely unsupervised. When the word 'supervision' was used it represented too often only a paper requirement. Where provisions have been made for staff to supervise clinical practice, far less attention has been paid to qualifications of persons performing that function than to qualifications of persons doing diagnostic and research work (p.17).

An early dissertation dealing with supervision in speech pathology (Shefte, 1959) focused on the student teaching practicum with an attempt to more clearly define its parameters. She outlined the development of educational programs that prepared personnel to work in the public schools. Shefte also described the standards that were emerging in state departments of education and in speech pathology programs across the country. Her dissertation documented the critical components of student teaching as perceived by supervisors and therapists. Anderson (1988) reported that many supervisory issues and concerns emerged from Shefte's work.

During this same time period, Elizabeth MacLearie, a supervisor for the Ohio State Department of Education reported that the only way to improve the quality of services was to improve the quality of the therapist. Anderson (1989) reported that in 1958, MacLearie stated in her published appraisal form to speech and hearing personnel, "Supervision is of no value unless it brings about learning situations. Assessment made as objectively as possible is the first step toward improvement. The appraisal should be equally acceptable to the supervisor and the speech therapist" (p. 18). 
In 1957 ASHA changed its practica requirements so that some of the 200 clinical clock hours could be earned in a public school practicum. However, "some states had already established certification requirements for speech pathologists who planned to work in the public schools" (Anderson 1988, p. 17). MacLearie's study (as cited in Anderson, 1988) reported the first results of a survey about student teaching for the speech pathologist that offered suggestions and recommendations for such experiences.

In the 1960s, school practica or student teaching continued to be addressed in the literature. A national study by ASHA (1961) which was supported by the U.S.

Department of Education concerning public school programs was conducted. A segment focused on the supervision of the school practicum, and the consequent quality of services provided later in the schools. This research provided comprehensive, descriptive data about school programs and about the supervision of school programs including state and local supervisors' responsibilities, activities and professional relationships (ASHA, 1961). The survey also revealed insufficient college and university staff for supervising the clinical practicum. Student clinicians reported deficiencies in their clinical practica (Irwin, Van Riper, Breakey, \& Fitzimmons, 1961). Regarding supervision in the schools, state supervisors expressed a need for more comprehensive supervision of the school experience. Anderson (1988) quoted Darley and Hanley (1961):

The facts concerning present operating procedures suggest significant lack of uniformity in the carrying out of supervisory responsibilities. Practices with regard to direct observation and guidance of clinicians vary widely, some relatively inexperienced clinicians reporting that they received only token supervision. There are indications that some supervisors do not receive information of sufficient scope and detail to permit effective program evaluation and enlightened program planning (p. 20). 
The first published attempt to define the supervisory process in speech-language pathology was when Miner, in 1967 (as cited in Anderson, 1988) identified eight elements critical to supervision in speech pathology. She described the important components as:

1. Understanding and utilizing the dynamics of human relationships which promote the growth of the student clinician.

2. Establishing realistic goals for the student clinician which are clearly understood by both student and supervisor.

3. Observing and analyzing the teaching act in the therapy procedures.

4. Providing the student with the necessary "feedback" which will enable him to become increasingly self-analytical.

5. Knowing and using a variety of materials, methods, and techniques which are based on sound theory, successful practice, or documented research.

6. Recognizing and setting aside the supervisor's personal prejudices and biases which influence perception and develop rigidity in order that the subjective task of evaluation may become as objective as possible.

7. Challenging and motivating the student clinician to strengthen his clinical competency without the supervisor's assistance.

8. Appreciating the individual differences among student clinicians to such an extent that supervisory programs and practices may be radically altered to suit his needs. (pp. 471-472)

In the early 1970s, several task forces were organized by ASHA to develop and make recommendations to assist in the improvement of the leadership, administration, and program development for speech and hearing services in the schools. One was a Task Force on Supervision in the Schools that developed guidelines and made recommendations concerning the supervision of students and support personnel as well as encouraging colleges and universities to develop programs for supervisor preparation. The task force also urged ASHA to establish special supervisor credentials in each state 
and to propose that supervisors get reimbursed from school districts (Anderson, 1988). A final project of the task forces resulted in a document, "Standards and Guidelines for Comprehensive Language, Speech and Hearing Programs in the Schools "(ASHA, 1973, 1974), which included a section on administration and supervision in the schools.

In the 1980s, several dissertations were completed which focused on the supervision of communication disorders students (Brassuer, 1980; Casey, 1980; Farmer, 1984; Kennedy, 1981; Larson, 1981; McCRea, 1980; Nilsen, 1983; Roberts 1982; Schneider, 1989; Shapiro, 1985; Tihen, 1984; Tufts, 1984). It was during also during this time that Anderson (1981) developed a model of supervision for speech-language pathologists which was based on the clinical models of supervision developed by Cogan (1973) and Goldhammer (1969). It emphasized the observation cycle of planning, observing, collecting data and analyzing the data together with the supervisee. Anderson's (1981) continuum of supervision included the following stages: evaluation feedback stage, transitional stage, and self-supervision.

Through the 1990s, interest in many aspects of the supervisory process in human communication disorders continued to grow. Dissertations were written, articles in professional journals were published, books were published and numerous conference presentations that focused on supervision were offered. In 1990, a special interest division (SID 11) was developed by ASHA to address the supervisory and administrative issues in the field of communication disorders. The Council of Supervisors in SpeechLanguage Pathology and Audiology (CSSPA) organized national and international conferences, promoted research and published The Supervisors' Forum to support and encourage research. 


\section{Summary}

Clinical practica has been an integral part of educational training programs in the field of communication disorders since their inception (Backus, 1953; Paden, 1970). The literature, over the decades, demonstrated an increasing awareness of the significance of supervision and the need for guidelines and regulations concerning the supervision of clinical practice.

In the 1960s, researchers began to study the supervision of student clinicians enrolled in university training programs (Erickson \&Van Riper, 1967; Miner, 1967) and it was also at this time, that Kleffner (1964) acknowledged that supervision should be carried over to the professional setting.

In the 1970s and 1980s, several research projects concerning supervision in human communication disorders were presented in journal articles, dissertations and conference presentations. It was also during this time that the primary focus of supervision was related to services in the schools (Anderson, 1970, 1981, 1988; ASHA, 1973-1974; Brassuer, 1980; Casey, 1980; Farmer, 1984; Kennedy, 1981; Larson, 1981; McCRea, 1980; Nilsen, 1983; Roberts 1982; Schneider, 1989; Shapiro, 1985; Tihen, 1984; Tufts, 1984).

During the 1990s, interest in the supervisory process in the field of communication disorders continued to grow. Research concerning many aspects of supervision was conducted (Donnelly \& Glasser, 1992; Dowling, 1992a, 1992b, 1998; Wagner, 1994; Weinrich, 1997). Also, the special interest division (SID 11), The 
Council of Supervisors in Speech-Language Pathology and Audiology and The

Supervisors' Forum were established.

\section{$\underline{\text { Research Literature Related to Supervision in Communication Disorders }}$}

The research concerning the supervisory process as it is practiced in speechlanguage pathology and audiology yields a wide range of both technical/ professional and interpersonal aspects of the supervisory process. For the purposes of this study, literature relative to perceptions of the critical aspects of supervision, the interpersonal relationship between supervisors and supervisees, and supervisor preparation is presented.

\section{Perceptions of the Critical Aspects of Supervision}

Several researchers (Blumberg, 1974; Cogan, 1973; Larson, 1981; Myers, 1980; Oratio, 1977; Pickering, 1997; Russell, 1976; Schneider, 1989) have recognized the significance of perception as an influencing factor on supervisory interactions. Pickering (1987), when describing the importance of perception stated, "Acknowledging the validity of individual perception means putting aside one's own frame of reference in order to hear the other. It also means honoring the affective, poetic, and intuitive side of human beings" (p. 206). Larson (1981) stated, "Perceptions, which involve awareness of people and events, influence interpersonal relationships" (p.2). Research that examined the supervisory process as it was perceived by student clinicians in communication disorders is presented in the following studies.

Russell, as cited in Anderson (1988) used a 171 item rating scale to investigate which supervisory behaviors were considered most important for student SLPs and which 
of those behaviors were actually exhibited by their supervisors. The competencies were grouped into the following categories: interrelational, instructional, evaluative and general. The following ten competencies were rated as being the most important behaviors that supervisors should exhibit as perceived by student clinicians:

1. Being fair and impartial in the evaluation of the clinician.

2. Treating the clinician in a fair and impartial manner.

3. Encouraging the clinician to question, disagree and express ideas.

4. Guiding the clinician to make clinical decisions.

5. Being flexible and adaptable.

6. Providing the clinician with constructive and evaluative feedback.

7. Being responsive to the clinician's feedback and evaluation.

8. Perceiving the clinician's feedback and evaluation.

9. Possessing a broad command of approaches to treating the disorder(s) of concern.

10. Providing the clinician with direct feedback and evaluation (p. 5).

When comparing the students' perceptions of most valued supervisor behaviors and perceptions of actual behaviors observed, some discrepancies were noted. The discrepancies were greatest in the evaluative category. The need for immediate feedback that was precise and sufficient was unmet. Students also indicated that more emphasis should be placed on training the student to self-evaluate. Other unmet needs were noted in the interrelational category that included the clinicians' needs for more supervisor concern regarding feelings and problems. The only item that appeared in both the actual and most valued behavior was "treating the clinician in a fair and impartial manner".

Myers (1980) explored the relationship between affective and technical supervisory needs and student level of clinical experience. Results indicated that students with less clinical experience required more technical assistance; however, affective needs continued throughout training. 
Larson (1981) investigated the perceived supervisory needs and expectations of two levels of student clinicians enrolled in pre-practicum or practicum in twenty-two different speech-language pathology or audiology university programs. Larson's study revealed that needs and expectations of experienced and inexperienced student clinicians were similar but the inexperienced reported slightly higher expectations and greater needs. She stated:

Both groups of students indicated high expectations and strong needs for their own active participation in the supervisory conference interactions. In the role of active supervisee, students expect to ask questions, and be allowed to express their opinions and have their ideas used during conferences. To a lesser extent, students expect and need their supervisors to function in an instructional role. Specifically, students expressed expectations and needs for supervisors to function as teachers by helping them with client goals and therapy techniques (Larson, 1981 p. 108).

Oratio, Sugarman \& Prass (1981) studied the principal components of effective clinical supervision based on the perceptions of supervisees. A 54-item rating-scale was developed to test six areas of supervision (administration, instruction, communication, interpersonal, professionalism, and flexibility). They found that the major factor was interpersonal (with 59 percent of total variance) and that the minor factor was administration (with 5 percent of variance).

Dowling and Wittkopp (1982) studied students' ratings of the following perceived supervisory needs: lesson plan and report writing, supervisory observation, conferencing, professional responsibility, and general supervisory practice. Subjects included undergraduate and graduate student clinicians from six universities with varying amounts of clinical experience. Results indicated that students with less clinical experience rated writing lesson plans and the need for frequent observations as being most valued. The more-experienced clinicians valued assuming more responsibility for the client. Results 
also indicated that students do not have preconceived notions about what supervision is, thus, lending support to the need for preparing students for the supervisory process. Schneider (1989) conducted a study to identify components perceived to be critical to the supervisory process by supervisors and supervisees. She asked the participants to rate 25 statements using a Likert scale to assess the most critical areas of supervision in speech pathology. Results indicated that both, supervisors and supervisees, rated 24 of the 25 statements as being critical. What differed was how critically they rated them. Analysis of the data ultimately resulted in the identification of several issues that were viewed as critically important by both groups. The critical issues included the following supervisor behaviors: supervisor serves as resource person, provides feedback, respects supervisee, communicates ideas and information clearly, demonstrates therapy techniques, is flexible, and establishes and maintains an interpersonal relationship with the supervisee. Schneider concluded that these issues should be highlighted in supervisor training programs.

Perceptions of supervisory effectiveness have been described in terms of types of social power exhibited by supervisors. Raven and French (1960) defined five social bases of power which were reward, coercive, legitimate, expert and referent. Wagner (1994) investigated supervisor and supervisee perceptions of supervisor social power bases and supervisor satisfaction with clinical supervision. The data from his study suggested that all levels of supervisees perceived their supervisory experience as being more satisfactory when supervisors used a greater degree of expert, referent, and reward power for all levels of practicum students. 


\section{The Interpersonal Relationship}

According to Anderson (1988) "The supervisory relationship may be one of the most intense interpersonal experiences in which a person may engage. The emotional dimensions of this vital relationship may influence both parties in ways that have not even begun to be identified" (p. 202). She further stated, "Perhaps supervisors have focused on teaching and instruction to the neglect of the interpersonal needs of their supervisees" (p. 202). Culatta (1992) offered a different perspective, "simply stated, my fear is that researchers have lost sight of the responsibility to provide a clinical education for speech-language clinicians. Instead, we have channeled the research focus into the study of principles of dyadic and small group communication" (p. 49).

Caracciolo, Rigrodsky \& Morrison (1978b) argued "student clinicians benefit from the same interpersonal conditions that are usually provided for client growth" (p. 467). Those authors also contended that the strength of the supervisor's ability to act as a change agent is directly related to his/ her level of interpersonal skills. In that same vein, Rogers (1962) stated "it is the quality of the interpersonal encounter with the client which is the most significant element in determining effectiveness" (p. 416).

McCrea (1980) adapted a scale developed by Gazda (1973) to assess the interpersonal component of the supervisory relationship. After analyzing 28 supervisory conferences she provided data about the presence or absence of the following five interpersonal dimensions of supervisor behavior: empathic listening, respect, facilitative genuineness, concreteness of expression, and the ability of the supervisee to self-explore. Results indicated that respect, facilitative genuineness and concreteness of expression were only minimally demonstrated. Results also revealed that empathic listening was 
rarely identified among supervisor behaviors and that supervisee self-exploration was not identified enough to be used in statistical analysis. Students at two levels of training, beginning clinicians and experienced clinicians, participated in this study. The results of this investigation revealed that supervisor behaviors were undifferentiated whether they were interacting with the beginning or the experienced clinician.

Pickering (1984) conducted a qualitative study in which she examined the interpersonal communication during supervision conferences. She derived her evaluation procedures from phenomenology (Guba \& Lincoln, 1985) and hermeneutics (Bender, 1975). She transcribed verbatim segments from audio taped supervisory conferences. The data were grouped into categories and then the themes and patterns were studied. Results of her study indicated that the emphasis on instruction and technical skills did not fit supervision models that call for collaboration, problem solving, self exploration, and intrapersonal growth.

Pickering (1987) described a paradigm shift from a male-centered perspective to a female-centered perspective on supervision that places a high emphasis on the interpersonal aspect of supervision. The female-centered perspective " is resulting in interpretations significantly different from traditional ones" (p.116). Pickering (1987) reported the following implications of feminist theory and its relationship to supervision: (a) the importance of shared collaborative decision-making, (b) the critique and demystification of power, (c) the importance of intimacy and nurturance and (d) the use of multiple perspectives in viewing and understanding the world (p. 116).

Other authors have offered perspectives on supervision from a feminist theory viewpoint. For example, Kadushin, (1992) stated: 
The traditional picture of the supervisor-manager replicates the male stereotype assertive, decisive, direct, authoritative, combative, rational and logical -the picture of the feminist supervisor tends to project an image that gives priority to elements in the female stereotype. The feminist supervisor is nonelitist, democratic, cooperative, intuitive, emotionally open, and informal. She attempts to minimize hierarchical differences and, while not indifferent to power and authority, tries to distribute power and authority more widely, using power when it needs to be used in a constructive, nondominating, facilitative manner (p. 506).

Atkins (1996) identified supervisor immediacy as critical to successful supervisory relationships. Immediacy is described as communication behaviors that enhance physical and psychological closeness with another that is associated with increased affective learning, perceived cognitive learning and motivation (Andersen, 1979; Christophel, 1990; Frymier, 1993; Gorham, 1988; \& Mehrabian, 1971). Her study revealed that student clinicians ranked the following statements: "The clinical supervisor should give the student clinician respect and attention" and "The clinical supervisor should be professional and competent" (p. 141) as 1 and 2 respectively, while clinical supervisors ranked them as 2 and 1 respectively.

\section{Training in Supervision}

Most researchers who study the supervisory process contend that preparation of supervisors is critical to the quality of the supervision (Anderson, 1988; Arredondo et al., 1995; Arredondo \& Rucinski, 1998; Barrow, 1990; Crago \& Pickering, 1987; Dowling, 1998; Donnelly \& Glasser, 1992; Gous, 1994; Kadushin, 1992; Sergiovanni, 1992). However, most students in speech-language pathology programs were supervised during clinical practica and during their CFY and then often themselves became "overnight supervisors" for other students or those completing a clinical fellowship year without formal training in supervision (Anderson, 1988). She further stated, 
Acceptance of the need for preparing supervisors in speech pathology and audiology has come slowly, although it has increased rapidly in the past few years. The idea that "anyone" can supervise is firmly entrenched. Various reasons are given. We've supervised all these years and we're doing OK. Why do we need to train supervisors? We don't have data to prove training supervisors makes them more effective. We don't know enough about the supervisory process to begin training programs. We can't afford to add another course to the curriculum. Such statements do not come from supervisors themselves, who generally express a great need for more information about what they are doing" (p. 255).

Barrow (1990) studied the effects of training supervisors in speech-language pathology. She compared the ability of trained and untrained supervisors to implement the supervisory process. An experimental group participated in a six-week training program while the control group received no training. She implemented the Individual Supervisory Conference Rating Scale to determine pre- and post treatment measures. Both supervisors and supervisees completed the rating scales that assessed both direct and indirect supervisory behaviors. Both groups, supervisors and supervisees, perceived significant changes in the behaviors of the experimental group during the supervisory conferences. Direct behaviors diminished and indirect behaviors increased. Supervisees appeared to correlate the perceived importance of the supervisory conference with their level of participation.

Donnelly \& Glasser (1992) conducted a study to determine if training speech pathologists in a specific self-supervision technique would improve their ability to evaluate their own professional work. Their sample included forty student speech pathologists who were near completion of a public school practicum and who were unfamiliar with the self-supervision process. The subjects were randomly divided into two groups to include thirty subjects and a control group of ten. The instrument used to measure the self-supervision skills was the Clinical Supervision Methods in Speech- 
Language Pathology (Glasser \& Donnelly, 1989). A pre-test was administered to all the subjects, then the thirty subjects participated in an eight week training session on the value and process of self-supervision. At the end of the eight weeks a post-test was administered to all forty subjects. The criteria used to compare the pre- and post-tests were amount of writing, specificity and use of behavioral terminology. The study revealed that significant increases in the criterion behaviors, relative to their own professional work, were evident for the group trained in self-supervision skills. Overall the researchers concluded, "training is necessary in order to become an effective selfsupervisor" (p. 85). Other researchers (Anderson, 1981; Leith, McNiece, \& Fusilier 1989; Oratio, 1977) have described self-supervision as the most critical skill a supervisee learns from a supervisor. "Without this skill there can be no further independent professional growth" (Leith et al., 1989, p. 75).

Gous (1994) conducted a study to explore the communicative interaction patterns between supervisors and student clinicians in speech pathology. The communicative behaviors of his subjects were analyzed using Blumberg's Interaction Analysis System (1970). Results of his study indicated that the supervisors were found to be predominately high-directive and low facilitative. Gous (1994) concluded that in order to effect change in supervisors' communicative behavior, to ultimately result in more effective supervisory conferences, specific training in the use of appropriate communication and other supervisory behaviors is necessary.

Dowling (1998) suggested that prospective graduate students "solicit information regarding a training program's commitment to supervisory training" (p. 9). She offered 
the following examples of appropriate questions that could be included in a letter of inquiry to university program chairs:

Have the supervisors in the program had formal training in supervision? Are training opportunities in supervision provided to externship supervisors? Are members of the supervisory staff involved in research on the supervisory process and its effects on clinical training?

Is there a supervision course in the curriculum? (p. 9).

Dowling (1998) stated "answers to these questions will allow the potential student to assess the value attached to quality supervision in a given program" (p. 9).

The following two studies suggested that professional preparation in supervision was not needed and may possibly be detrimental to the process. Schubert \& Acheson (1975) found that supervisors depicted themselves as having little or no training in supervision, but they felt they had adequate skill and experience.

Johnson (1994) conducted a study and concluded that supervisors who completed coursework in supervision while maintaining a personal caseload separate from supervision, and had at least five years experience supervising, expressed less confidence and practicality for accomplishing their supervisory purpose. The supervisory strategies used were (1) demonstration, (2) observation assignments, (3) pairing students, and (4) referral to a reading list. The author suggested that the experience and education in supervision provided the supervisors, not with pessimism, but with a sense of reality about the tasks of supervision.

\section{Summary}

In this section, a review of the literature and research related to perceptions the critical aspects of supervision, the interpersonal relationship, and supervisor training were presented. The major aspects of this review are presented in the following paragraphs. 
Perceived supervisory needs included both the technical/ instructional and the affective/ interpersonal. Generally, student clinicians with less clinical experience required more technical support than those with more experience. However, the need for strong interpersonal relationships continued as clinical experience was gained (Larson, 1981; Myers, 1980).

The research demonstrated that successful supervisor/ supervisee interpersonal relationships were critical to effective supervisory interactions. Some researchers found that supervisory behaviors that lend themselves to successful, collaborative relationships were minimally evident (McCrea, 1980; Pickering, 1984). Others offered a feminist perspective on the supervisory process (Kadushin, 1992; Pickering, 1987) which included more collaboration, the demystification of power, the importance of nurturing and intimacy, and more democratic, cooperative, open, and informal supervisory behaviors.

Researchers have demonstrated that training in supervision was necessary in order to more effectively implement the supervisory process (Barrow, 1990; Donnelly \& Glasser, 1992; Gous, 1994). While ASHA also continues to emphasize the need for training supervisors, and especially with the current recommendations for the educational requirement for those who supervise SLPAs, the reality of well-trained supervisors in the field of speech-language pathology is on the horizon. ASHA's commitment to training, and the concomitant sophisticated supervisory techniques available such as those described by Arredondo \& Rucinski (1998) offer evidence that "the most reliable fact about supervision in speech-language pathology is that those doing it have had no or little training for what they are doing" (Anderson, 1988, p.29) may become obsolete. 


\section{Supervision of Support Personnel}

The following section of this review includes information pertinent to the supervision of support personnel in occupational therapy, physical therapy, psychology and speech-language pathology. No research was located regarding the supervisory relationship between certified occupational therapy assistants and physical therapy assistants and their respective supervisors. Hence, the bulk of this section regarding supervision of support personnel in those two professions outlines the guidelines for the supervision as described by their national governing bodies: The American Occupational Therapy Association and The American Physical Therapy Association. Research concerning the supervision of psychology assistants and speech-language pathology assistants is presented.

\section{Occupational Therapy}

The American Occupational Therapy Association (1994) described the supervision between registered occupational therapists, certified occupational therapy assistants and other support personnel as:

A process in which two or more people participate in a joint effort to promote, establish, maintain, and/ or elevate a level of performance and service. Supervision is a mutual undertaking between the supervisor and the supervisee that fosters growth and development; assures appropriate utilization of training; encourages creativity and innovation; and provides guidance, support, encouragement and respect while working toward a goal (p. 1027).

In setting forth guidelines for the amount and type of supervision for occupational therapy personnel, the American Occupational Therapy Association has stated, "The amount of supervision varies, depending upon the occupational therapy practitioner's clinical experience, responsibilities, and level of expertise. Supervision occurs along a 
continuum that includes close, routine, general and minimal" (p.1027). The American

Occupational Therapy Association described the levels along the continuum as:

Close supervision requires daily, direct contact at the site of work.

Routine supervision requires direct contact at least every two weeks at the site of work, with interim supervision occurring by other methods, such as telephonic or written communication.

General supervision requires at least monthly direct contact, with supervision available as needed by other methods.

Minimal Supervision is provided only on a need basis, and may be less than monthly. (AOTA, 1993a, p. 1088).

The American Occupational Therapy Association also stated that all levels of certified occupational therapy assistants (COTAs), entry, advanced and intermediate, may supervise those whose scope of practice, level of education or experience is lesser than their own. For example, entry-level COTAs may supervise occupational therapy technicians, intermediate-level COTAs may supervise entry-level COTAs and technicians, and an advanced level COTA may supervise technicians, entry and intermediate level COTAs (AOTA, 1993a). The American Occupational Therapy Association recognized that state regulations may dictate parameters of certified occupational therapy assistant practice (AOTA, 1993b).

It is evident that the American Occupational Therapy Association recognized the importance of supervision for certified occupational therapy assistants, however, no published research describing the supervisory relationship between COTAs and registered occupational therapists was located.

\section{Physical Therapy}

The physical therapist assistant (PTA) also must work under the direction and supervision of the physical therapist (PT). When the PTA and the PT do not work in the same practice setting, the following requirements must be observed by the supervisor: (a) 
the qualified physical therapist must be accessible by telecommunications to the physical therapy assistant at all times while the PTA is treating patients, (b) the initial visit must be made by the qualified PT for evaluation of the patient and establishment of a plan of care, and (c) there must be regularly scheduled and documented conferences with the PTA regarding patients, the frequency of which is determined by the needs of the patient and the needs of the PTA.

As long as the physical therapy assistant is involved in the care of a patient, a supervisory visit by the qualified physical therapist will be made upon the following requests or conditions. The physical therapy assistant requests a re-evaluation of a client, when a change in treatment plan of care is needed, prior to any planned discharge, in response to a change in the patients medical status, and at least once a month, or at a higher frequency when determined by the physical therapist based on the needs of the patient.

Further, the American Physical Therapy Association's guidelines for the supervision of physical therapy assistants state that a supervisory visit should include: (a) an on-site re-assessment of the patient, (b) on site review of the plan of care with appropriate revision or termination, and (c) assessment and recommendation for utilization of outside resources (APTA, 1996, program 32).

Like the certified occupational therapy assistant, the physical therapy assistant may supervise lower level support personnel, such as physical therapy aides. The American Physical Therapy Association also stated that when physical therapy assistants and physical therapists are not "continuously within the same physical setting, greater emphasis in directing the PTA must be placed upon oral and written reporting" (p. 2). 


\section{$\underline{\text { Psychology }}$}

Research relative to the supervision of psychology assistants is presented in a study by Magelssen (1989). He examined individual state laws in an effort to determine how closely the states followed the recommended guidelines for the supervision of assistants as set forth by the American Psychology Association. Magelssen found that even though researchers generally agreed upon the importance of supervision, many state guidelines did not clearly delineate minimum requirements for the supervision of unlicensed psychological service providers such as psychology assistants and trainees. He studied two aspects of the problem: the qualifications of the assistants and trainees and the amount of supervision required. Results of his study indicated that states varied widely regarding the regulation of the practice of unlicensed providers. He studied the laws of seven states and results indicated that no state included all the recommendations proposed by American Psychological Association.

Theiner (1969) described the use of psychology assistants to address the "man power problem". "Regarding the use of psychology assistants, the rationale is that the psychologist, by virtue of his advanced training, can function more efficaciously as a theoretician and overall planner than as a full -time therapist" (p.686).

\section{Speech-Language Pathology}

An eleven-state survey was conducted by Coufal, Steckelberg \& Vasa (1991) to examine the utilization of support personnel in communication disorders. The respondents were administrators of communication disorders programs and special education directors in every educational agency in the mid-western states. The study addressed four major areas: (1) Current employment trends, (2) current training practices, 
(3) general awareness of ASHA guidelines for support personnel, and (4) current professional practices in supervision and evaluation of paraprofessionals.

The component of their study that focused on the professional practices in supervision and the evaluation of paraprofessionals addressed three issues which were (a) to identify the person responsible for the supervision of the paraprofessional, (b) to identify standards for the supervision and (c) to explore the requirements necessary for supervisor training. The results of this part of their study showed that the speechlanguage pathologist, the special education administrator and the building administrator all had extensive responsibility for evaluation. The study also revealed that "there appears to be a lack of training for supervising speech-language pathologists and a general lack of written polices specifying the standards for supervision" (p. 55).

Slater (1992) reported results of a national survey that collected data describing the perceptions of certified SLPs and audiologists concerning the need for support personnel in speech-language pathology and audiology. At that time, $41 \%$ of the audiologists who responded reported low or no need while $72 \%$ of the speech pathologists reported moderate to high need for support personnel.

Iskowitz (1997) described the utilization of speech-language pathology assistants as it has occurred in Florida. He stated, "the shortage of seats in master's level programs is fueling the demand for assistants in speech-language pathology and audiology" (p. 3). The "shortage of seats" was reflective of ASHA's Council on Academic Accreditation (CAA) standard which proposes strict guidelines for the ratios between graduate students and professors in accredited training programs in communication disorders (ASHA, 
1993). Iskowitz (1997) further stated that agencies expressed reservation about hiring SLPAs. Even though Florida has developed and implemented strict guidelines for the use of SLPAs, the "lack of consistent national guidelines pertaining to assistants is the biggest barrier to hiring support personnel in any setting" (Iskowitz, 1997, p. 3). In Florida, the guidelines for the supervision of assistants, who hold an associate's degree, required direct supervision of the assistant that required the physical presence of the supervising SLP. If the supervising SLP was not on the premises, the assistant could only perform duties that did not include direct client contact [Chapter 59BB-8.4.004, Florida Administrative Code (FAC)]. The supervision for those who have earned a bachelor's degree was not as restrictive. It was noted that several school districts do not hire associate level assistants, and they do not hire those with baccalaureate degrees who will not be eligible to be admitted into a master's program. Iskowitz (1997) reported:

In addition to certification for professionals with associate's degrees, Florida issues a temporary two-year certificate for speech-language pathology clinicians who have earned a bachelor's degree in communication disorders. During this period, the individual must be accepted into a graduate program in communication disorders. The certificate cannot be renewed. Once accepted into a graduate program, the individual is issued a five-year, nonrenewable certificate by the state. The person has five years to complete the master's program (p. 11).

In a national survey sent to SLPs employed in educational settings, several topics were investigated including the use of support personnel. Peters-Johnson (1998) reported that $15 \%$ of the respondents indicated that support personnel were employed in their schools and $12 \%$ indicated that support personnel were employed in their school district, but not their school. The survey revealed that the support personnel performed the following activities: Implementing therapy, keeping records, planning and preparing for intervention, attending meetings, conducting screenings, and performing diagnostic 
evaluations. The majority of the respondents described the impact of the support personnel as a positive one. Comments from the SLPs "signified that having these staff alleviated the speech-language pathologist's burden by taking care of most of the paper work and the coordination of services" (p.125). However, some of the respondents disagreed and reported that the use of support staff has not been positive. For example, some reported that the benefits of support personnel has been minimal or has resulted in an increased burden on them, while others described concerns about using non-certified staff and the quality of services being offered.

Summary

Clear definitions and expectations of the supervision requirement for certified occupational therapy assistants and physical therapy assistants have been delineated by the American Occupational Therapy Association and the American Physical Therapy Association. The proposed supervision requirements for SLPAs are more rigid than the recommended guidelines for occupational therapy and physical therapy assistants. While other allied health professions, specifically occupational therapy and physical therapy have developed guidelines for the use, credentialing, and supervision of support personnel, published research relative to the supervision of those assistants is limited.

Like the occupational and physical therapy associations, ASHA also stated that the amount and type of supervision required for assistants should be based on the skills and experience of the SLPA. However, ASHA proposed a minimum requirement that included at least some direct supervision every week (ASHA, 1996). Also, assistants in speech-language pathology may not supervise other assistants regardless of their level of experience. 


\section{Chapter III}

\section{Research Design and Methodology}

The purpose of this study was to examine the supervisory relationship between licensed speech-language pathology assistants and their supervising speech-language pathologists. Specifically the study was designed (a) to explore supervisory behaviors that occurred during supervisory interactions as perceived by the assistants, (b) to examine the extent to which certain supervisory behaviors were perceived as needed by the practicing speech-language pathology assistants, (c) to determine whether or not any differences existed between the supervisory behaviors that occurred and the supervisory behaviors that were perceived to be needed, and (d) to investigate whether demographic variables such as age, gender, years of experience as an assistant, level of licensure, and level of education were related to the speech-language pathology assistants' perceived supervision and supervisory needs.

\section{Subjects}

For this study, the 173 SLPAs licensed by the Louisiana State Board of Examiners in Speech Pathology and Audiology were the population. The sample consisted of the total population in the study. The names and addresses of the licensed SLPAs were formally requested from the state licensing board. 


\section{Observations}

\section{Instrument}

A survey instrument used by Larson (1981) was modified and adapted for this

study. It collected information about the supervisory experience between licensed SLPAs and their supervising SLPs.

The survey instrument consisted of three sections. The first section contained 29 statements that were each rated twice by the respondents using a five point Likert scale. The first rating identified the extent to which the supervisory behavior or characteristic suggested by each item occurred. The second rating identified the extent to which the supervisory behavior or characteristic suggested by each item was perceived as needed. The Likert rating scale ranged from 1 to 5 with 1 representing "to a very little extent" and 5 representing "to a very great extent".

The survey items were organized into three categories of supervisory behaviors and characteristics: (a) instructional (b) interrelational, and (c) general. The behavior variables that constituted the instructional and interrelational categories were based on situational leadership theory (Hersey \& Blanchard, 1982). The instructional category was related to Hersey and Blanchard's 'task behavior' category which "explains activities each is to do and when, where and how tasks are to be accomplished" (p. 96). The interrelational category was related to Hersey and Blanchard's 'relationship behavior' category which described "the extent to which leaders are likely to maintain personal relationships between themselves and members of their group (followers) by opening up channels of communication, providing socioemotional support, 'psychological strokes', and facilitating behavior" (p. 96). Both the instructional and interrelational categories 
included supervisory behaviors that were typically viewed as supervisor focused. In other words, the supervisor was primarily responsible for initiating or accomplishing the supervisory task or behavior suggested.

The behaviors represented in the general category were concerned with the professional growth of the SLPA, the methods of dyad communication, and the methods of self-analysis of clinical behavior used by the assistants. Those behaviors were typically supervisee focused or initiated. For example, in order for the behaviors in the general category to be accomplished, the supervisee should have taken an active role in initiating the supervisory behaviors suggested (Larson, 1981; Russell, 1976). The categories of supervisory behaviors and the survey items that constituted each category are included in the appendix.

The second section contained eleven open-ended or discussion questions. Of the eleven questions, six required a yes or no response. These items also requested further information such as an explanation or description. The remaining five open-ended questions were designed to collect additional information about the extent and nature of the supervisory process as it occurred between licensed SLPAs and their supervising SLPs.

The third section collected demographic information about the respondents. Again, a copy of the survey instrument is included in the appendix.

Validity

Based on a thorough review of the literature, the survey rating scale exhibited good construct validity (ASHA, 1985; ASHA, 1997; Larson, 1981; Russell, 1976). After adaptation and modification of Larson's (1981) needs and expectations rating scales, five 
experts reviewed the instrument. The experts were supervisors who had at least eight years experience in supervision who were employed in either a public school or university setting. The experts were selected based on their years of experience and their expertise in supervision. Overall, they agreed that the instrument tested what it was designed to test. They offered comments that primarily were related to the wording of the items on the survey instrument. For example, one expert suggested rewording item 7 in Part I of the survey from, "Your supervisor functions as a teacher who instructs you" to "Your supervisor functions as a teacher who helps you learn." Another expert suggested rewording item 35 in Part II of the survey from, "Is there a specific skill or behavior that your supervisor exhibits that is especially helpful? Please describe" to "What specific skills or behaviors does your supervisor exhibit that are especially helpful? Please describe." After informally soliciting the comments from the experts, some minor changes were made in the wording of the stimulus items on the survey instrument. In addition, SLPAs enrolled in graduate courses (voice disorders and phonological disorders) at Southeastern Louisiana University during the spring semester of 1998 fieldtested the instrument. Their comments indicated that the instrument tested what it was designed to test, for example, one SLPA who field tested the instrument commented, "The survey addresses the issues I think are most important" thus, no other modifications were made.

\section{Reliability}

Cronbach's Alpha Coefficients were computed to assess the internal consistency reliability of the survey instrument. These internal consistency estimates determined how consistently individuals responded to the items on the scale. For example, the Cronbach's 
Alpha measures the extent to which item responses obtained at the same time correlate highly. Cronbach's Alpha unifies several meanings of internal consistency and is commonly used in research when determining internal reliability (Nunnally \& Bernstein, 1994).

Table 1 displays the Cronbach's Alpha Coefficients. Alpha reliabilities for each rating scale and the alpha reliability for the total scale are presented. These scores indicated reliability of at least .86 .

Table 1

$\underline{\text { Cronbach's Alpha Coefficients }}$

$\underline{\text { Rating Scale }}$ $\begin{array}{ll}\stackrel{\text { Alpha }}{\text { Coefficients }} & \underline{\text { No. of }} \\ \underline{\text { Items }}\end{array}$

Supervisory behaviors occurred

.9682

29

Supervisory behaviors were needed

.8679

29

Combined Scales

.9540

58

\section{$\underline{\text { Administration }}$}

Data collection occurred between April 15, 1998 and May 31, 1998. A letter of introduction and the survey instrument were mailed to all licensed SLPAs in Louisiana. After two weeks, the non-respondents were sent a post card again requesting their response to the previously mailed survey. A second letter and a duplicate survey were mailed following the fourth week to those who had not previously responded. Selfaddressed, postage paid envelopes were provided. 


\section{Analyses of Data}

As previously described, the survey instrument was comprised of three parts. Each part was analyzed through the use of different statistical procedures. Four different methods of analyzing the data were employed: reliability testing, descriptive techniques, analysis of variance and qualitative techniques.

\section{Quantitative Methods: Coding for Parts I, II, and III.}

The behavioral variable ratings in Part I of the survey, as well as, the responses to the yes or no questions in Part II and the demographic data gathered from Part III of the survey were entered into SPSS -75. A total of 70 columns, representing one variable in each column, were used on the SPSS spreadsheet. Each row on the spreadsheet included the data from one subject's survey.

The first column of the spreadsheet was used to identify the subjects. Each subject was given a subject identification number (1-88). The next 29 columns were labeled T1-T29, in those columns subjects' ratings representing the extent to which the behavioral variable occurred were recorded. The next 29 columns were labeled as N1$\mathrm{N} 29$, in those columns subjects' ratings representing the extent to which the behavior variable was perceived as needed were recorded. The next six columns were allocated to report the yes or no responses from Part II of the survey and the remainder of the columns that comprised the spreadsheet were labeled with demographic variables: gender, education, years of experience, setting, license, and age.

The six questions that requested a yes or no response were numerically coded as $0=$ no, $1=$ yes, $2=$ sort of, and $3=\mathrm{I}$ don't know. The subject's gender was coded as $0=$ male and $1=$ female. The subject's level of education was coded as $1=$ associate's degree, 
$2=$ bachelor's degree, $3=$ =bachelor's degree plus some graduate coursework, and 4=master's degree. The subject's work setting was coded as $1=$ public school and $2=$ other. The subject's level of licensure was coded as $0=$ provisionally licensed and $1=$ fully licensed. The subjects' years of experience as a speech-language pathology assistant and ages were also entered on the spreadsheet.

The 29 behavioral variables from Part I were coded according to the subjects rating of 1 to 5 . In scoring the objective portion of the survey, the items were assigned values as follows:

5 points 5- To a very great extent

4 points 4- To a great extent

3 points 3- To some extent

2 points 2- To a little extent

1 points 1- To a very little extent

The two ratings for each of the behavioral variables, as well as the yes and no responses, and demographic data created the 70 variables in the data pool.

\section{Part I}

Responses to Part I of the survey, which examined the extent to which certain supervisory behaviors occurred and the extent to which they were perceived as needed, were analyzed using the SPSS-75 computer program. An acceptable level of internal consistency reliability was established by calculating Cronbach's Alpha. The survey responses on Part I were analyzed using descriptive statistics that included the mean, standard deviation, lowest rating, highest rating, and number and percentage of assistants that responded to each item. A t- test for analysis of variance, with a probability level of .05 was then employed to measure the differences between the mean scores of the first 
and second ratings of the 29 individual items. In addition to the analyses of the individual items, differences between the means for the ratings that identified the extent to which behaviors occurred and were perceived as needed for the categories of behavioral variables, instructional, interrelational and general were calculated.

\section{Part II}

Part II of survey was analyzed using descriptive statistics and qualitative techniques. This portion of the survey consisted of yes/ no and open-ended questions. Questions that required yes or no responses were analyzed by computing frequencies and percentages of yes's and no's. Also the number of assistants that responded to each of the questions was reported. The subjects were asked to provide comments for each of the eleven yes/ no or open ended discussion questions. Content analysis was used to examine the participants' comments. Patton (1990) defined content analysis as the "process of identifying, coding, and categorizing the primary patterns in the data" (p.381). Content analysis can be performed with either quantitative or qualitative procedures. In these data analyses, both were used. Miles and Huberman (1994) stated that qualitative data can be treated quantitatively by "counting the frequency and sequencing of particular words, phrases or concepts" (p.49).

The content analysis that was performed for the subjects' comments to the openended questions on the survey consisted of the following procedure: (a) For each question asked, the researcher transcribed verbatim each subject's comment; (b) the researcher identified each concept within a response and transcribed it onto an individual strip of paper; (c) the information on the strips of paper was organized into categories; (d) a 
frequency count of the number of subjects who expressed a specific comment was recorded (e) emerging themes, categories and patterns were identified and reported; and (f) a frequency count of the number of subjects that responded to each of the open-ended question was recorded.

\title{
Part III
}

Part III of the completed surveys, which included demographic data about the respondents, was analyzed using the following methods. First, a frequency distribution of the demographic data regarding gender, level of licensure and academic degree was reported. Also, measures of central tendency including the means, standard deviations, minimums, maximums, modes and ranges were reported for the age and years of experience variables.

\begin{abstract}
Summary
In this chapter, the purposes of the dissertation and the methods and procedures employed in this study were described. Included in the description were subject selection, description of the instrument and data collection procedures. The methods of data analyses including descriptive statistics, analysis of variance, and content analysis were presented.
\end{abstract}




\section{Chapter IV}

\section{Findings and Results}

Chapter IV presents the analyses of the data for this study. Results from both, the quantitative statistics and the content analysis are presented.

\section{$\underline{\text { Data Analyses }}$}

Data collected in this study were analyzed using a number of procedures.

Reliability was ascertained as the first step in the analysis of the data derived from the 29 items on Part I of the survey instrument. Descriptive statistics including frequencies and measures of central tendency and analyses of variance were then calculated to describe and analyze the data collected with Part I of the survey. Analyses of this part of the survey were performed on the individual item scores as well as the categories of behavior variables. The items were grouped into instructional, interrelational and general categories of behavior.

The data collected on Part II of the questionnaire were examined by calculating frequencies of responses and by employing content analysis procedures. For example, themes were identified and categories were developed and frequencies and percentages of subjects who expressed specific responses were calculated.

In addition, the demographic data were used to determine if perceptions of supervisory behaviors and needs varied by the assistant's age, gender, education, level of licensure, years of experience, and work setting. The analysis of variance (ANOVA) was calculated and the variance reported. 


\section{Subjects}

The subjects for this study were the licensed speech-language pathology assistants in the state of Louisiana. At the time of this study, there were 173 licensed SLPAs in the state who were each mailed a survey requesting participation in the study.

Of the 173 surveys mailed, 92 were returned. Four of the 92 surveys that were returned were not useable because the SLPA, even though licensed, had never been employed as an SLPA and thus, were unable to participate in the study. The return rate of $51 \%$ was based on the 88 surveys returned by those assistants that were employed or at some time had been employed as an SLPA. Even though 88 SLPAs returned surveys, several were only partially completed. This resulted in fewer than 88 pairs of data being used when analyzing the variance between the means for Part I of the survey. This limitation of the study is discussed in Chapter V.

\section{Quantitative Analyses}

Table 2 presents the descriptive statistics for each of the items on Part I of the survey. Results of both rating scales are presented. The first scale indicated the extent to which supervisory behaviors occurred and the second rating scale indicated the extent to which supervisory behaviors were perceived as needed. Based on the calculated mean scores for each item, it was found that 21 of the 29 supervisory behaviors presented in Part I of the survey occurred more than they were perceived as needed. Those behaviors are described in items $1,3,4,5,6,7,9,10,11,12,14,15,16,17,18,21,23,25,26,27$, and 29. Two of the items (7 and 14) were negatively worded, which means that even though they occurred more than needed, a positive occurrence was not reflected. Seven of the 29 behaviors were needed more than they occurred. They are described in items 8 , 
$13,19,20,22,24$, and 28 . The behavior described in Item 2 occurred as it was needed. These data are based on the total number of SLPAs who responded to the items as presented on Part I of the survey. 
Table 2

Descriptive Statistics for the Extent to Which Supervisory Behaviors Occurred and the Extent to Which They Were Needed.

\begin{tabular}{|c|c|c|c|c|c|c|c|c|c|c|}
\hline & & & \multicolumn{4}{|c|}{ Behavior Occurred } & \multicolumn{4}{|c|}{ Behavior Needed } \\
\hline Item & Category/ Focus & Key words & Mean & SD & No. & $(\%)$ & Mean & SD & No. & $(\%)$ \\
\hline 1 & Instruc. Supervisor & Goal setting & 3.69 & 1.35 & 81 & (92) & 3.44 & 1.15 & 56 & (63) \\
\hline 2 & Instruc. Supervisor & Demo. TX techniques & 3.57 & 1.38 & 77 & (88) & 3.57 & 1.14 & 59 & (67) \\
\hline 3 & Interr. Supervisor & Express opinions & 4.57 & 0.98 & 82 & (93) & 4.27 & 1.13 & 54 & (61) \\
\hline 4 & Instruc. Supervisor & Identifies resources & 4.01 & 1.20 & 81 & (92) & 3.83 & 1.07 & 56 & (64) \\
\hline 5 & Interr. Supervisor & Collaboration & 4.41 & 1.09 & 81 & $(92)$ & 4.36 & 1.20 & 52 & (59) \\
\hline 6 & Supervisor & Motivation & 4.28 & 1.15 & 81 & (92) & 4.20 & 1.17 & 55 & (63) \\
\hline 7 & Interr. Supervisor & Dominance & 2.48 & 1.51 & 82 & (93) & 2.14 & 1.07 & 54 & (61) \\
\hline 8 & Instruc. Supervisor & Functions as teacher & 3.85 & 1.36 & 81 & (92) & 3.87 & 1.32 & 56 & (64) \\
\hline 9 & Interr. Supervisor & Listens to problems & 4.33 & 1.12 & 80 & $(91)$ & 3.94 & 1.37 & 53 & $(60)$ \\
\hline 10 & Supervisor & Provides recognition & 4.32 & 1.11 & 82 & (93) & 4.22 & 1.23 & 54 & (61) \\
\hline 11 & Supervisor & Challenges & 4.14 & 1.20 & 82 & (93) & 3.94 & 1.38 & 55 & (63) \\
\hline 12 & Interr. Supervisor & Supportive & 4.56 & 1.03 & 83 & (94) & 4.38 & 1.18 & 54 & (61) \\
\hline 13 & Instruc. Supervisor & Evaluation of clients & 3.78 & 1.24 & 83 & (94) & 4.01 & 1.15 & 54 & (61) \\
\hline 14 & Interr. Supervisor & Superiority & 2.78 & 1.55 & 82 & (93) & 2.46 & 1.30 & 52 & (59) \\
\hline 15 & Instruc. Supervisor & Client behavior & 3.71 & 1.23 & 83 & (94) & 3.64 & 1.25 & 56 & (64) \\
\hline 16 & Instruc. Supervisor & Suggests TX techniques & 3.91 & 1.21 & 81 & (92) & 3.82 & 1.23 & 56 & (64) \\
\hline 17 & General Supervisee & Inform when need assist. & 4.30 & 1.05 & 81 & (92) & 3.92 & 1.34 & 55 & (63) \\
\hline 18 & Interr. Supervisor & Values ideas & 4.25 & 1.08 & 82 & (93) & 4.16 & 1.27 & 54 & (61) \\
\hline 19 & General Supervisee & Professional growth & 4.14 & 1.16 & 82 & (93) & 4.16 & 1.29 & 54 & $(61)$ \\
\hline 20 & Interr. Supervisor & Sensitivity and concern & 4.21 & 1.32 & 83 & (94) & 4.22 & 1.25 & 54 & (61) \\
\hline 21 & General Supervisee & Comm. outside conf. & 4.22 & 1.21 & 83 & (94) & 3.88 & 1.36 & 54 & (61) \\
\hline
\end{tabular}


Table 2 Cont.

Descriptive Statistics for the Extent to Which Supervisory Behaviors Occurred and the Extent to Which They Were Needed.

\begin{tabular}{c|l|l|cccc|cccc}
\multicolumn{4}{c}{} & \multicolumn{4}{c}{ Behavior Occurs } & \multicolumn{4}{c}{ Behavior Needed } \\
\hline Item & Category/ Focus & Key words & Mean & SD & No. & $(\%)$ & Mean & SD & No. & $(\%)$ \\
\hline 22 & General Supervisee & Comm. via email & 1.44 & 1.13 & 70 & $(80)$ & 1.96 & 1.44 & 66 & $(75)$ \\
23 & General Supervisee & Comm. via telephone & 3.54 & 1.41 & 82 & $(93)$ & 3.10 & 1.42 & 55 & $(63)$ \\
24 & General Supervisee & Comm. journal writing & 1.48 & 1.08 & 72 & $(82)$ & 1.73 & 1.11 & 60 & $(68)$ \\
25 & Instruc. Supervisor & Encourage independence & 4.20 & 1.16 & 80 & $(91)$ & 4.09 & 1.29 & 53 & $(60)$ \\
26 & Instruc. Supervisor & Encourages analysis & 3.47 & 1.38 & 80 & $(91)$ & 3.45 & 1.28 & 55 & $(63)$ \\
27 & General Supervisee & Analysis via dialogue & 3.60 & 1.34 & 79 & $(90)$ & 3.29 & 1.34 & 54 & $(61)$ \\
28 & General Supervisee & Analysis via written & 2.27 & 1.51 & 73 & $(83)$ & 2.43 & 1.37 & 62 & $(71)$ \\
29 & General Supervisee & Requests conferences & 4.21 & 1.24 & 82 & $(93)$ & 4.10 & 1.30 & 56 & $(64)$
\end{tabular}

Note: The \% indicates the percent of SLPAs who responded to a specific item based on the total number who participated in the study. For each item, a maximum score of 5 and a minimum of 1 were obtained. 
Table 3 shows results of the analysis of variance for each item in Part I of the survey. The degrees of freedom, means, standard deviations, and the " $\mathrm{t}$ " values are presented. The differences between the means for the following behaviors: Item 7, Your supervisor dominates discussion in the meeting; and Item 14, Your supervisor is the superior and you are the subordinate in the relationship, occurred more than needed, $\mathrm{p} \leq .05$. Supervisory behaviors described in Item 22 , You communicate with your supervisor outside of the planned meeting via email; and Item 24, You communicate with your supervisor through journal writing, were needed more than they occurred, $\mathrm{p} \leq .01$. 
Table 3

Analysis of Variance of Rating Scale Items: Extent to Which Supervisory Behaviors Occurred and Were Needed.

Behavior Occurred Behavior Needed

$\begin{array}{ccccccc}\text { Statement No. } & \underline{\mathrm{df}} & \underline{\mathrm{M}} & \underline{\mathrm{SD}} & \underline{\mathrm{M}} & \underline{\mathrm{SD}} & \underline{\mathrm{t}} \\ 1 & 52 & 3.56 & 1.36 & 3.41 & 1.16 & .650 \\ 2 & 51 & 3.42 & 1.40 & 3.55 & 1.14 & -.627 \\ 3 & 51 & 4.40 & 1.17 & 4.25 & 1.15 & .693 \\ 4 & 51 & 3.84 & 1.25 & 3.80 & 1.08 & .179 \\ 5 & 50 & 4.30 & 1.21 & 4.34 & 1.22 & -.165 \\ 6 & 51 & 4.09 & 1.25 & 4.21 & 1.18 & -.462 \\ 7 & 50 & 2.56 & 1.55 & 2.05 & 1.00 & 2.269^{*} \\ 8 & 51 & 3.71 & 1.44 & 3.88 & 1.32 & -.669 \\ 9 & 48 & 4.20 & 1.18 & 4.00 & 1.32 & .773 \\ 10 & 50 & 4.13 & 1.20 & 4.19 & 1.26 & -.234 \\ 11 & 51 & 3.94 & 1.30 & 3.92 & 1.39 & .071 \\ 12 & 51 & 4.38 & 1.23 & 4.38 & 1.20 & .000 \\ 13 & 51 & 3.71 & 1.27 & 3.98 & 1.16 & -1.171 \\ 14 & 49 & 2.82 & 1.48 & 2.40 & 1.27 & 2.037^{*} \\ 15 & 53 & 3.66 & 1.22 & 3.61 & 1.26 & -.262 \\ 16 & 52 & 3.73 & 1.28 & 3.79 & 1.26 & -.242 \\ 17 & 51 & 4.17 & 1.20 & 3.90 & 1.36 & 1.275 \\ 18 & 51 & 4.03 & 1.23 & 4.13 & 1.28 & -.401 \\ 19 & 51 & 3.94 & 1.28 & 4.13 & 1.31 & -.764 \\ 20 & 51 & 4.23 & 1.38 & 4.21 & 1.27 & .080 \\ 21 & 51 & 4.19 & 1.28 & 3.88 & 1.38 & 1.477 \\ 22 & 53 & 1.31 & .94 & 1.83 & 1.34 & 3.111^{* *} \\ 23 & 51 & 3.36 & 1.41 & 3.09 & 1.40 & 1.345 \\ 24 & 49 & 1.40 & 1.03 & 1.76 & 1.15 & 2.990^{* *} \\ 25 & 48 & 4.14 & 1.22 & 4.20 & 1.17 & -.343 \\ 26 & 50 & 3.35 & 1.36 & 3.37 & 1.29 & -.089 \\ 27 & 50 & 3.49 & 1.33 & 3.21 & 1.33 & 1.385 \\ 28 & 50 & 2.11 & 1.40 & 2.27 & 1.26 & -.709 \\ 29 & 52 & 4.07 & 1.34 & 4.09 & 1.31 & -.077\end{array}$

$* \underline{p}<.05 \quad * * \underline{p}<.01$ 
Table 4 presents the ten highest ranked items of the 29 behavioral variables according to the extent to which the supervisory behaviors were perceived as needed. Further, Table 4 presents the respondents' ratings of those statements according to the extent to which those behaviors occurred. The rankings are based on the calculated mean scores for each item. It was found that eight of the top ten ranked behaviors that were perceived as needed were represented in the interrelational category and the remaining two were represented in the general category.

It was also found that the behaviors described in the following three items were ranked either first, second or third for both rating scales: Item 3, Your supervisor gives you the opportunity to express your opinions; Item 5, Your relationship with your supervisor is a collaborative one; and Item 12, Your supervisor is supportive of you.

Of the top ten items, four additional items were reported as both needed and occurring. They were: Item 6, Your supervisor motivates you to perform at your highest potential; Item 10, Your supervisor provides recognition and positive feedback for you work; Item 18, Your supervisor appears to value your ideas; and Item 29, Your supervisor is able to meet with you at your request.

The behaviors that ranked in the top ten as being needed, but not in the top ten as occurring were: Item 19,You are growing professionally as a result of conferences with your supervisor; Item 20, Your supervisor is sensitive to work stresses and concerned with your well-being; and Item 25, Your supervisor is available for support, but encourages you to function independently. 
Table 4

Ten Highest Ranked Items According to Behaviors that were Perceived as Needed.

Behavior Needed Behavior Occurred

\begin{tabular}{rlll}
\hline & & & \\
Mean & Rank Mean Rank \\
\hline
\end{tabular}

Interrelational Category

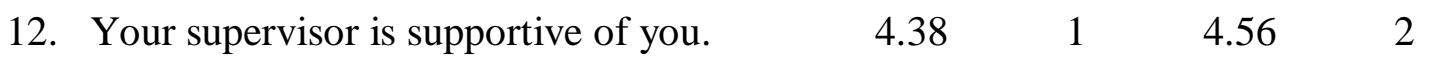

5. Your relationship with your supervisor is $\quad \begin{array}{lllll}4.36 & 2 & 4.41 & 3\end{array}$ a collaborative one.

3. Your relationship with your supervisor is a collaborative one.

$\begin{array}{llll}4.27 & 3 & 4.57 & 1\end{array}$

20. Your supervisor is sensitive to work stresses and concerned about your wellbeing.

$\begin{array}{llll}4.22 & 4 & 4.21 & 11\end{array}$

10. Your supervisor provides recognition and positive feedback for your work.

$\begin{array}{llll}4.22 & 5 & 4.39 & 5\end{array}$

6. Your supervisor motivates you to perform at your highest level.

$\begin{array}{llll}4.20 & 6 & 4.28 & 7\end{array}$

17. Your supervisor appears to value your ideas.

10

12 independently.

\section{General Category}

18. You are growing professionally as a result of conferences with your supervisor.

29. Your supervisor is able to meet with you at your request.

$\begin{array}{llll}4.10 & 9 & 4.21 & 10\end{array}$


Table 5 reports the descriptive statistics and the analysis of variance for the instructional, interrelational and general categories of supervisory behaviors. The behaviors represented in the instructional category were perceived as being needed more than they occurred, though not significantly so, $\underline{p}>.10$. The supervisory behaviors that constituted the interrelational and general categories occurred more than perceived as needed. The differences between the means were not significant for the interrelational category, $\mathrm{p}>.10$, however, the differences between the means for the general category were significant, $\mathrm{p}<.10$. These data are based on the total number of SLPAs who responded to the survey. 
Table 5

Analysis of Variance for the Categories of Supervisory Behaviors

\begin{tabular}{lcccccc} 
& \multicolumn{3}{c}{ Behaviors Occur } & \multicolumn{3}{c}{ Behaviors Needed } \\
& $\underline{\mathrm{df}}$ & $\underline{\mathrm{M}}$ & $\underline{\mathrm{SD}}$ & $\underline{\mathrm{M}}$ & $\underline{\mathrm{SD}}$ & $\underline{\mathrm{t}}$ \\
$\underline{\text { Instructional }}$ & 59 & 3.63 & 1.04 & 3.76 & 1.35 & -.541 \\
$\underline{\text { Interrelational }}$ & 55 & 4.25 & .99 & 4.05 & .92 & 1.09 \\
$\underline{\text { General }}$ & 66 & 3.25 & .83 & 2.96 & 1.06 & $1.815^{*}$ \\
$* \mathrm{p}<.10$ & & & & & &
\end{tabular}


Table 6 reports a demographic analysis, including descriptive statistics and the analysis of variance for the instructional category. When analyzing these data it was found that the following groups of SLPAs indicated that the supervisory behaviors in this category were needed more than they occurred; however, the differences between those means were not statistically significant, $p>.10$. The groups were public school and nonpublic school SLPAs, both fully and provisionally licensed SLPAs, those with bachelors' and masters' degrees, those with work experience from 1-5 years and those who were between 20 and 30 years of age. The SLPAs who had a bachelor's degree plus some graduate coursework and those who were over 31 years of age reported that instructional supervisory behaviors occurred more than they were needed.

When examining the data presented in this table, it was found that those who work in settings other than public schools needed more instructional supervision than those who work in public schools. The results also indicated that provisionally licensed SLPAs required more instructional supervision than those who were fully licensed and SLPAs with bachelor's or master's degrees needed more instructional supervision than those with a bachelor's degree plus some graduate coursework. Also, those with both, 1 and 3 years of experience needed these supervisory behaviors more than those with 2 years of experience, and the SLPAs over 40 years of age needed less instructional supervision than any of the other age groups. 
Table 6

Instructional Category: Compared Mean Scores of Supervisory Behaviors.

A Demographic Analysis

\section{Work Setting}

School setting

Other

$\underline{\text { Licensure }}$

Provisionally Licensed

Fully Licensed

$\underline{\text { Education }}$

Bachelor's Degree

Bachelor's + Grad. Courses

Master's Degree

Experience

1 year

2 years

3 years

$\underline{\text { Age }}$

20-25

26-30

$31-40$

$>40$

$20-25$
$26-30$
$1-40$
40

Behaviors Occurred Behaviors Needed

$\begin{array}{lllll}\text { df } & \underline{\mathrm{SD}} & \underline{\mathrm{M}} & \underline{\mathrm{SD}} & \underline{\mathrm{t}}\end{array}$

$\begin{array}{rrrrrr}48 & 3.63 & 1.08 & 3.65 & .94 & -0.125 \\ 9 & 3.60 & .91 & 4.55 & 2.39 & -1.036\end{array}$

$\begin{array}{llllll}16 & 3.82 & .90 & 4.02 & .72 & -.819\end{array}$

$\begin{array}{llllll}41 & 3.54 & 1.10 & 3.71 & 1.49 & -0.566\end{array}$

$23 \quad 3.49$

$1.12 \quad 4.02$

$1.76-1.215$

3.67

$.98 \quad 3.56$

$1.05 \quad 4.22$

$.85 \quad .495$

$1.07-1.000$

4.15

$26 \quad 3.83$

$21 \quad 3.32$

$10 \quad 3.73$

.87

1.28

4.02

.73

$-.877$

.95

3.44

$\begin{array}{ll}.90 & -.350\end{array}$

4.25

$2.55 \quad .537$

28

$18 \quad 3.62$

1.04

3.78

$.74 \quad-.951$

$5 \quad 3.95$

1.18

3.99

$2.02 \quad-.604$

$7 \quad 3.67$

.72

3.95

.72

.000

1.03

3.33

1.4

.723 
Table 7 presents a demographic analysis, including descriptive statistics and the analysis of variance for the interrelational category. It was found that the supervisory behaviors in this category occurred more than they were needed for those in the following demographic categories: public school and non public school settings, fully and provisionally licensed SLPAs, those with a bachelor's degree plus some graduate course work and those with a master's degree, the SLPAs with one year of experience and three years or more experience, and the SLPAs who were 26 years of age or more. The following three groups indicated that interrelational behaviors were needed more than they occurred: SLPAs with a bachelor's degree, those with 2 years experience, and those between 20 and 25 years of age, however, the differences between the means were minimal.

An inspection of the calculated means revealed that SLPAs employed in settings other than public schools appeared to need the supervisory behaviors represented in the interrelational category more than the SLPAs employed in public schools. It was also noted that those who were provisionally licensed needed these behaviors more than those who were fully licensed. It was reported that those with bachelors' or masters' degrees needed the supervisory behaviors in this category more than those with a bachelor's degree plus graduate coursework. Additionally, the SLPAs with 1 and 3 years of experience reported they needed these behaviors more than those with 2 years of experience, while those in the first age group, between 20 and 25 years, appeared to need these relationship related behaviors more than any of the other age groups. 
Table 7

Interrelational Category: Compared Mean Scores of Supervisory Behaviors.

$\underline{\text { A Demographic Analysis }}$

Work Setting

School setting

Other

Licensure

Provisionally Licensed

Fully Licensed
Behaviors Occurred Behaviors Needed

$\underline{\mathrm{df}} \quad \underline{\mathrm{M}} \quad \underline{\mathrm{SD}} \quad \underline{\mathrm{M}} \quad \underline{\mathrm{SD}} \quad \underline{\mathrm{t}}$

$\begin{array}{llllll}44 & 4.22 & 1.06 & 4.09 & .95 & .648\end{array}$

$\begin{array}{llllll}9 & 4.29 & .65 & 4.13 & .50 & .744\end{array}$

Education

$\begin{array}{lrrrrrr}\text { Bachelor's Degree } & 22 & 4.06 & 1.12 & 4.17 & .76 & -.405 \\ \text { Bachelor's + Grad. Courses } & 26 & 4.31 & .96 & 3.98 & 1.03 & 1.268 \\ \text { Master's Degree } & 4 & 4.60 & .21 & 4.38 & .43 & 2.018\end{array}$

$\underline{\text { Experience }}$

1 year

2 years

3 years

$16 \quad 4.39$

.88

4.31

$.70 \quad .330$

38

4.16

1.04

4.00

.94

.729

Age

20-25

26-30

31-40

$>40$

\section{3}

18

9

4.35

3.94

4.44

.87

1.32

.40

4.31

3.99

.64

.79

4.24

.61

.229

$-.204$

1.297

$\begin{array}{rrcrrr}27 & 4.16 & 1.04 & 4.23 & .60 & -.333 \\ 14 & 4.22 & 1.24 & 4.10 & .87 & .327 \\ 4 & 4.36 & .23 & 4.21 & .69 & .568 \\ 6 & 4.45 & .52 & 3.45 & 1.63 & 1.501\end{array}$


A demographic analysis, including descriptive statistics and the analysis of variance for the general category are presented in Table 8. The SLPAs in each demographic group reported that the behaviors or characteristics examined in this category occurred more than they were perceived as needed. The SLPAs with a bachelor's degree plus some graduate coursework indicated that these behaviors occurred significantly more than were needed, $\underline{p}<.10$. 
Table 8

General Category: Compared Mean Scores of Supervisory Behaviors.

A Demographic Analysis

\section{Work Setting}

School setting

Other

$\underline{\text { Licensure }}$

Provisionally Licensed

Fully Licensed

$\underline{\text { Education }}$

Bachelor's Degree

Bachelor's + Grad. Courses

Master's Degree

Experience

1 year

2 years

3 years

$\underline{\text { Age }}$

20-25

26-30

$31-40$

$>40$

$* \mathrm{p}<.10$
Behaviors Occurred Behaviors Needed

$\underline{\mathrm{df}} \quad \underline{\mathrm{M}} \quad \underline{\mathrm{SD}} \quad \underline{\mathrm{M}} \quad \underline{\mathrm{SD}} \quad \underline{\mathrm{t}}$

$\begin{array}{rrrrrr}53 & 3.26 & .89 & 2.96 & 1.07 & 1.592 \\ 10 & 3.17 & .52 & 3.05 & 1.02 & .499\end{array}$

$\begin{array}{rrrrrr}21 & 3.44 & .71 & 2.96 & 1.19 & 1.579 \\ 42 & 3.14 & .89 & 2.99 & .99 & .849\end{array}$

$\begin{array}{ll}27 & 3.17 \\ 30 & 3.29\end{array}$

.94

3.07

1.07

.423

$2.91 \quad 1.06 \quad 1.695^{*}$

$7 \quad 3.33$

.72

2.94

$1.14 \quad .743$

$31 \quad 3.43$

$21 \quad 2.89$

.75

1.01

3.11

2.81

$1.12 \quad 1.349$

$11 \quad 3.40$

.53

3.30

$.91 \quad .286$

$.69 \quad .583$

$\begin{array}{rrrrrr}31 & 3.19 & .70 & 3.16 & .96 & .163 \\ 15 & 3.30 & 1.14 & 3.19 & 1.12 & .314 \\ 7 & 3.47 & .82 & 2.51 & .92 & 1.831 \\ 8 & 3.15 & .77 & 2.38 & 1.19 & 1.601\end{array}$


Table 9 reports the demographic information collected from the SLPAs. It was found that the majority were female, fully licensed, had earned a bachelor's degree plus some graduate credit, and worked in the public school setting. 
Table 9

Frequency Distribution of Selected Demographic Variables for SLPAs

$\underline{\text { Variable }}$

Gender

Female

Male

$\underline{\text { Level of Licensure }}$

Provisionally Licensed

Fully Licensed

$\underline{\text { Academic Degree }}$

Associate's

Bachelor's

Bachelor's + graduate coursework

Master's

Work Setting

Public School

Other
No.

82

2

27

57
0

34

39

11

70

14

Measures of Central Tendency for Selected Variables for SLPAs

$\underline{\text { Variable }}$

Age

Years of Experience
$\underline{\mathrm{M}}$

29

21 months
$\underline{\mathrm{SD}}$

7.99

$\underline{\text { Mode }}$

25

1
20-56

1-5 


\section{Analysis of the Qualitative Data}

Comments chosen by the researcher are direct quotes from the data that broadly reflected the general nature of the responses to the discussion questions given by the speech-language pathology assistants. Below are listed the questions and their respective responses. A frequency count was recorded indicating the number of SLPAs who responded to each question: $\mathrm{N}=$ the number of assistants who responded to the question, and for some questions it was appropriate to include (n) which represents a frequency count of the number of subjects who expressed a specific comment.

\section{Are you receiving the supervision you expected when you became employed} as a speech pathology assistant?

$\mathrm{N}=82$

$\underline{\text { Yes }} \underline{80 \%}$

No $20 \%$

The overwhelming majority (80\%) of SLPAs reported that "yes" they were receiving the supervision they expected when they became employed as an SLPA. One assistant said, " I am actually receiving more than I expected. It is great for professional growth" others commented along similar lines.

\section{COMMENTS:}

I'm very pleased with the supervision I receive.

I have a wonderful supervisor.

I couldn't have asked for a better one.

I am receiving more supervision than required, which I like. 
Some of the assistants responded "yes" but then offered comments that were somewhat negative in nature. For example, one assistant said, "At the beginning of the year, but not toward the end" and another commented "Yes, although at times I wish she would give more therapy techniques."

However, about $20 \%$ disagreed and indicated that they were not receiving the supervision they expected. Some SLPAs simply stated "no" in response to this question without offering comments. The following quotes echo the feelings of those who did not believe they were receiving the supervision they expected when they became employed as an SLPA.

\section{COMMENTS:}

No, a little less.

No, it could be improved.

It is sufficient for the requirements needed.

She demonstrates lack of knowledge in the field. SLPA demonstrates greater ability and knowledge.

\section{Does your supervisor evaluate your job performance? If yes, to whom is the evaluative data reported?}

$\mathrm{N}=77$

$\underline{\text { Yes }} \underline{75 \%}$

$\underline{\text { No }} \underline{25 \%}$

Approximately $75 \%$ of the assistants reported that they were evaluated by their supervising SLP and that the evaluative data were reported primarily to Central Office personnel, the Director of Special Education and/or to Louisiana Board of Examiners for Speech Pathology and Audiology. There did not appear to be differences in overall 
feelings about the supervisory behaviors depending on to whom the evaluative data were reported. The following comments were offered.

\section{COMMENTS:}

The evaluation is not very detailed.

Oral evaluation by supervisor is ongoing.

It's kept on file.

If yes, to whom is the evaluative data reported?

$\mathrm{N}=58$

(n) To whom the evaluative data were reported

$\begin{aligned} 21 & \text { Central Office } \\ 14 & \text { Director of Special Education } \\ 8 & \text { Louisiana Board of Examiners for Speech Pathology and Audiology } \\ 7 & \text { To the SLPA } \\ 2 & \text { Principal } \\ 2 & \text { Head SLP } \\ 2 & \text { No one } \\ 1 & \text { Coordinator of Speech in our Appraisal Office. } \\ 1 & \text { Superintendent }\end{aligned}$

\section{Does someone other than your SLP supervisor evaluate your job performance formally? For example, a principal or a central office supervisor?}

$\mathrm{N}=84$

$\underline{\text { Yes }} \underline{86 \%}$

No $14 \%$

The majority of SLPAs indicated that they were evaluated by someone other than their supervising SLP. Those who were primarily responsible for evaluating the assistants were school principals and SLP coordinators from Central Office. Comments offered by the SLPAs are presented below. 


\section{COMMENTS:}

The principal does one observation a year. Sometimes I'm not sure anyone besides the SLP knows what our jobs really are!

Every time I asked the principal for results, something came up.

I am a part-time employee and thus nothing is formally written up by my principal or central office supervisor.

(n) $\quad \underline{\text { Evaluator }}$

39

20

7

Principal

SLP coordinator from Central Office

Special education director (local)

Assistant Principal

Director of Children's Services.

\section{Do you meet with your supervisor during regularly scheduled conferences? If so, how often do you meet? If not, how do you and your supervisor schedule conferences?}

$\mathrm{N}=83$

$\underline{\text { Yes }} \underline{83 \%}$

$\underline{\text { No }} \underline{17 \%}$

Most of the SLPAs meet with their supervisors during regularly scheduled conferences. The majority meets once a week; some meet more than once a week and others meet once or twice a month.

$\begin{aligned} \text { (n) } & \text { Frequency } \\ 38 & \text { Once a week } \\ 13 & \text { Twice a week } \\ 8 & \text { Two or three times per week } \\ 5 & \text { Three or four times a week } \\ 3 & \text { Once a month. } \\ 2 & \text { Twice a month }\end{aligned}$


Those SLPAs who do not meet regularly explained their circumstances as either very positive or very negative. The positive comments usually indicated that the SLPAs worked in the same facility and often even shared an office with their supervisors so they were able to communicate in an ongoing fashion or at least daily. Those who responded negatively, usually indicated a lack of supervisor availability. Specific comments follow.

\section{NEUTRAL COMMENTS:}

We meet weekly, but it is not scheduled. We meet when we have time.

No, maybe once every 3-4 weeks.

There is no formal or regularly scheduled conference. We usually meet during our spare time or discuss issues on the telephone.

The conferences are not regularly scheduled, we meet when we can.

\section{POSITIVE COMMENTS:}

Not regularly scheduled--informal but frequent (daily).

We basically meet and talk about cases as needed. She attends all IEP meetings with me and we discuss the cases beforehand.

No scheduled conferences because supervisor at same school in adjoining room three days a week. We email the days she is at anther school.

No, we discuss issues consistently. We are both full-time employees sharing an office.

\section{NEGATIVE COMMENTS:}

Conferences were scheduled when she had time

No, she works 3 days per week and does not make time.

No, she schedules when she has the time then criticizes my performance. 
What general themes or agendas are usually discussed during conferences with your supervisor?

$\mathrm{N}=78$

The themes that emerged as a result of this question are presented below. Also, a frequency count of the SLPAs who expressed the specific themes is reported.

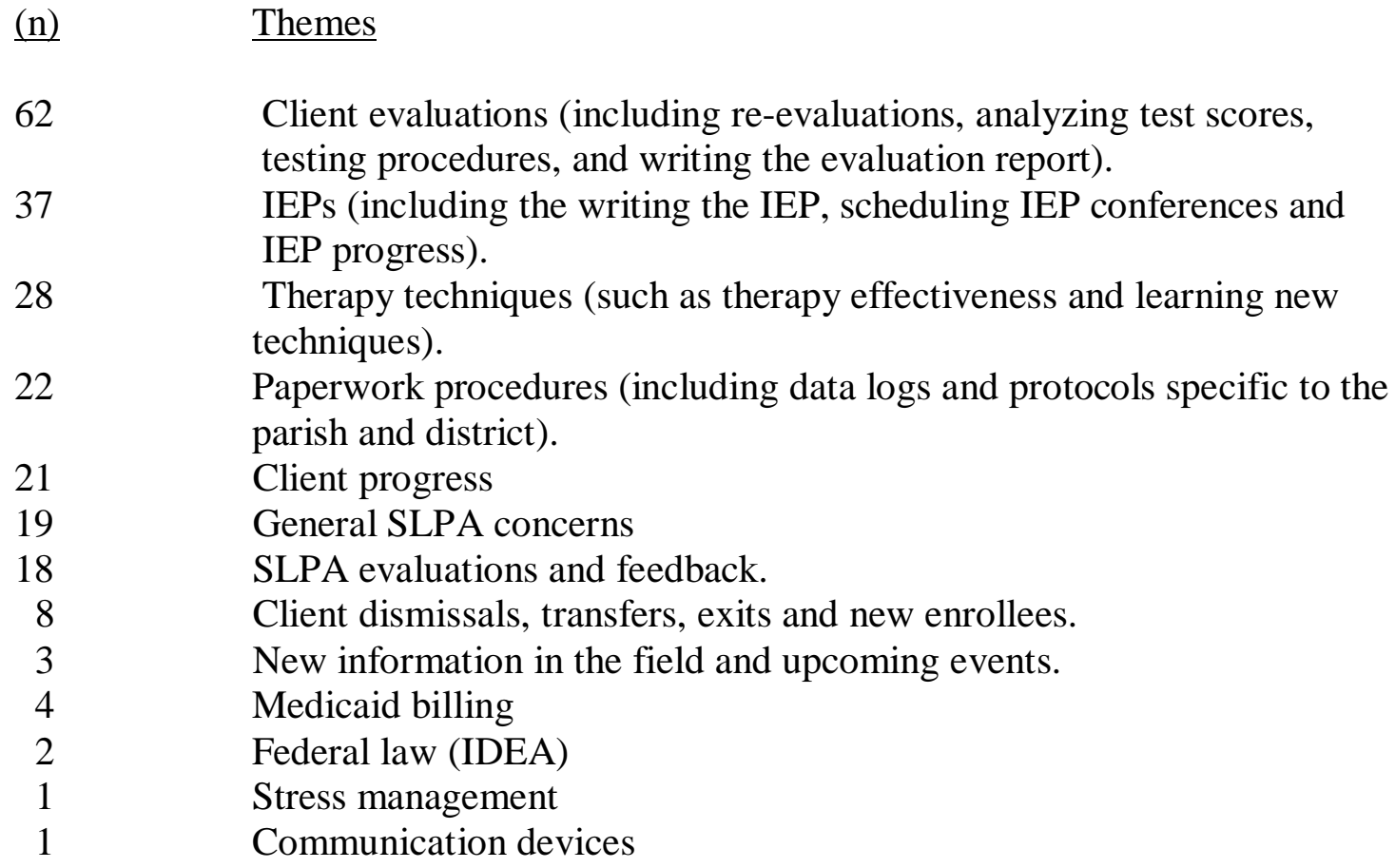

\section{What specific skills or behaviors does your supervisor exhibit that are especially helpful? Please describe.}

$\mathrm{N}=76$

The themes that emerged as a of result of this question were associated with the following categories of supervisory behaviors: the instructional category which encompassed supervisory behaviors that were task related; the interrelational category which was concerned with relationship behaviors; and a general category which described overall professional developmental. A frequency count of specific skills or behaviors that the supervisors exhibited that were especially helpful for the assistants are reported below followed by direct quotes provided by the SLPAs. 
38 The following concepts were noted that fit into the Instructional category: suggesting therapy techniques and materials, modeling management and assessment techniques, report writing, behavior management and general organizational skills.

31 Responses that were related to the Interrelational category included the following terms and phrases: kind, supportive, encouragement, sense of humor, good listener, positive, understanding, patient, honest, respect, and concern.

Responses that were related to overall professionalism, experience and knowledge were also observed.

\section{COMMENTS:}

She is very professional. She is also very knowledgeable about the profession. I respect her and the work she does. I trust her suggestions and respect her opinions. I have learned a lot about different children with different disorders and how to go about therapy with each individual.

She is personable, professional, informative, treats me as an equal, open to new ideas as well as gives me new ideas, gives great constructive criticism.

Encouragement and guidance.

She gives lots of feedback and recommends certain therapy materials for specific clients. She also helps with therapy goals and objectives if I need guidance with them.

Positive and encouraging; always available, even after school hours; demonstrates therapy and testing skills for me to observe.

She gives helpful hints for therapy, for instance she will describe in detail measures used in therapy. She often asks what I think professionally and elaborates on my response (whether good or bad); she sometimes asks unique hypothetical questions and asks how I would respond to a particular problem and/or deficit.

My supervisor is always ready to demonstrate techniques or find materials to utilize. 
She has been very understanding and almost is like a Dprotector over me, she counsels me when IDam feeling like I'm not making progress with tough cases and puts things into perspective for me. It's good to have someone like that around.

My supervisor is approachable, helpful and knowledgeable. She offers suggestions and listens to my questions or needs.

She is honest, dependable, patient, positive, supportive, concerned and kind.

She is always listening to what I have to say. She listens objectively and gives good, professional advice.

Her years of experience help! She has great ideas and suggestions to make me a better clinician.

\section{What do you feel are the primary supervisory needs of a speech pathology} assistant?

$\mathrm{N}=78$

The primary needs of the SLPAs are instructional in nature. Several assistants also indicated a need for a strong interpersonal relationship with their supervisor. The categories and the primary elements that comprised them and direct comments from the SLPAs follow.

(n) $\quad$ Category of supervisory behavior

71 Responses that were related to the Instructional category included: observing therapy techniques; screening and assessment; paper work; IEPs (development and conferences); school and parish procedures; record keeping; feedback and client scheduling.

Responses that were related to the Interrelational category included the following: support, guidance, availability, understanding, patience, equality, encouragement and communication.

\section{COMMENTS:}

Support from a master's level SLP who WANTS an SLPA

To be truly supervised once or twice a week. Being offered assistance and helpful tips to enhance SLPAs skills. 
The primary needs from a supervisor are support and good communication.

My primary need is with therapy techniques. When I'm doing something and it's not working, it's nice to have someone to ask about a different technique.

I feel that I am able to get along mostly without much support on a day to day basis because I've been doing this for three years. However, when I first began, she sat with me and helped with each client's therapy program, giving me ideas about what might work, what programs work best for that child and general ideas that work for any child. Just helping in the general day to day programs.

The supervisor needs to be patient, available and understanding. The assistant needs to be assertive, and willing to learn and practice and work around others.

To be there for questions about paperwork, skills, techniques, unique clients, behaviors, and what to expect from the system.

Coach the assistant as needed, provide encouragement and encourage furthering their education.

A person who encourages me and analyzes my behavior (good or bad). A person who encourages me to function independently when necessary. A person who is available when needed (supportive/not judgmental). A person who treats you as an individual capable of doing the job and not dependent on the supervisor and not making the assistant feel she (the supervisor) is always in control.

Guidance in learning the paper work trail- that has been the one thing she needed to coach me on because there is an official form for everything

... AND how to dredge through the paperwork!

A SLP assistant is faced with many new experiences and these experiences should be discussed as often as possible. These discussions should include a good therapy plan, what materials should be used and progress should be monitored. In my case the person who is "supposedly" my supervisor is never around for such discussion and when complaints come from parents or anyone else my job is threatened. I feel I needed or need much more direction than what I'm receiving to be successful at what I do.

To become a confident therapist by observing the supervisor, having the supervisor share therapy techniques, and provide the assistant with ample conference time to have question/answer periods for the assistant concerns.

Teach and supervise how to write IEPs and evaluations. Be available and assist in parent meetings. Give positive therapy techniques. 
Complying with regulations, understanding parish-wide practices and reporting procedures.

To have guidance and support as needed, but able to have some freedom to practice therapy the best way you think will work for person with some supervision.

Scheduled conference times is what I need the most. There is no conference time and that is needed very much. For example, weekly meeting, monthly meetings, etc.

For the supervisee to be able to observe the supervisor several times during the year. The supervisor should discuss different therapy techniques with the assistant. Give positive and critical feedback to the assistant. Continually find educational materials that will help the assistant.

Help with paperwork that goes along with being a speech therapist.

\section{Overall, do you feel your supervisory needs are being met as a practicing speech-language pathology assistant?}

$\mathrm{N}=77$

$\underline{\text { Yes }} \underline{81 \%}$

No $\underline{15 \%}$

Somewhat $\underline{2 \%}$

Once again, the overwhelming majority (81\%) of SLPAs believed their supervisory needs were being met, while $15 \%$ indicated their needs were not being met and about $2 \%$ reported that their needs were "somewhat" met. Several respondents did not offer comments regarding this question. Comments were more frequently provided when the response to this question was negative.

\section{POSITIVE COMMENTS:}

I'm pleased with my supervisor. Many assistants are not allowed the open relationship that I have.

Absolutely! 
Yes, I do feel my needs are being met.

Definitely, I have a wonderful supervisor that goes the extra mile to help me out.

I am supervised enough indirectly...

NEUTRAL OR NEGATIVE COMMENTS:

...But not enough directly. I don't get enough feedback.

... However my supervisor has been out of school for 20 years and I feel she is out of date with new techniques and technology.

I don't see my supervisor enough.

My supervisor works on a part-time basis. I feel the supervisor needs to be more available at least for the first year.

Fairly, the supervisor does not have her CCC; she is bachelor's level so knowledge base in communication disorders is not what I'd expect from a supervisor.

Supervisors are not always available because of their other responsibilities.

\section{Do you believe your supervisory needs will change as you continue to practice? If so, please describe what types of changes may be most helpful for you.}

$\mathrm{N}=66$

$\underline{\text { Yes }} \underline{75 \%}$

No $20 \%$

$\underline{\text { I don't know } 3 \%}$

Most SLPAs expected to require less supervision as they practiced and gained experience. Some, however, indicated they did not want the supervision to decrease because they "love the feedback." Others also indicated they did not expect supervision to decrease because the SLPAs expected caseloads to increase or become more complex as they continued to work so they expected to continue to need the help afforded by the 
supervision. Some SLPAs said they "did not know" whether or not they believed their supervisory needs would change. Direct comments from the assistants follow.

\section{COMMENTS:}

As I learn more, I'll need less supervision, just a support system.

Needs will change due to increase in knowledge of area and work place.

Yes, learning and becoming more independent.

Yes, less supervisor ideas and more giving input about my ideas.

Will need supervision, but less--hope to have someone available as needed.

More availability.

I would like to work in any setting where I am not told that "I don't need to know because of confidentiality". I would like to be respected and treated fairly. I would like to learn more and be the best SLPA around.

No. I love the feedback and support.

I am eager to learn more speech techniques that are beneficial to my students. Thus I would like my supervisor to continue to share techniques that would assist me to help my students achieve their goals.

Doubtful of change because SLPAs can only work with articulation and language cases.

No, not really.

As I gain experience, the severity of my caseload may increase. It would be helpful if supervision remained the same and did not lessen.

It will depend on the new clients that I get, it is hard to say how those needs will change because my caseload changes every year.

It depends on the caseload and clients. I'll need help as to how to go about handling certain situations about office, school or therapy.

Don't know yet.

I may need feedback when changing therapy techniques. 


\section{What suggestions would you offer as to how your supervision could be enhanced? Please describe.}

$\mathrm{N}=69$

The primary theme that emerged as a result of this question was "'availability".

Other, less prominent themes were instructional in nature such as receiving more assistance developing therapy techniques and completing the paper work. Also, several SLPAs again indicated that they were satisfied with the supervision they received and reported that they could not think of anything that would enhance their supervision.

Direct comments follow.

\section{COMMENTS:}

My supervisor is most helpful in all aspects of my job. I am very fortunate to have her. I couldn't ask for any better.

I can not think of anything. My supervisor has gone the extra mile in every way possible.

Assistants are best when paired with one supervisor and one assistant sharing the same school. This enhances constant communication.

I feel my supervisor should have half a regular caseload; it is just a lessened loadapproximately 10 students less.

My supervisor seems to be one of those people who "knows it all". I wish she would stop trying so hard to show me that she knows more than I do.

Have examples of paper work, so we know what it is supposed to look like.

More specific intervention ideas, more specific information about guidelines.

Maybe when a new client is assigned have supervisor explain how she might handle it (If it is a unique case).

To be truly supervised at least once or twice a week, helpful assistance and tips to enhance SLPAs skills.

A supervisor is one who is up on new technology and can adjust to change a little bit. 
More contact with the assistants.

More time at the school, more direct answers.

Actually see my supervisor

More availability

I feel that my supervisor should be more readily available. She should make more time to meet and discuss my therapy problems.

More accessible, more overall supervision in diagnosis, evaluations and treatment.

Introducing any new therapy techniques they may have learned or new programs. Also inform SLPA of any new info learned at workshops or conferences.

All that is needed is more conference time. I have no time to confer with her.

To be supervised more directly. To actually sit with you during therapy sessions and not just being in the room. This way she could praise you or critique you.

More feedback after supervising direct therapy and help with locating better instructional materials.

Do her job!

More supervisors, maybe.

I think that I would benefit from observing my supervisor more than I have been able to.

Generally, I would like to meet with other speech therapists on a regular basis to discuss new issues and input on techniques, materials, etc.

I am comfortable with this year's supervision because I am treated more as an individual/co-worker. Last year it appeared that my supervisor was trying to control me, my way of thinking and/or my thought process. Provisional license during first year of CFY was a very controlling situation and almost unbearable. I was not able to address any situation w/o my supervisor changing my techniques and /or my reports. Once she changed my reports to her way of writing, I felt short-changed and like I was still in school, which was difficult in itself. I also felt that I could not address a situation and/or session using her rapport, which was difficult for parents and students to understand. Supervisors should continue to be supervisors but at the same time allow us to be thinking individuals. For one day soon, we may be speech-language pathologists and not assistants, looking over someone else, possibly not being able to assist because we were never 
allowed to think for ourselves. So, how can we help others if we were never properly supervised? Thanks. I am finally content that someone has taken an interest in this area and hope that your results will be very helpful and most of all inform supervisors of what we feel is necessary, being the supervisee.

\section{Are there any other comments or suggestions you can offer about the supervision you are receiving and the nature of your supervisory conferences? Please explain.}

$\mathrm{N}=61$

The primary themes that emerged as a result of this question were: (a) General overall satisfaction with the supervisory conferences, (b) lack of recognition for their level of academic training and clinical experiences, and (c) supervisor availability. Comments follow.

\section{COMMENTS:}

Negative comments will not help this survey. I do however feel that SLPAs are a positive addition to the profession and can grow professionally with adequate supervision.

The conferences are fine. I just wish there was more time to discuss issues because my supervisor is always busy. He is the coordinator of speech services so he oversees a lot of people. I think you should also know my view point; well, I started later in the school year so I missed orientation, therefore I wasn't briefed on lots of issues and often I feel lost.

This is the second school system SLPA job I have had. The first job was in another parish. I was supervised and treated like a second class citizen because I did not have my master's degree. I hated my job and considered changing professions. This school year has been much different. I have been taught much information by my college professor which was reinforced by the system I now work for. My supervisor has built on the foundation I received at SLU and it has made me become a better therapist assistant.

In order to work in public schools, universities should focus courses to prepare students for work in this setting.

I believe the SLPAs are being abused by parishes who are starving for SLPs. There are not enough SLP-MA-CCC (master's level, ASHA certified speechlanguage pathologists) in some parishes to provide supervision for the SLPAs. 
At IEP meetings with parents my supervisor makes sure that she lets them know that I am an ASSISTANT. I dislike it when she tries to "Keep me in my place". I am working on my master's degree; maybe one day I'll be her supervisor!

Be flexible and cooperative. People make mistakes and are learning.

There is not enough time for the type of conferencing and interaction expected. Should be mandatory that supervisor have CCC.

The supervisor needs to have days set aside when they can meet with the assistants.

For the supervisory staff to remember we do possess valid college degrees.

I feel that supervision is necessary and that it should be enforced more strictly than it is at this time. SLPAs are not getting the supervision they need and the children will suffer in the long run.

I have no complaints about my supervision. I'm receiving quality supervision. She is a true professional and I love and respect her very much.

My supervisor has been very helpful. She will, at times, help me see big groups and she makes sure all paperwork gets done right. Supervision is very important for your first year at work.

I am very pleased with my supervisor. She is supportive and encouraging. We both have large caseloads and she is always willing to help out and visit my students if a special need arises.

\section{Summary}

Chapter IV presented results of the data analyses regarding the supervisory behaviors and supervisory needs for licensed SLPAs. These data were analyzed using both quantitative and qualitative procedures. Individual items and the categories of behavioral variables (instructional, interrelational, and general) were analyzed by computing measures of central tendency on the subjects' rating scale scores and by using the t-test for analysis of variance to identify the differences between supervisory behaviors that occurred and those behaviors perceived as being needed by the SLPAs. Items that represented the behaviors in the instructional category were generally 
perceived as being needed more than they occurred, but not significantly so, $(\mathrm{p}=.59)$.

Behaviors represented in the interrelational category generally occurred more than perceived as needed, but once again, not significantly so, $(\mathrm{p}=.28)$. The behaviors in the general category also occurred more than they were perceived as being needed, $(p=.07)$. The analysis also included internal reliability testing which was determined by computing Cronbach's alpha coefficient. It was found that internal reliability was high with an alpha of .9540 .

The discussion questions that were answered on the survey were analyzed using content analysis procedures. These analyses included both qualitative and quantitative procedures. Emerging themes, categories and patterns were identified and reported. Additionally, frequency counts of the number of subjects who expressed a specific comment, and the number of subjects who responded to each question were calculated and reported. Generally the responses revealed a strong need for instructional support, supervisor availability and the desire for effective, collaborative interpersonal relationships between the supervisors and the assistants.

Demographic variables were analyzed in a descriptive manner. Most of the subjects were female, were employed in the educational setting, were fully licensed and had obtained a bachelor's degree or a bachelor's degree, plus some graduate credit. Implications of these findings will be discussed in the following chapter. 


\section{Chapter V}

\section{Conclusions, Limitations and Recommendations}

Chapter $\mathrm{V}$ includes a review of the study along with an interpretation of the results presented in the previous chapter. A summary of the results previously reported and the interpretations for each research question answered are presented. The relationship of findings to the literature, as well as a summary of findings, limitations of the study and suggestions for future research are also provided. Finally, a summary of the study is offered. The conclusions of this chapter should be treated as preliminary and in need of confirmation in further studies describing the supervisory relationship between SLPAs and their supervising SLPs.

\section{Review of the Study}

Supervised clinical practica in the field of communication disorders has long been an integral component of the educational process for those completing college degree or CFY requirements. The critical areas of the supervisory process have been studied from the perspectives of student clinicians and clinical fellows and from the perspectives of supervisors, both university supervisors and off campus supervisors. However, since the American Speech-Language-Hearing Association recently recommended guidelines for the training, credentialing, use, and supervision of speech-language pathology assistants, it seemed reasonable that the supervisory process, as perceived by licensed SLPAs and their supervising SLPs was also important. Even though the perceptions of both, the supervisees and supervisors are critical, this study focused on the views of the 
supervisees. Hence, this research explored the supervisory relationship between licensed SLPAs and their supervising SLPs as perceived by the assistants.

The licensed SLPAs in the state of Louisiana served as the subjects who provided the data for this study. All of the SLPAs in the state were mailed a questionnaire that requested information regarding their perceptions of the supervisory process as it occurred between them and their supervising SLPs. Of the 173 licensed SLPAs in Louisiana at the time of this study, 88 completed and returned the surveys for a return rate of 51\%. Since Ferber (1974) reported that an expected return rate was usually less than $30 \%$, the return rate for this study was considered high. This high return rate may be an indication of the importance and concern that SLPAs place on the supervision they receive.

The survey consisted of three parts. Part I contained 29 statements describing supervisory behaviors that the subjects rated twice using a Likert-type scale from 1-5, with 1 indicating "to a very little extent" and 5 indicating "to a very great extent". The first rating identified the extent to which the supervisory behavior occurred and the second rating identified the extent to which the behavior was perceived as needed. Part II of the survey included open-ended questions that were designed to collect additional information about the supervisory relationship and Part III collected demographic information about the respondents.

The items on Part I of the survey were grouped into three categories: instructional, interrelational and general. The instructional category was concerned with the technical aspects of supervision. For example, supervisory behaviors that dealt with specific teaching and professional functions such as demonstrating diagnostic and therapeutic 
techniques, assisting with the evaluation of client progress and client management, and explaining paperwork procedures were included in the category. The interrelational category consisted of the supervisory behaviors that were concerned with the interpersonal relationship between the assistant and the supervisor. Concepts in this category included supervisor behaviors such as offering support and recognition, motivating and challenging, listening to professional problems of the assistants, and demonstrating concern for work related stress and concern for the over all well-being of the assistants. The behaviors in the general category were those supervisory behaviors that were supervisee driven. In order for these behaviors to have occurred, the assistant would have initiated certain supervisory behaviors such as requesting meetings with the supervisor, informing the supervisor when assistance was needed, and self-analyzing professional behavior.

The present study was undertaken to identify the extent to which certain supervisory behaviors occurred and to describe the extent to which those supervisory behaviors were deemed necessary as perceived by licensed speech-language pathology assistants. To date, no research has been conducted concerning the supervisory behaviors and supervisory needs as perceived by licensed SLPAs.

\section{Interpretation of Results}

Below are listed the research questions that were answered as a result of this study. An interpretation of the analyzed data and the relationship of findings to the literature are presented. 
1. To what extent did certain instructional, interrelational and general supervisory behaviors occur during supervisory interactions between licensed speech-language pathology assistants and their supervising speech-language pathologists?

Interpretation of Results

As reported in Table 5, supervisory behaviors that were represented in the interrelational category emerged as the most frequently occurring with a mean of 4.25. The behaviors in the instructional category occurred second most frequently with a reported mean of 3.63 and the behaviors in the general category reported a mean occurrence of 3.25 .

As reported in Table 4, the five most frequently occurring supervisory behaviors, based on the calculated mean scores for each item, were behaviors included in the interrelational category. The supervisory behaviors that constituted the interrelational category included behaviors that were concerned with the interpersonal aspects of the supervisory process such as collaboration, motivation, support, listening, providing recognition and positive feedback, challenging, valuing the ideas of the SLPAs, sensitivity, concern and encouragement.

Several researchers in various disciplines such as education, psychology, social work and communication disorders have contended that successful interpersonal relationships are critical to the success of the supervisory process (Anderson, 1988; Atkins, 1996; Caracciolo, et.al, 1978a; Dussault, 1970; Kadushin, 1992; Pickering, 1984; Rogers, 1961, 1962, 1977). However, results of specific studies that focused on the extent to which those behaviors actually occurred were different than the results of this study. For example, in a study conducted by McCrea (1980) designed to explore the 
interpersonal relationships between student clinicians and their supervisors, it was found that respect, facilitative genuineness, and concreteness were minimally identified while empathic understanding and supervisee self-exploration were not identified enough to be included in statistical analysis. Pickering (1984) examined the interpersonal aspects of the supervisory conference. She found that during the conferences, an emphasis was placed on instructional and technical skills that did not fit supervision models that called for collaboration, problem solving, self exploration and intrapersonal growth. Again, the results from those studies were different than the results of this current study, which revealed that behaviors represented in the interrelational category emerged as the most frequently occurring. In addition, Caracciolo et al. (1978) argued that "student clinicians benefit from the same interpersonal conditions that are usually provided for client growth" (p. 467) and Dussault (1970) argued that if a positive interpersonal relationship existed between the supervisor and the supervisee, it would lend itself to positive changes in the supervisee.

Some authors described leadership or supervision from a feminist perspective. For example, Kadushin (1992) described feminine supervision as "nonelitist, democratic, cooperative, intuitive, emotionally open and informal" (p. 506). Pickering (1987) also described feminine leadership in terms of a nurturing, intimate, collaborative relationship. Since the majority of SLPs are female, one might expect that aspects of feminine leadership theory may have been incorporated in the supervision of SLPAs.

Responses to the open ended questions revealed that instructional/technical or professional themes or agendas were most frequently discussed during the supervisory conferences. The respondents typically provided lists of the topics or themes that were 
discussed during supervisory interactions. The lists included, to a large extent, items concerned with performing client evaluations, writing IEPs and scheduling IEP conferences, learning therapy techniques, learning paperwork procedures and documenting client progress. To a lesser extent, the lists included concerns such as SLPA evaluations and feedback, client transfers and dismissals, Medicaid billing, federal law, communication devices and stress management. Even though the instructional behaviors were identified as concrete behaviors that occurred during the supervisory interactions, further comments from the assistants suggested that the most helpful supervisory behaviors exhibited during the conferences dealt with the way they perceived they were treated both personally and professionally. For example, one assistant wrote of her supervisor, "She is honest, dependable, patient, supportive, concerned and kind". Another SLPA reported about her supervisor's behavior, "She is always listening to what I have to say, she listens objectively and gives good, professional advice." Others commented that their supervisors offered encouragement and guidance and that the supervisors were patient and protective. It seems reasonable to presume that behaviors from all three categories (instructional, interrelational and general) can, should, and do occur simultaneously.

The majority of SLPAs (75\%) reported that they were evaluated by their supervising SLPs and that the primary recipients of the evaluative data were central office personnel. Comments indicated that the evaluation "was not very detailed" and "oral evaluation by the supervisor is ongoing". The majority (84\%) also reported that they were evaluated by someone other than their supervising SLP. The school principal was the person primarily responsible for administering the evaluation. One respondent 
commented, "The principal does one observation a year. Sometimes I'm not sure anyone besides the SLP knows what are jobs really are!" Even though the depth and scope of the professional evaluation of the SLPAs was not a focus of this study, these behaviors were reported as occurring during supervisory interactions.

Results of this study indicated that Anderson's (1988) statement, "Perhaps supervisors have focused on teaching and instruction to the neglect of the personal needs of their supervisee" ( $\mathrm{p}$ 202) does not ring true concerning the supervision of SLPAs. These results are also different than Culatta's (1992) assertions. He argued that SLPs "have lost sight of the responsibility to provide a clinical education for speech-language clinicians" (p. 49) and he further contended, "Instead, we have channeled the research focus into the study of principles of dyadic and small group communication" (p. 49). It appears that, for the most part, both the instructional and the interpersonal aspects of the supervisory process are being more than adequately addressed for SLPAs.

2. To what extent did speech-language pathology assistants need instructional, interrelational and general supervision during supervisory interactions? Interpretation of Results

As reported in Table 5, behaviors in the interrelational category, which were those behaviors associated with the interpersonal aspects of the supervisory process, were most frequently perceived to be needed by the assistants with a mean of 4.05. Instructional behaviors, which were associated with the technical/ instructional aspects of supervision, were perceived as needed with a reported mean of 3.76. The behaviors in the general category, those behaviors that were supervisee driven and were concerned with issues such as professional development and self-analysis, were perceived as being needed with 
a reported mean of 2.96. Also, as reported in Table 4, of the top ten ranked supervisory behaviors that were needed, eight of them were categorized as interrelational.

Consistent with prior research, this study demonstrated that positive interpersonal relationships between supervisors and supervisees were essential for the supervisory process to be effective. Caracciolo et al. (1978) argued that the supervisor's ability to act as a change agent was directly related to his or her level of interpersonal skill. Atkins (1996) contended that supervisor immediacy, which was described as communication behaviors that enhanced physical and psychological closeness with one another, was critical to supervisory effectiveness and Anderson (1988) described the supervisory relationship as possibly "one of the most intense interpersonal experiences in which a person may engage" (p. 202). Those researchers suggested that strong interpersonal relationships were necessary for the professional and personal development that should occur as a result of the supervisory process. Results of this current study also indicated that SLPAs need strong, positive interpersonal relationships with their supervisors.

Inconsistent with Larson's (1981) findings, however, this study found instructional (teaching) behaviors were needed more than the behaviors represented in the general (supervisee driven) category as reported in Table 5. Even though results presented in Table 4, show that two behaviors from the general category emerged in the top ten as needed and no instructional behaviors ranked in the top ten, based on overall mean scores, the instructional behaviors were needed more than the general or supervisee focused behaviors. Larson (1981) found that supervisees had "high expectations and strong needs for their own active participation in the supervisory conference interactions" (p. 108) and that the instructional behaviors were needed to a lesser extent than the 
general/ supervisee focused behaviors. Perhaps the respondents in this study did not view general behaviors to be needed as much as instructional behaviors because the general behaviors were already perceived as occurring more than they were needed. Or, perhaps overall, less value was placed on the items that represented general supervisory behaviors compared to items that represented instructional behaviors because the general behaviors were viewed as less concrete or less critical.

Most of the responses to the open-ended questions concerning the primary supervisory needs of SLPAs, were described as instructional/ technical in nature. The assistants expressed the need to observe therapy, screening and assessment techniques. They also expressed a need for assistance with paper work and administrative procedures such as record keeping and client scheduling and additionally they expressed a need for helpful feedback about the work they perform. It is likely that the technical/ procedural needs that were identified were merely on-the-job skills that anyone may encounter when beginning a new career. The need to observe therapeutic and assessment techniques may be "due to the ever changing nature of the profession" (Schneider, 1989, p. 84). Schneider (1989) further stated, "New concepts, theories and techniques are constantly being introduced in the field of speech-language pathology" (p. 84) which may further explain the need for instructional supervision. In addition to the constantly changing field, the instructional behaviors may be needed because of the limited academic and clinical experience the assistants possess as compared to SLPs.

In addition to the instructional behaviors, the SLPAs expressed a need for a positive, strong interpersonal relationship with their supervising SLP. They expressed needs for guidance, patience, support, availability, encouragement and communication. 
For example, one assistant wrote, "The supervisor needs to be patient, available and understanding". Another assistant reported that a supervisor is one who, "encourages me to function independently, is available when needed and is supportive", and one who, "treats you as an individual capable of doing the job and not dependent on the supervisor and not making the assistant feel as though the supervisor is always in control". Others commented more directly about supervisor availability. For example, one assistant wrote, "I don't see my supervisor enough", and another reported, "Supervisors are not always available because of their other responsibilities".

The SLPAs also offered comments and suggestions to enhance or to improve the supervision they received. These needs emphasized more availability, more instructional support and more respect. Sample comments were, "All that is needed is more conference time. I have no time to confer with her", "I think I would benefit from observing my supervisor more than I have been able to", "I believe SLPAs are being abused by parishes that are starving for SLPs. There are not enough master's level, certified SLPs to provide adequate supervision", "There is not enough time for the type of conferencing and interaction expected. It should be mandatory that the supervisor have CCCs", and "For the supervisory staff to remember we do possess college degrees". These statements clearly reflected that some level of frustration was felt by some assistants. Even though the majority of SLPAs indicated they were satisfied with the supervision they received, for others it was perceived as inadequate.

3. To what extent, if any, were differences noted between supervisory behaviors that occurred and supervisory behaviors that were perceived as being needed during the supervisory interactions? 
Interpretation of Results

As reported in Table 5, there were no significant differences between what occurred and what was perceived as needed regarding the supervisory behaviors represented in the instructional and the interrelational categories. The supervisory behaviors represented in the general category occurred more than needed, $p=.07$. It is worthwhile to note, that in spite of overall congruence between what occurred and what was needed for each category, there were three specific items, as reported in Table 3, that demonstrated significant differences between what was perceived as needed and what occurred. The items were concerned with supervisor dominance in the conferences, $\mathrm{p}<.05$, and dyad communication through journal writing and email, $\mathrm{p}<.01$. Supervisor dominance was needed less and dyad communication via journal writing and email were needed more.

Researchers have shown that more effective supervisory interactions occurred when less dominance and more collaboration were perceived in the relationship (Arredondo, Brody, Zimmerman \& Moffett, 1995). As cited by Arredondo et al. (1995), "We do know, however, that unless the supervisor can function as an equal and establish trust and collegiality, neither the supervisor nor the teacher will grow from classroom experiences" (p. 76). They further stated, "The shift toward more collaborative supervisory processes is bringing about a softening of the hierarchy of supervision" (p. 78). The need for more communication via journal writing may indicate a need for additional and or alternative methods of receiving feedback and assistance from the supervisors. The need for more communication via email may be based on the relatively new emphasis on incorporating technology in the classroom and in the work place. 
The overall results of this study were inconsistent with prior research conducted by Russell (1976) in which she explored the most valued and the actual supervisory behaviors that occurred as perceived by student clinicians. In her study, discrepancies were noted between what occurred and what was perceived as the most important, primarily for behaviors represented in the interrelational category. Differences that were noted dealt primarily with the supervisor's mindfulness to the clinicians needs, feelings and problems.

Even though the frequencies and the percentages reported in the content analysis section of the study indicated high levels of supervisory satisfaction, several comments suggested a sense of frustration and a need for more supervision. For example, several assistants reported that they needed their supervisors to be more accessible and they indicated a need for more conference time and more direct supervision. However, as a whole, results of this study supported the conclusion that most SLPAs were receiving the supervision they perceived they needed.

\section{To what extent, if any, do demographic variables predict speech-language} pathology assistants' perceptions of actual supervisory behaviors and supervisory needs?

Interpretation of Results

As reported in Tables 6, 7, and 8, it was evident the SLPAs represented in each of the five demographic groups received the supervision they perceived that they needed. The groups were (1) work settings, either public school or other work setting; (2) level of licensure, either provisionally or fully licensed; (3) level of education, either bachelor's degree, bachelor's degree plus some graduate hours, or master's degree; (4) level of 
experience, either one, two or three years of experience; and (5) age, including those from 20 to over 40 years.

Based on the calculated mean scores for each demographic group, the supervisory behaviors that were represented in the instructional category, as presented in Table 6, revealed that the differences between the behaviors that occurred and those that were perceived as needed were minimal. Research has shown that clinicians with more clinical experience required less instructional supervision than their peers who had less clinical experience (Larson, 1981; Myers, 1980). In this study, some contradiction was noted with regard to which demographic group required more instructional supervision, based on examining the means for each group. For example, the SLPAs who were provisionally licensed indicated a greater need for instructional support than those who were fully licensed. That finding was consistent with other research (Larson, 1981; Myers, 1980) given that fully licensed SLPAs typically have more clinical experience than those who are provisionally licensed. However, the SLPAs who indicated they had three years of professional experience as an assistant, reported a greater need for instructional supervision than those with one or two years of experience. Based on prior research and personal experience, it was expected that those with three years of experience would need less instructional supervision than those with one or two years of experience. At this time, the reason is unclear and no explanation is offered as to why those with the most experience indicated the greatest need for the instructional support.

Also noted in Table 6, those who work in a setting other than public schools needed more instructional supervision than those who work in public schools. This may be because the undergraduate curriculum is usually geared more toward the educational 
setting and the graduate course work is usually geared more toward the medical field. For example, at Southeastern Louisiana University, the undergraduate curriculum includes the following courses: Speech and Language Development, Articulation and Phonology Disorders, Public School Speech, Language, and Hearing Services: Methods and Materials, and Management of Child Language Disorders. The graduate curriculum includes course work in the following areas: Voice and Voice Disorders, Stuttering and Related Disorders, Aphasia, Speech Science and Perception, Neurophysiological Bases of Human Communication, Dysphagia, Motor Speech Disorders, Neuropathologies of Communication, and Craniofacial Anomalies (Southeastern Louisiana University, General Catalogue, 1998-1999).

It was noted that those with masters' degrees indicated a greater need for instructional supervision than either those with bachelors' degrees or those with bachelors' degrees plus some graduate credit. That may be because the SLPAs with graduate degrees may have earned those masters' degrees in a field other than speech pathology (Currie \& Mead, 1998). Also, based on the known shortage of masters' level SLPs, it is unlikely that one would be employed as an assistant if the master's degree had been granted in field (ASHA, 1998).

As reported in Table 7, the behaviors represented in the interrelational category occurred as needed, meaning minimal differences between the means were noted for all of the groups except two. For those two groups, the SLPAs with masters' degrees and those over 40 years of age, the interrelational behaviors occurred significantly more than needed. These results demonstrated that effective interpersonal relationships have developed between the SLPAs and their supervising SLPs. Again, these results are 
inconsistent with prior research that focused on the interpersonal behaviors between student clinicians and their supervisors (McCrea, 1981; Pickering, 1984; Russell, 1976).

The behaviors represented in the general category, as reported in Table 8, occurred more than needed for all demographic groups. These results are consistent with prior research which suggested that supervisees need and expect to take an active role in the supervisory process (Larson, 1981). Interestingly, according to this study, SLPAs appear to be taking a greater role in the supervisory process than even they believe they need.

\section{Summary}

After analyzing the extent to which certain supervisory behaviors occurred and the extent to which they were perceived as needed for the categories of behaviors, the results indicated that the differences between what occurred and what was needed were minimal. For several of the behaviors, the extent to which the behavior occurred was greater than what was perceived as needed. These results were different than anticipated. It was expected that the SLPAs would perceive that they needed more supervision than they received. This expectation was based on two factors. First, SLPAs have limited course work and clinical experience when they become employed as assistants. That fact alone may have been a reason to believe they would need extensive assistance, instruction or supervision. It also seemed reasonable to presume that it may have been difficult for the supervising SLPs to provide the necessary supervision as well as maintain their own burgeoning caseloads. In addition to the time necessary to provide the required direct and indirect supervision, additional time may have been needed to 
travel to the sites where the SLPAs were employed. Furthermore, SLPs who supervise SLPAs may also supervise university practicum students, which would involve further time constraints. University practicum coordinators and central office SLP coordinators both vie for the same pool of certified or licensed supervisors. Given those anticipations, the results of this study may have been due to any of the following factors: (a) The undergraduate speech-language pathology curriculum is demanding, resulting in strong clinicians, thus, a lessened need for instructional supervisory tasks, (b) there was a great amount of work, planning and effort by the Louisiana State Board of Examiners of Speech-Language Pathology and Audiology in the implementation and licensure of SLPAs, and/or (c) local school districts may have taken an initiative and provided the necessary resources, training and support for the supervisors.

When examining the results of this study, there were three items on Part I of the survey that were perceived as being possible areas for improvement. That conclusion was based on the significant statistical differences between what occurred and what was perceived as needed for the behaviors suggested by the three items. Those items dealt with the hierarchical difference between the SLPA and the supervisor as perceived by the assistants, self-analysis methods via journal writing and dyad communication via email. Even though items 7 and 14, which dealt with the hierarchical structure, Your supervisor dominates discussion in the meetings and Your supervisor is the superior and you are the subordinate in the relationship, respectively, earned low mean scores, there was, neverthe-less a statistically significant difference, $\mathrm{p}<.05$, between what occurred and what was needed. The supervisors were more dominant than the assistants perceived they needed them to be. The items that represented the behaviors describing dyad 
communication via journal writing and email also earned low mean scores, but once again, there was a statistically significant difference, $p<.01$, between what occurred and what was needed. Those behaviors were needed more than they occurred.

After analyzing the data according to the categories of supervisory behaviors, the findings revealed no statistical differences between what occurred and what was needed for the instructional, $\mathrm{p}=.59$ and interrelational categories, $\mathrm{p}=.28$. For the general category, the results indicated that these behaviors occurred more than they were perceived as being needed, $\mathrm{p}=.07$. These data demonstrated that the SLPAs in this study were receiving the supervision they perceived they needed or were receiving more than they perceived they needed.

It was noted that those who were employed in a setting other than public schools needed more instructional supervision than those who worked in public schools. This may be because the undergraduate curriculum is likely to be geared more toward the educational setting and the graduate curriculum is likely to be geared more toward the medical field. Sample curricula for both graduate and undergraduate programs were described above.

Regarding the instructional category, it was noted that those who had earned a master's degree needed more instructional supervision than those in either of the other two education categories, those who had earned a bachelor's degree and those who had earned a bachelor's degree plus some graduate coursework credit. This may be because those with masters' degrees have earned those degrees in a field other than speech pathology. As previously stated, it is unlikely that a person with a master's degree in speech pathology would be employed as an assistant because of the known shortage of 
master's level SLPs. Research conducted by Currie and Mead (1998) suggested that SLPAs with masters' degrees had earned those degrees in related fields of study such as special education or elementary education. The assistants did, however, have bachelors' degrees in speech-language pathology.

Data analysis also demonstrated that the SLPAs were taking an active role in the supervisory process and were taking some responsibility for the supervision they received. For example, the assistants requested professional assistance from their supervisors, communicated with their supervisors outside of the planned meetings, selfanalyzed clinical performance, and requested meetings with their supervisors. These are behaviors that were represented in the general category.

Results of the content analysis, for the most part, supported the results in the objective portion of the study. The overwhelming majority of SLPAs who participated in this study indicated that they were satisfied with the supervision they received. One assistant described her supervisor as "kind and supportive and has a sense of humor. She is personable, professional and informative. She treats me as an equal and is open to new ideas as well as provides new ideas. She gives great constructive criticism". Others, however, disagreed and reported that they were "treated like second class citizens" and "that SLPAs are not getting the supervision they need and the children will suffer in the long run". In spite of the apparent frustration felt by some, the overall results of this study revealed that most SLPAs are receiving the instructional supervision they believe they need, they have developed strong interpersonal relationships with their supervisors and they are taking an active role in the supervisory process. 


\section{Limitations of the study}

One limitation of this study may be related to respondent confusion about the directions for completing Part I of the survey. The subjects were instructed to rate each statement twice using a Likert-type rating scale. The first rating indicated the extent to which the behavior suggested by the item occurred, while the second rating indicated the extent to which the behavior was needed. From the responses, it appeared that some respondents believed that they were to rate each of the statements only once. For example, if the supervisory behavior were perceived as occurring, it was rated on the scale that indicated the extent to which the behavior occurred. Then, since the item was perceived as occurring, it may not have been perceived as being needed, and so it was not rated on the scale that indicated the extent to which the behavior was needed and vice versa. Hence, several items on Part I of the survey were only rated once, rather than twice as directed. Therefore, results of the data analyses may not be valid because of the possible effects of the missing data.

Even though attempts were made to minimize instrumentation problems, there was the issue concerning the missing data. Content validity was determined from the literature review (ASHA, 1996; Larson, 1981; Russell, 1976) and by informal comments by supervisors and by SLPAs enrolled in graduate courses in the Communication Sciences \& Disorders program at Southeastern Louisiana University.

A second limitation of the study may be the degree to which the state, as a whole, was represented in this study. Since the participants were not asked to identify the parish in which they were employed, it is not known whether or not the respondents fairly represented the state. It can be presumed that some parishes employ more masters' level 
SLPs than others. Thus, the appropriate supervision for SLPAs may be more likely to occur in some parishes than in others.

\section{$\underline{\text { Suggestions for further research }}$}

Even though the responses to this survey strongly indicated that SLPAs are receiving the supervision they perceive they need, further studies of this nature would be helpful in understanding the supervisory process that is necessary for achieving the supervisory goals for SLPAs. Suggestions for future research are presented in the following paragraphs.

1. A replication of this study to include SLPAs from states other than Louisiana should be conducted. This information would be helpful to further generalize the results on a regional or a national basis.

2. An investigation should be conducted to examine the perceptions of the supervising SLPs concerning the supervisory process for the SLPAs. It would be helpful to compare the supervisory behaviors as perceived by the assistants with the supervisory behaviors as perceived by the supervisors. This information would be valuable in bridging the gap between the perceptions of both parties, if differences were discovered.

3. Research to explore central office concerns and resources for implementing the supervisory component for SLPAs should be undertaken. It makes sense that central office administrators have had to be creative in implementing the use of SLPAs. It would be helpful to know, in order to share with others, what successes and pitfalls have occurred in local school districts with regard to employing SLPAs. 
4. A study should be undertaken to investigate the evaluation procedures for SLPAs as performed by building level administrators. Future research should be conducted to determine whether or not SLPAs are evaluated differently than the certified SLPs, and it would also be helpful to know what methods of evaluation or which evaluation instruments are employed.

5. Future research should also be conducted to explore alternative methods of achieving the supervisory goals for SLPAs. For example, a study should be conducted to examine reflective and dialogic support/ challenge strategies (Arredondo \& Rucinski, 1998) as a model for implementing the supervisory process for SLPAs. It would be helpful to know if the structured interactions would prove beneficial for both, supervisors and supervisees in the field of communication disorders.

\section{Summary of the Study}

The supervisory process as it occurs in the field of human communication disorders has been studied for several decades. The primary focus of those studies has been on student clinicians completing clinical practica and on those individuals completing a clinical fellowship year. However, faced with the challenge of expanding quality speech-language pathology services, the Legislative Council of the AmericanSpeech-Language-Hearing Association recently sanctioned a strategic plan to implement guidelines for the training, credentialing, use, and supervision of speech-language pathology assistants (ASHA, 1996). A section of the proposed guidelines described the 
amount and type of supervision recommended for the assistants. That supervisory component of the proposed guidelines was the focus of this investigation.

The primary goals of this investigation were to: (a) Identify which supervisory behaviors occurred during supervisory interactions between licensed SLPAs and their supervising SLPs, (b) describe which supervisory behaviors were deemed necessary as perceived by the SLPAs, (c) determine if there were differences between supervisory behaviors that occurred and those that were needed, and (d) investigate whether or not demographic variables such as age, gender, work setting, years of experience, level of licensure, and level of education were related to the speech-language pathology assistants perceived supervision and supervisory needs.

The licensed speech-language pathology assistants in Louisiana served as the subjects for this study. Of the 173 licensed SLPAs, 88 completed and returned surveys that were mailed to them requesting information about their perceptions of the supervision they received and the supervision they needed.

The survey consisted of three parts. Part I contained 29 items that were each rated twice. The first rating indicated the extent to which a supervisory behavior occurred and the second rating represented the extent to which that behavior was perceived as needed. The survey also consisted of open-ended questions that further explored the relationship between the assistants and the supervising SLPs. In addition, selected demographic data about the respondents were requested.

The data analyses were performed on the individual items that described supervisory behaviors and on the categories of supervisory behaviors. The items were grouped into the following three categories: (1) Instructional, which dealt with the 
professional /technical aspects of supervision; (2) interrelational, which focused on the interpersonal relationship between the assistants and their supervisors; and (3) general, which was concerned with dyad communication, supervisee self-analysis and professional development. The behaviors represented in the instructional and interrelational categories were primarily supervisor initiated and the behaviors represented in the general category were primarily supervisee initiated.

The data were analyzed using a variety of procedures. Statistical methods included descriptive measures such as calculating means, standard deviations, frequencies, percentages and analysis of variance. Content analysis was also performed by identifying and categorizing patterns and themes that emerged.

The results of this study revealed that most licensed SLPAs were receiving the supervision they perceived they needed. After analyzing the categories of supervisory behaviors, the findings indicated that there were no significant differences between what occurred and what was perceived as needed for the instructional and interrelational categories, $\mathrm{p}>.10$. Interestingly, the behaviors represented in the general category, those that were supervisee initiated, occurred significantly more than they were perceived as needed, $\underline{p}=.07$

Regarding the individual items on Part I of the survey, the data analysis revealed that there were significant differences between what occurred and what was perceived as being needed for three of the items. The items were concerned with supervisor dominance in the conference setting which occurred more than needed, and dyad communication via journal writing and email which occurred less than the SLPAs perceived they needed. 
The following conclusions can be made regarding the content analysis of the data collected in Part II of the survey. The overwhelming majority of SLPAs $(81 \%)$ reported that they believed their supervisory needs were being met. For example, one SLPA reported, "I have a wonderful supervisor", and others echoed similar sentiments, "I am very pleased with the supervision I receive" and "I couldn't have asked for a better one". However, some SLPAs, indicated that the supervision was only sufficient enough to meet minimum requirements and that it could be improved. One assistant wrote, "I don't see my supervisor enough", and another reported, "Supervisors are not always available because of their other responsibilities". The comments suggested that the primary needs were both instructional and interrelational in nature. For example, they indicated they would like the opportunity to observe more therapy and diagnostic sessions and they also expressed strong needs for help with "dredging through the paper work". They also valued and needed a supervisor who was sensitive to their work stresses and who was patient, encouraging and available.

Based on the results of this study, the overall impression was that the majority of the licensed SLPAs in the state of Louisiana were receiving the supervision they believed they needed to perform their jobs well. Furthermore, it can be concluded that personal and professional growth were fostered as a result of the supervisory relationships that have developed between the SLPAs and the supervising SLPs.

These data analyses, together with the regulations that have been written and promulgated in the legislature, suggest that the state of Louisiana is positioned to be a model for other states as they develop guidelines for the licensing and supervision of SLPAs. However, it is worthwhile to note that some assistants expressed concerns about 
the supervision received. They believed it was inadequate and they offered suggestions as to how their supervision could be improved. They indicated that they would like to be treated more professionally and that they would like to be recognized for their academic training and clinical experiences. They also reported that they would like more communication with their supervisors, for example via journal writing and email. In order to address those concerns, the following recommendations are offered. First, preparing supervisors to incorporate non-directive supervisory behaviors may foster more collegiality between the assistants and the supervisors. Since reflective practice is considered a non-directive behavior, this same training may address the need for more dyad communication via journal writing. The need for more interaction via email is tied to the previous recommendation. Some technology training may be involved, but once again the result is supervision in a reflective manner. 


\section{References}

Acheson, K. A. \& Gall, M. D. (1980). Techniques in the clinical supervision of teachers: Preservice and inservice applications. NY: Longman.

Acheson, K. A. \& Gall, M. D. (1992). Techniques in the clinical supervision of teachers: Preservice and inservice applications ( $3^{\text {rd }}$ ed.). NY: Longman.

American Occupational Therapy Association. (1994). Guidelines for occupational therapy support personnel. American Journal of Occupational Therapy, 48, 1045-1046. American Occupational Therapy Association. (1993a). Occupational therapy roles. American Journal of Occupational Therapy, 45, 1085-1092.

American Occupational Therapy Association. (1993b). Statement: The role of occupational therapy in the independent living movement. American Journal of Occupational Therapy, 47, 1079-1080.

American Physical Therapy Association. (1996). Direction, delegation, and supervision in physical therapy services; HOD 06-96-30. Alexandria, Va.: The American Physical Therapy Association.

American Speech-Language and Hearing Association. (1942). Amendments to by-laws. Journal of Speech and Hearing Disorders, 7, 61-63.

American Speech-Language and Hearing Association. (1961). F. Darley (Ed.), Public school speech and hearing services. Journal of speech and Hearing Disorders. (Monograph Suppl. 8). 
American Speech-Language and Hearing Association. (1970). Guidelines for the roles, training, and supervision of the communication aide. American Speech-Language Hearing Association, 12, 79-80.

American Speech-Language and Hearing Association. (1972). Supervision in the schools: Report of task force on supervision. Language, Speech and Hearing Services in the Schools, 3, 4-10.

American Speech-Language and Hearing Association. (1973-1974). Program supervision guidelines for comprehensive language, speech, and hearing services in the schools. Rockville, MD: American Speech and Hearing Association.

American Speech-Language and Hearing Association. Committee on supervision in speech pathology and audiology. (1985). Clinical supervision in speech-language pathology and audiology: A position statement. American Speech-Language Hearing Association, 27, 57-60.

American Speech-Language and Hearing Association Clinical Certification Board. (1991a, March). Standards for the certificate of clinical competence. ASHA, 3, $121-122$.

American Speech-Language and Hearing Association. (1993, March). Implementation procedures for the standards for the certificates of clinical competence. ASHA, 35, 76-83.

American Speech-Language and Hearing Association. (1993). Standards for the Accreditation of Educational Programs in Speech-Language Pathology and Audiology. Rockville, Maryland: ASHA. 
American Speech-Language and Hearing Association. (1995, March). Position statement for training, credentialing, use and supervision of support personnel in speechlanguage pathology. ASHA, 37 (Suppl. 14), 21.

American Speech-Language Hearing Association. (1996, Spring). Guidelines for the training credentialing, use and supervision of speech-language pathology assistants. ASHA, 38 (Suppl. 16), pp. 21-34.

American Speech-Language and Hearing Association. (1997). Preparing and using speech-language pathology assistants. Tele-seminar presented from American Speech-Language Hearing Association, Rockville, Maryland.

American Speech-Language and Hearing Association. (1998). Membership and certification handbook: Speech-language pathology. Rockville, Maryland: American Speech-Language Hearing Association.

Andersen, C. (1981). The effect of supervisor bias on the evaluation of student clinicians in speech-language pathology and audiology. (Doctoral dissertation, Indiana University, 1981). Dissertation Abstracts International 41, 4479B. (University Microfilms No. 81-12, 499).

Andersen, J. F. (1979). Teacher immediacy as a predictor of teaching effectiveness. In D. Nimmo (Ed.) Communication Yearbook 3 (pp. 543-549). New Brunswick, NJ: Transaction Books.

Anderson, J. (Ed.). (1970). Proceedings of conference on supervision of speech and hearing programs in the schools. Bloomington, IN: Indiana University. Anderson, J. (1981). Training of supervisors in speech-language pathology and audiology. ASHA, 23, 77-82. 
Anderson, J. (1988). The supervisory process in speech-language pathology and audiology. Boston, MA: College-Hill Press/ Little, Brown \& Company.

Anderson, R. (1993). Clinical supervision: Its history and current context. In R. Anderson \& K. Snyder (Eds.), Clinical supervision: Coaching for higher performance. (pp. 5-18). Lancaster, PA: Technomic Publishing Co., Inc.

Argyris, C. (1962). Interpersonal competence and organizational effectiveness. Homewood, IL: Richard D. Irwin.

Arredondo, D., Brody, J., Zimmerman, D., \& Moffett, C. (1995). Pushing the envelope in supervision. Educational Leadership, 53 (3), 74-78.

Arredondo, D. \& Rucinski, T. (1998). Using structured interactions in conferences and journals to promote cognitive development among mentors and mentees. Journal of Curriculum and Supervision, 13 (4), 300-327.

Atkins, C. (1996). Clinical supervisors...Are you immediate? The Clinical Supervisor, 14 (2), 135-146.

Backus, O. (1953). Letters to the editor. Journal of Speech and Hearing Disorders, 18, 193-203.

Barrow, M. (1990). The effectiveness of training clinical supervisors in conducting the supervisory conference. (Doctoral dissertation, Adelphi University, 1990). Dissertation Abstracts International, 51, 06B, 2844.

Bender, H. (1975). Dilthey's voice in the emerging consciousness of humanistic education. Journal of Education, (Boston University), 157(1), 31-34.

Bennis, Warren G. (1989). On becoming a Leader. Reading, Mass: AddisonWesley Publishing Co. 
Blumberg, A., Amidon, E., \& Weber, W. (1967). Supervisor-teacher interaction as seen by supervisors. Unpublished manuscript, Philadelphia: Temple University Blumberg, A. (1968, Spring). Supervisory behavior and interpersonal relations. Educational Administration, 34-45.

Blumberg, A. (1970). A system for analyzing supervisor-teacher interaction. In A. Simon \& G. Boyer (Eds.), Mirrors for Behavior, VIII (pp. 34-1.1-34-1.15). Philadelphia: Research for Better Schools, Inc.

Blumberg, A. (1974). Supervisors and teachers: A private cold war. Berkley, CA: McCutchan Publishing Corp.

Blumberg, A. (1980). Supervisors and teachers: A private cold war $\left(2^{\text {nd }}\right.$ ed.). Berkley, CA: McCutchan Publishing Corp.

Bolin, F. (1987). On defining supervision. Journal of Curriculum and Supervision, 2, 368-380.

Bolin, F. \& Panaritis, P. (1992). Searching for a common purpose: A perspective on the history of supervision. In C. Glickman (Ed.) Supervision in transition: The 1992 ASCD Yearbook (pp.30-43).

Brasseur, J. (1980). The observed differences between direct, indirect, and direct/indirect videotaped supervisory conferences by speech-language pathology supervisors, graduate students, and undergraduate students. (Doctoral dissertation, Indiana University, 1980). Dissertation Abstracts International, 41, 2131B. (University Microfilms No. 80-29, 212).

Brown A. \& Bourne I. (1996). The social work supervisor. Philadelphia: Open University Press. 
Burton, W. \& Brueckner, L (1955). Supervision: A social process. NY: Appleton-Century-Crofts.

Caracciolo, G. L., Rigrodsky, S., \& Morrison, E.B. (1978a). A Rogerian orientation to the speech-language pathology supervisory relationship. ASHA, 20, 286290.

Caracciolo, G., Rigrodsky, S \& Morrison, E.B. (1978b). Perceived interpersonal conditions and professional growth of master's level speech-language pathology students during the supervisory process. ASHA, 20, 467-477.

Carkhuff, R. (1969a). Helping and human relations: A primer for lay and professional helpers-I. NY: Holt, Rinehart and Winston.

Carkhuff, R. (1969b). Helping and human -II. NY: Holt, Rinehart and Winston. Casey, P. (1980). The validity of using small segments for analyzing supervisory conferences with McCrea's Adapted system. (Doctoral dissertation, Indiana University, 1980). Dissertation Abstracts International, 41, 1729B. (University Microfilms No. 8024, 566).

Christophel D.M. (1990). The relationship among teacher immediacy behaviors, student motivation, and learning. Communication Education, 39, 323-340

Churukian, G. \& Cryan, J. (1972). Interpersonal perceptions as a factor in teaching perceptions of supervisory style. Paper presented at the meeting of the American Educational Research Association, Chicago, April, 1972. (ERIC Document Reproduction Service No. ED 064 233)

Cogan, M. (1973). Clinical supervision. Boston, MA: Houghton, Mifflin. 
Costa, A. \& Garmston, R. (1994). Cognitive coaching: A foundation for renaissance schools. Norwood, MA: Christopher-Gordon Publishers, Inc.

Coufal, K., Steckelberg, A. \& Vasa, S. (1991). Current trends in the training and utilization of paraprofessionals in speech and language programs: A report on an elevenstate survey. Language, Speech, and Hearing Services in Schools, 22, 51-59.

Covey, S. (1991). Principle-centered leadership. NY: Simon and Schuster.

Crago, M.B. \& Pickering, M. (Eds.). (1987). Supervision in human communication disorders: Perspectives on a process. Boston, MA: College-Hill Press / Little, Brown \& Company.

Culatta, R. (1992). Where has the master clinician gone: Process vs. Content. ASHA 34, 49-50.

Currie, P. \& Mead, J. (1998)._Speech-language pathology assistants: Impact on graduate programming]. Unpublished raw data.

Donnelly, C. \& Glasser, A. (1992). Training in self-supervision skills. The Clinical Supervisor, 10, 85-96.

Dowling, S. (1992a). Implementing the supervisory process: Theory and practice. Englewood Cliffs, NJ: Prentice-Hall.

Dowling, S. (1992b.). Total quality supervision: Effecting optimal performance. Proceedings of a national conference on supervision. Council of Supervisors in SpeechLanguage Pathology and Audiology. Houston: University of Houston.

Dowling, S. (1998). Facilitating clinical training: Issues for supervisees and their supervisors. Contemporary Issues in Communication Sciences and Disorders 25, 5-11. 
Dowling, S. \& Wittkopp, M. (1982). Students' perceived supervisory needs. Journal of Communication Disorders, 15, 319-328.

Dussault, G. (1970). Theory of supervision in teacher education. NY: Teachers College, Columbia University.

Eisner, E. (1982). An artistic approach to supervision. In Thomas Sergiovanni (Ed.), Supervision of teaching, 1982 ASCD Yearbook. Alexandria, VA: Association for Supervision and Curriculum Development.

Erickson, R. \& Van Riper, C. (1967). Demonstration therapy in a university training center. ASHA, 9, 33-35.

Farmer, S. (1984). Supervisory conferences in communication disorders: Verbal and non-verbal interpersonal communication pacing. (Doctoral dissertation, University of Colorado, 1983). Dissertation Abstracts International, 44, 2715B. (University Microfilms No. 84-00, 891).

Fayol, H. (1916). Industrial and general administration. Paris: Dunod.

Ferber, R. (1974). Handbook of marketing research. NY: McGraw Hill.

Fiedler, F. (1967). Theory of leadership effectiveness. New York: McGraw-Hill.

French, J. \& Raven, B. (1960). The basis of social power. In D. Cartwright \& A. Zander (Eds.). Group Dynamics ( $2^{\text {nd }}$ ed.). Evanston IL: Row \& Peterson.

Frymier, A.B. (1993). The impact of teacher immediacy on students' motivation: Is it the same for all students? Communication Quarterly, 41, 454-464.

Gazda, G. (1973). Human relations development. Boston: Allyn and Bacon, Inc. Glasser, A. \& Donnelly, C. (1989). A data based supervision model for speechlanguage pathology. Language Speech and Hearing Services in the Schools, 20, 296-304. 
Glickman, C. (1990). Instructional supervision: A developmental approach $\left(2^{\text {nd }}\right.$ ed.). Boston, MA: Allyn and Bacon.

Glickman, C. (1980). The developmental model to supervision. Educational Leadership, 38 (2) 178-180.

Goldhammer R. (1969). Clinical supervision. New York: Holt, Rinehart and Winston.

Goldhammer, R., Anderson, R., \& Krajewski, R., (1980). ed.). New York: Holt, Rinehart and Winston.

Gorham, J. (1988). The relationship between verbal teacher immediacy behaviors and student learning. Communication Education, 37, 40-53.

Gouran, D. (1970). Conceptual and methodological approaches to the study of leadership. Central States Speech Journal, 21, 217-223.

Gous, R. (1994). Communication-interaction patterns between supervisors and students in speech pathology (Afrikaans Text). (Doctoral dissertation, University of Pretoria, South Africa, 1994). Dissertation Abstracts International, 32, 06, 1495).

Guba, E. \& Lincoln, Y. (1981). Effective evaluation. San Francisco: Jossey-Bass. Hersey, P. \& Blanchard, K. (1982). Management of organizational behavior: Utilizing human resources (4th ed.). Englewood Cliffs, NJ: Prentice Hall. Hunter, M. (1986). Let's eliminate the pre-observation conference. Educational Leadership, 43, 69-71.

Irwin, R., Van Riper, C., Breakey, M., \& Fitzsimmons, R. (1961). Professional standards in training. In F. Darley (Ed.). Public school speech and hearing services. Journal of Speech and Hearing Disorders, (Monograph Suppl. 8). 
Iskowitz, M. (1997). State guidelines restrict use of support personnel. Advance for Speech-Language Pathologists and Audiologists, 7, (3), 11.

Johnson, B. (1994). Pursuing excellence in clinical supervision: Selecting continuing education activities. Paper presented at the meeting of the American SpeechLanguage Hearing Association, New Orleans, LA.

Joyce, B. \& Showers, B. (1982). The coaching of teaching. Educational Leadership, 40, (1), 4-10.

Kadushin, A. (1976). Supervision in social work. NY: Columbia University Press.

Kadushin, A. (1992). Supervision in social work ( $3^{\text {rd }}$ ed.). NY: Columbia University Press.

Kegan, R. (1994). In over our heads: The demands of modern life. Cambridge, MA: Harvard University Press.

Kennedy, K. (1981). The effect of two methods of supervisor preconference written feedback on the verbal behaviors of participants in individual speech pathology supervisory conferences. (Doctoral dissertation, University of Oregon, 1981). Dissertation Abstracts International, 42, 2071A. (University Microfilms No. 81-23, 492).

Kleffner, F. (Ed.). (1964). Seminar on guidelines for the internship year. Washington, D.C.: The American Speech-Language-Hearing Association.

Larson, L. (1981). Perceived supervisory needs and expectations of experienced vs. inexperienced student clinicians (Doctoral dissertation, Indiana University, 1981). Dissertation Abstracts International, 42-12B, 4578. 
Lass. N., Panbacker, M., Schmitt, J., Middleton, G., Saniga, R., \& McLaughlin, A. (1994). Mentoring in speech-language pathology and audiology. Paper presented at the meeting of the American Speech-Language Hearing Association, New Orleans, LA.

Leith, W. R., McNiece, E. M., \& Fusilier, B. B. (1989). Handbook of supervision: A cognitive behavioral system. Austin, TX: Pro-Ed.

Likert, R. (1967). The human organization: Its management value. NY: McGraw- Hill.

Lincoln, Y. \& Guba, E. (1985). Naturalistic inquiry. Newbury Park: Sage Publications.

Louisiana Administrative Code, Title 46, Professional and occupational standards: Part LXXV. Speech pathology and audiology. ( 1996).

Magelssen, N. H. (1989). Laws, ethics and the supervision of unlicensed providers (Doctoral dissertation, Hannemann University, 1989). Dissertation Abstracts International, 50, 06B, 2628.

Maslow, A. (1970). Motivation and personality $\left(2^{\text {nd }}\right.$ ed.). New York: Harper and Row.

McCrea, E. (1980). Supervisee ability to self-explore and four facilitative dimensions of supervisor behavior in individual conferences in speech-language pathology (Doctoral dissertation, Indiana University, 1980). Dissertation Abstracts International 41(6), 2134-B. (University Microfilms No. 80-29, 239).

McGreal, T. J. (1997). Can a supervisor be a coach? Yes. In J. Glanz \& R.F. Nelville (Eds.), Educational supervision: Perspectives, issues, and controversies (pp.9299). Norwood MA: Christopher-Gordon Publishers, Inc. 
Mehrabian, A. (1971). Silent messages. Belmont CA: Wadsworth.

Miles, B. \& Huberman, A. (1994). Qualitative data analysis: An expanded sourcebook. Thousand Oaks, CA: Sage Publications.

Miner, A. (1967). A symposium: Improving supervision of clinical practicum. ASHA, 9, 471-482.

Mosher, R. \& Purpel, D. (1972). Supervision: The reluctant profession. Boston, MA: Houghton Mifflin Co.

Myers, F. (1980). Clinical needs in the practicum setting. SUPERvision, 4.

Nilsen, J. (1983). Supervisor's use of direct/indirect verbal conference style and alteration of clinical behavior. (Doctoral dissertation, University of Illinois, 1983). Dissertation Abstracts International, 43, 3935B. (University Microfilms No. 83-09, 991).

Nunnally, J.C. \& Bernstein, I.H. (1994). Psychometric theory ( $3^{\text {rd }}$ ed.). New York: McGraw Hill.

Oratio, A. (1977). Supervision in speech pathology: A handbook for supervisors and clinicians. Baltimore, MD: University Park Press.

Oratio, A., Sugarman, M. \& Prass, M. (1981). A multivariate analysis of clinicians' perceptions of supervisory effectiveness. Journal of Communication Disorders, 14, 31-42.

Paden, E. (1970). A History of the American Speech and Hearing Association 1925-1928. Washington D. C.: American Speech and Hearing Association.

Pajak, E. (1993). Approaches to clinical supervision: Alternatives for improving instruction. Norwood, MA: Christopher-Gordon Publishers, Inc. 
Patton, M. (1990). Qualitative evaluation and research methods. Newbury Park, CA: Sage Publications.

Peters-Johnson, C. (1998). Action: School services. Language, Speech and Hearing Services in the Schools, 29, (2), 120-126.

Pickering, M. (1984). Interpersonal communication in speech-language pathology supervisory conference: A qualitative study. Journal of Speech and Hearing Disorders, 49, 189-195.

Pickering, M. (1987). Interpersonal communication and the supervisory process. In M. B. Crago,. \& M. Pickering (Eds.), Supervision in human communication disorders: Perspectives on a process (pp.203-225). Boston, MA: College-Hill Press / Little, Brown \& Company.

Reiman, J. \& Theis-Sprintall, L. (1993). Promoting the development of mentor teachers: Theory and research programs using guided reflection. Journal of Research and Development, 26, 179-185.

Roberts, J. (1982). An attributional model of supervisors' decision-making behavior in speech-language pathology (Doctoral dissertation, Indiana University, 1981). Dissertation Abstracts International, 42, 2794B. (University Microfilms No. 81-28, 040).

Rogers, C. (1961). On becoming a person: A therapist's view of psychotherapy. Boston: Houghton, Mifflin.

Rogers, C. (1962). The interpersonal relationship: The core of guidance. Harvard Educational Review, 32, 416-429.

Rogers, C. (1977). Carl Rogers on personal power. NY: Delacorte. 
Russell, L. (1976). Aspects of supervision. Unpublished manuscript. Pittsburgh, PA: Temple University.

Schneider, H. (1989). An investigation of the critical areas in the supervisory process of speech-language pathologists (Doctoral dissertation, Adelphi University, 1989). Dissertation Abstracts International 50, 10B, 4485.

Sergiovanni, T. (1992). Moral leadership: Getting to the heart of school improvement. San Francisco: Jossey-Bass Publications.

Shapiro, D. (1985). An experimental and descriptive analysis of supervisees' commitments and follow-through behaviors as one measure of supervisory effectiveness in speech-language pathology and audiology (Doctoral dissertation, Indiana, University, 1984). Dissertation Abstracts International, 45, 2889B. (University Microfilms No. 84$26,682)$.

Shefte, L. (1959). An evaluation of certain aspects of student teaching programs for public school speech and hearing therapists. Unpublished doctoral dissertation, University of Wisconsin.

Slater, S. (1993). Mentoring: An enriching experience. ASHA, 35, p.55.

Slater, S. (1992). 1992 omnibus survey: Portrait of the professions. ASHA, 34 , 61-65.

Smith, K. (1989). The supervisory process: An introduction. Language, Speech and Hearing Services in the Schools 20, (3), 269-273.

Southeastern Louisiana University. (1998-1999). Southeastern Louisiana University General Catalogue. Hammond, LA: Southeastern Louisiana University. 
Strayer, G. \& Scott, Z. (1930). The meaning and necessity of supervision. In The Superintendent Surveys Supervision. Eighth Yearbook of the Department of Superintendence. Washington, DC: National Education Association.

Tanner, D. \& Tanner, L. (1987). Supervision in education: Problems and practices. NY: Macmillan Publishing Company.

Theiner, E. (1969). An approach to the manpower problem: Psychodrama as conducted in a military setting. American Psychologist, 24, (7), 686-687.

Tihen, L. (1984). Expectations of student speech-language clinicians during their clinical practicum (Doctoral dissertation, Indiana University, 1983). Dissertation Abstracts International, 44, 3048B. (University Microfilms No. 84-01, 620).

Tufts, L. (1984). A contents analysis of supervisory conferences in communicative disorders and the relationship of the content analysis to the clinical experience of supervisees (Doctoral dissertation, Indiana University, 1983). Dissertation Abstracts International, 44, 3048B. (University Microfilms No. 84-01, 588).

VanRiper, C. (1965). Supervision of clinical practice. ASHA, 3, 75-77.

Vargus, I. (1977). Supervision in social work. In D. Kurpis, R. Baker \& I. Thomas (Eds.), Supervision of applied training. Westport, CT: Greenwood Press.

Vygotsky, L. (1978). Mind in society: The development of higher psychological processes. Cambridge, MA: Harvard University Press.

Wagner, B. (1994). Supervisors' social power bases in speech-language pathology: Perceptions and satisfaction (Doctoral dissertation, Indiana University, 1994). Dissertation Abstracts International, 55, 10-B, 4338.

Weinrich, B. (1997). Validation of a clinical skills evaluation instrument in 
speech-language pathology and audiology (Doctoral dissertation, University of Cincinnati, 1997). Dissertation Abstracts International, 58, 06B, 2996.

Wilhelms, F. (1946). Tomorrow's assignment. In T. Sergiovanni (Ed.)

Leadership through supervision. Washington, D.C.: ASCD. 
April 15, 1998

Dear ,

I am a doctoral student at West Virginia University studying the supervisory relationship between speech-language pathology assistants and their supervising speech-language pathologists. Through this research I hope to gather information concerning the extent and the nature of the assistant-supervisor relationship. I expect to discover the tasks of supervision that are believed to be most important for the practicing speechlanguage pathology assistant.

I am requesting information from all licensed speech-language pathology assistants in the state of Louisiana; your participation in this study is important and appreciated. Your response to this survey will be helpful in the development of the professional relationship between speech-language pathology assistants and their supervisors.

Please complete the questionnaire and return it in the enclosed postage paid envelope. I am genuinely interested in your ideas about the supervision of speech-language pathology assistants. Your participation is voluntary and all data will be treated in a confidential manner and even though you do not have to answer every question, it would be most helpful if you did.

Sincerely,

Jean S. Mead

Please respond by April 30, 1998.

Thank you for your assistance. I will be happy to share results of my study if you request them by emailing me at: jmead@selu.edu. 
Appendix B: Follow-up Letter to Subjects

May 15, 1998

Dear ,

Recently I mailed to you a survey requesting information about the supervision you receive as a practicing speech-language pathology assistant (SLPA). You may not have received the survey or it may have been misplaced. Therefore, enclosed is a second copy of the survey.

I know that this is a busy time of the year, but if you would take just a few minutes and complete the survey and return it in the enclosed postage paid envelope, I would be most appreciative. In order to accurately describe the SLPA supervision process, it is critical that I gather as many responses as possible.

Louisiana is on the cutting edge with regard to use of SLP assistants. We are one of a few states that has developed and implemented procedures for licensing SLPAs and I believe we can be a model for others. I am genuinely interested in your thoughts about the supervision you receive. Please assist me with my research if at all possible. I hope to make an impact on our field and to develop a model of supervision that will be beneficial for all speech-language pathology assistants.

If you have already responded to my survey please disregard this letter and accept my appreciation.

Thank you for your time and response.

Sincerely,

Jean S. Mead

Please respond by May 31, 1998. 
Appendix C: Permission to Adapt Larson's Instrument

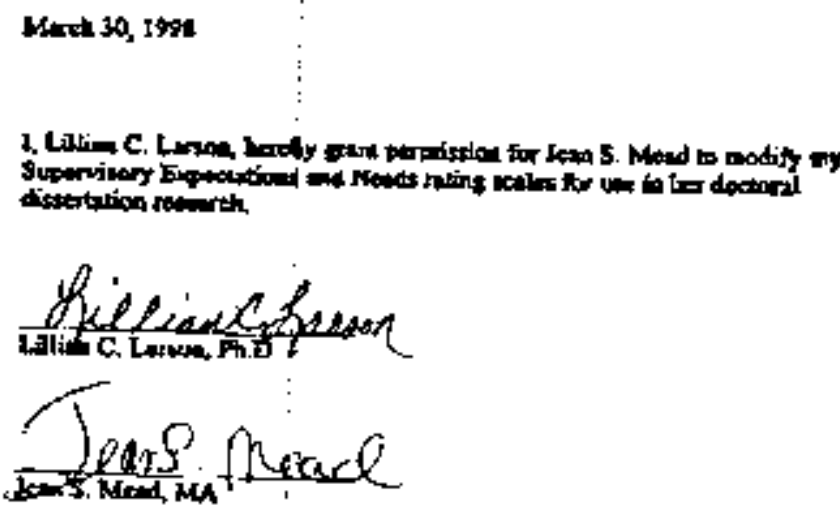


Please circle the number that in your opinion best represents the extent to which the following behaviors occur or ar true (left column) and the extent to which the behaviors suggested by each item are needed (right column). The numbers correspond to the following categories:

Extent to which

the behavior

suggested by

each item $\underline{\text { s }}$

true or does occur.

54321

54321

54321

54321

54321

54321

54321

54321

54321

54321

54321

54321

54321

54321

54321

54321

54321

54321

54321

54321

54321
Part I.

1. Your supervisor helps you set goals for your clients.

2. Your supervisor demonstrates therapy techniques.

3. Your supervisor gives you the opportunity to express your opinions.

4. Your supervisor identifies and obtains available resources for therapy.

5. Your relationship with your supervisor is a collaborative one.

6. Your supervisor motivates you to perform at your highest potential.

7. Your supervisor dominates discussion in the meetings.

8. Your supervisor functions as a teacher who helps you learn.

9. Your supervisor listens to your professional problems.

Extent to which the behavior suggested by each item is

needed.

$\begin{array}{lllll}5 & 4 & 3 & 2 & 1\end{array}$

$\begin{array}{lllll}5 & 4 & 3 & 2 & 1\end{array}$

$\begin{array}{lllll}5 & 4 & 3 & 2 & 1\end{array}$

$\begin{array}{lllll}5 & 4 & 3 & 2 & 1\end{array}$

$\begin{array}{lllll}5 & 4 & 3 & 2 & 1\end{array}$

$\begin{array}{lllll}5 & 4 & 3 & 2 & 1\end{array}$

$\begin{array}{lllll}5 & 4 & 3 & 2 & 1\end{array}$

$\begin{array}{lllll}5 & 4 & 3 & 2 & 1\end{array}$

$\begin{array}{lllll}5 & 4 & 3 & 2 & 1\end{array}$

10. Your supervisor provides recognition and positive feedback

$\begin{array}{lllll}5 & 4 & 3 & 2 & 1\end{array}$ for your work.

11. Your supervisor challenges you to perform at your highest level. $\begin{array}{llllll}5 & 4 & 3 & 2 & 1\end{array}$

12. Your supervisor is supportive of you.

$\begin{array}{lllll}5 & 4 & 3 & 2 & 1\end{array}$

13. Your supervisor assists you in evaluating client progress.

$\begin{array}{llllll}5 & 4 & 3 & 2 & 1\end{array}$

14. Your supervisor is the superior and you are the subordinate

$\begin{array}{lllll}5 & 4 & 3 & 2 & 1\end{array}$ in the relationship.

15. Your supervisor offers suggestions for managing client behavior. $\begin{array}{llllll}5 & 4 & 3 & 2 & 1\end{array}$

16. Your supervisor offers suggestions on therapy techniques.

$\begin{array}{lllllllll}5 & 4 & 3 & 2 & 1\end{array}$

17. You inform your supervisor when you need professional

$\begin{array}{lllll}5 & 4 & 3 & 2 & 1\end{array}$ assistance.

18. Your supervisor appears to value your ideas.

$\begin{array}{lllll}5 & 4 & 3 & 2 & 1\end{array}$

19. You are growing professionally as a result $\begin{array}{lllll}5 & 4 & 3 & 2 & 1\end{array}$ of conferences with your supervisor.

20. Your supervisor is sensitive to work stresses and concerned

$\begin{array}{lllll}5 & 4 & 3 & 2 & 1\end{array}$ about your well-being.

21. You communicate with your supervisor outside of the

$\begin{array}{lllll}5 & 4 & 3 & 2 & 1\end{array}$ planned meetings. 
Extent to which

the behavior

suggested by

each item is

true or does occur.

54321

54321

54321

54321

54321

54321

54321

54321

Part II.

30. Are you receiving the supervision you expected when you became employed as a speech pathology assistant

31. Does your supervisor evaluate your job performance? If yes, to whom is the evaluative data reported?

32. Does someone other than your SLP supervisor evaluate your job performance formally? For example, a principal or a central office supervisor?

33. Do you meet with your supervisor during regularly scheduled conferences? If so, how often do you meet? If not, how do you and your supervisor schedule conferences?

34. What general themes or agendas are usually discussed during conferences with your supervisor?

35. What specific skills or behaviors does your supervisor exhibit that are especially helpful? Please describe.

36. What do you feel are the primary supervisory needs of a speech pathology assistant?

37. Overall, do you feel your supervisory needs are being met as a practicing speech-language pathology assistant?

38. Do you believe your supervisory needs will change as you continue to practice?

If so, please describe what types of changes may be most helpful for you.
Extent to which the behavior suggested by each item is

needed.

\section{$\begin{array}{lllll}5 & 4 & 3 & 2 & 1\end{array}$}

$\begin{array}{lllll}5 & 4 & 3 & 2 & 1\end{array}$

$\begin{array}{lllll}5 & 4 & 3 & 2 & 1\end{array}$

$\begin{array}{lllll}5 & 4 & 3 & 2 & 1\end{array}$

54321

$\begin{array}{lllll}5 & 4 & 3 & 2 & 1\end{array}$

$\begin{array}{lllll}5 & 4 & 3 & 2 & 1\end{array}$ your request. 
39. What suggestions would you offer as to how your supervision could be enhanced?

Please describe.

40. Are there any other comments or suggestions you can offer about the supervision you are receiving and the nature of your supervisory conferences? Please explain.

Part III.

Would you please provide the following information about yourself?

1. Gender: __ Female _ _ Male

2. Highest level of education: ___ Associate's Degree

_ Bachelor's Degree

Number of graduate courses

Master's Degree

3. Years of experience as a speech-pathology assistant:

4. Work setting: __ Public Schools __ Hospital __ Other

5. License: ___ Provisional SLP Assistant

6. Age: SLP Assistant

Please return the completed survey to:

Jean S. Mead

Southeastern Louisiana University

Dept. of Special Education and Communication Sciences and Disorders

SLU 879

Hammond, LA 70402

Any questions?

W (504) 549-2214

H (504) 542-6531

Email: jmead@selu.edu 
Appendix E: Behavioral Variables that Constitute Each Category

\section{Behavioral variables that constituted the "Instructional" category.}

1. Your supervisor helps you set goals for your clients.

2. Your supervisor demonstrates therapy techniques.

4. Your supervisor identifies and obtains available resources for therapy.

8. Your supervisor functions as a teacher who helps you learn.

13. Your supervisor assists you in evaluating client progress.

15. Your supervisor offers suggestions for managing client behavior.

16. Your supervisor offers suggestions on therapy techniques.

26. Your supervisor encourages you to analyze your professional behavior.

\section{Behavioral variables that constituted the "Interrelational" category.}

3. Your supervisor gives you the opportunity to express your opinions.

5. Your relationship with your supervisor is a collaborative one.

6. Your supervisor motivates you to perform at your highest potential.

7. Your supervisor dominates discussion in the meetings.

9. Your supervisor listens to your professional problems.

10. Your supervisor provides recognition and positive feedback for your work.

11. Your supervisor challenges you to perform at your highest level.

12. Your supervisor is supportive of you.

14. Your supervisor is the superior and you are the subordinate in the relationship.

18. Your supervisor appears to value your ideas.

20. Your supervisor is sensitive to work stresses and concerned about your wellbeing.

25. Your supervisor is available for support, but encourages you to function independently.

\section{Behavioral variables that constituted the "General" category.}

17. You inform your supervisor when you need professional assistance.

19. You are growing professionally as a result of conferences with your supervisor.

21. You communicate with your supervisor outside of the planned meetings.

22. You communicate with your supervisor outside of the planned meetings via email.

23. You communicate with your supervisor by telephone.

24. You communicate with your supervisor through journal writing.

27. You analyze your clinical behavior through dialogue with your supervisor.

28. You analyze your clinical behavior through written self-analysis.

29. Your supervisor is available to meet with you at your request. 


\section{VITA}

\section{Jean Suzanne Mead}

In 1974, Jean Suzanne Ruhlman Mead graduated from East Jordan High School in East Jordan, Michigan. After several years of "experiencing" life, in 1987, she enrolled at Marshall University in Huntington, West Virginia. Several majors were pursued including education, Spanish, and journalism. Ultimately she found communication disorders and earned the BA in 1992 and the MA in 1993 in that field. Immediately following graduation from that master's program she was admitted to the Doctorate of Educational Leadership Studies Program, that was offered cooperatively through West Virginia University (WVU) and Marshall University, with WVU being the degree granting institution.

While pursuing her doctoral program of study, Jean experienced the speechlanguage pathology profession from various perspectives. She has been a full time speech-language pathologist for the Cabell county school system in West Virginia and she has provided consulting services for several state and private agencies. In 1994, she accepted a position as a full time faculty member in the department of communication disorders at Marshall University. In 1997, she moved to Hammond, Louisiana and became a full time member of the faculty at Southeastern Louisiana University in the communication sciences and disorders program. She continues to hold that position.

Two teen-aged children also occupy her time. Ryan, who is 18 years old and a senior at Oak Forest Academy in Amite, LA, enjoys basketball and baseball. He declared baseball as his 'first' sport, but he can nail a pretty mean three-pointer on the basketball court. Stephanie is a 16 year old who attends Hammond High School; her primary 
interests include talking on the telephone or any other means of socializing with her friends. As a family, they enjoy visiting with friends, attending Ryan's basketball and baseball games and hanging out on the French Quarter. 